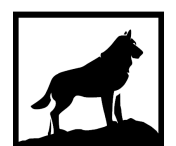

Michigan

Technological

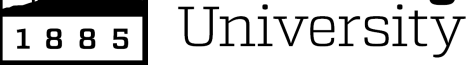

Michigan Technological University

Digital Commons @ Michigan Tech

Dissertations, Master's Theses and Master's Reports

2016

\title{
ARBUSCULAR MYCORRHIZAL FUNGI OF NORTHERN WHITE CEDAR (Thuja occidentalis L.): HABITAT EFFECTS ON FUNGAL COMMUNITIES AND INOCULUM EFFECTS ON PLANT GROWTH ON ACID PEAT SOILS
}

Guswarni Anwar

Michigan Technological University, ganwar@mtu.edu

Copyright 2016 Guswarni Anwar

Recommended Citation

Anwar, Guswarni, "ARBUSCULAR MYCORRHIZAL FUNGI OF NORTHERN WHITE CEDAR (Thuja occidentalis L.): HABITAT EFFECTS ON FUNGAL COMMUNITIES AND INOCULUM EFFECTS ON PLANT GROWTH ON ACID PEAT SOILS", Open Access Dissertation, Michigan Technological University, 2016.

https://doi.org/10.37099/mtu.dc.etdr/70

Follow this and additional works at: https://digitalcommons.mtu.edu/etdr

Part of the Environmental Microbiology and Microbial Ecology Commons, and the Forest Biology Commons 


\title{
ARBUSCULAR MYCORRHIZAL FUNGI OF NORTHERN WHITE CEDAR (Thuja occidentalis L.): HABITAT EFFECTS ON FUNGAL COMMUNITIES AND INOCULUM EFFECTS ON PLANT GROWTH ON ACID PEAT SOILS
}

\author{
By \\ Guswarni Anwar \\ A DISSERTATION \\ Submitted in partial fulfillment of the requirements for the degree of \\ DOCTOR OF PHILOSOPHY \\ In Forest Science
}

MICHIGAN TECHNOLOGICAL UNIVERSITY

2016

(C) 2016 Guswarni Anwar 
This dissertation has been approved in partial fulfillment of the requirements for the Degree of DOCTOR OF PHILOSOPHY in Forest Science

School of Forest Resources and Environmental Science

Dissertation Co-Advisor : $\quad$ Dr. Erik A. Lilleskov

Dissertation Co-Advisor : $\quad$ Dr. Rodney A. Chimner

Committee Member : $\quad$ Dr. Molly A. Cavaleri

Committee Member: $\quad$ Dr. Noel R. Urban

School Dean : $\quad$ Dr. Terry L. Sharik 


\section{Table of Contents}

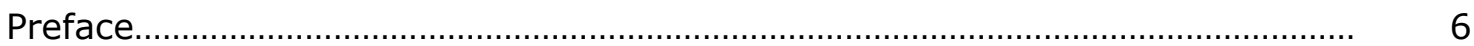

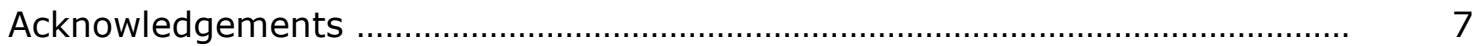

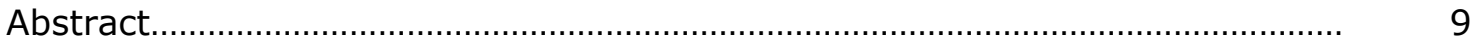

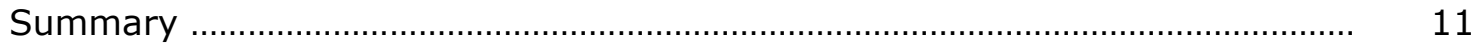

Chapter 1. Effects of mycorrhizal inoculation, fertilization, and liming on growth and nutrient acquisition of Thuja occidentalis L. seedlings on acidic

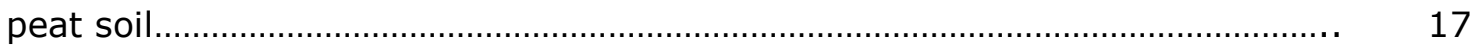

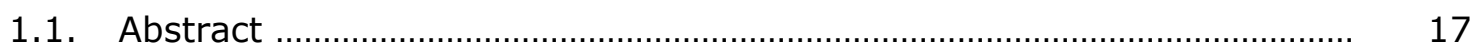

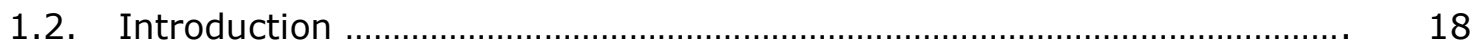

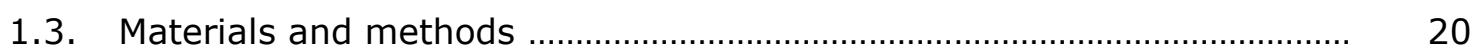

1.3.1. Study site.................................................................................. 20

1.3.2. Experimental treatments ...................................................... 20

1.3.3. Data collection ............................................................................ 22

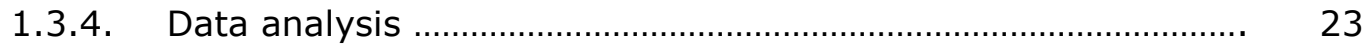

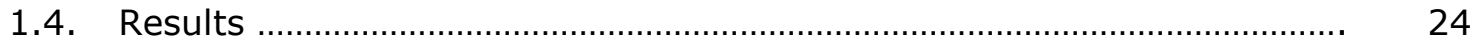

1.4.1. AM structures presence.......................................................... 24

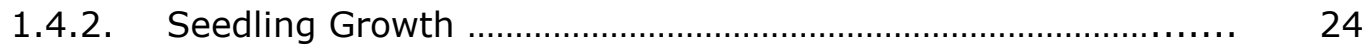

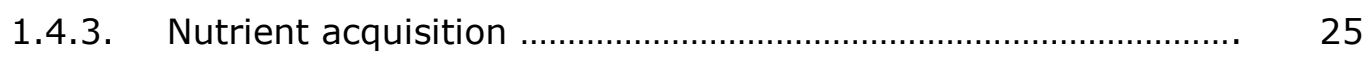

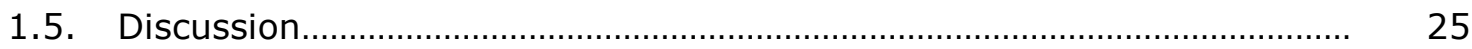

1.5.1. Mycorrhizal inoculation effects on growth and nutrient acquisition ................................................................................. 25

1.5.2. Interaction of mycorrhizal inoculation with fertilization and liming 


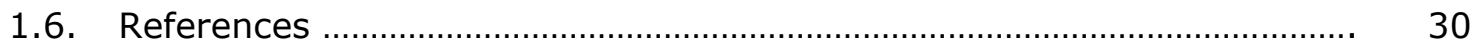

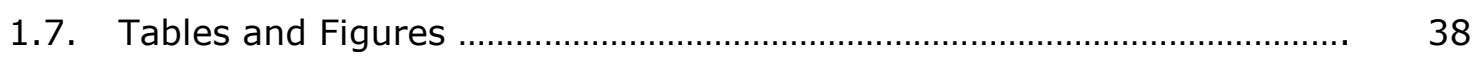

Chapter 2. The effect of arbuscular mycorrhizal inoculum, AM host proximity, and other environmental factors on growth and survival of Thuja occidentalis

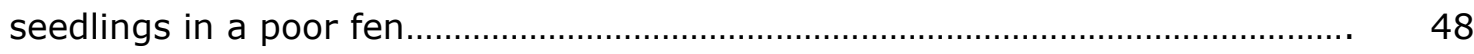

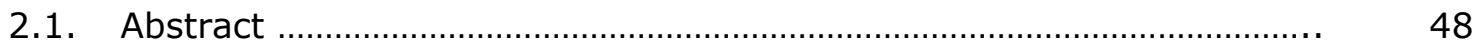

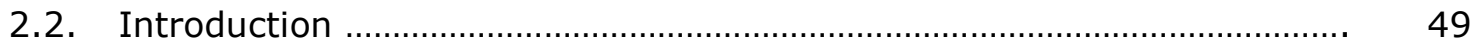

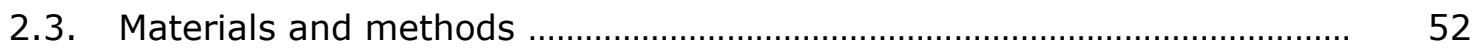

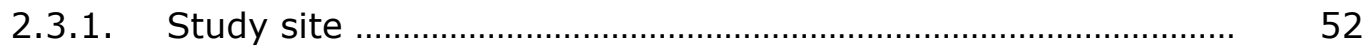

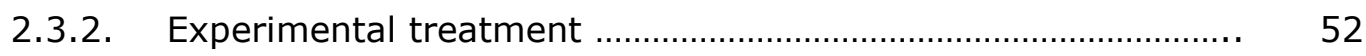

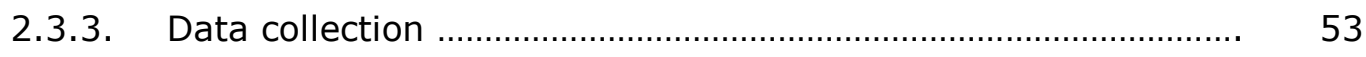

2.3.4. Data analysis....................................................................... 55

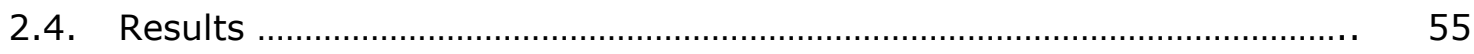

2.4.1. PCA of plant cover.......................................................... 55

2.4.2. Survival rate ............................................................................ 56

2.4.3. Seedling growth and nutrient acquisition ................................ 56

2.4.4. Relationship between AM plant proximity and other predictors $\quad 57$

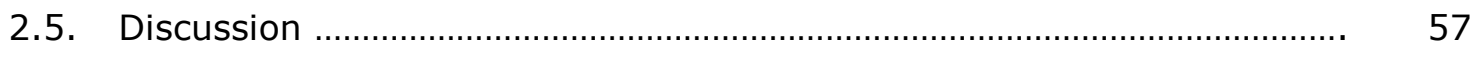

2.5.1. AM Fungi: inoculation success and effectiveness ................... 57

2.5.2. AM host proximity and plant community effects ..................... 59

2.5.3. Other environmental effects ...................................................... 62

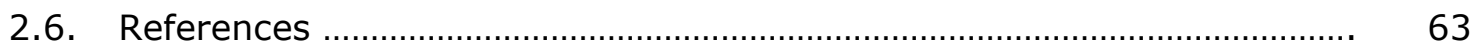

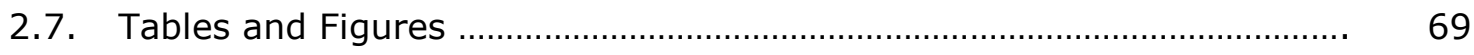


Chapter 3: Structure and composition of arbuscular mycorrhizal community on Thuja occidentalis roots in peatland, mesic upland, and mine tailing

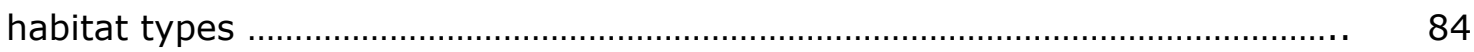

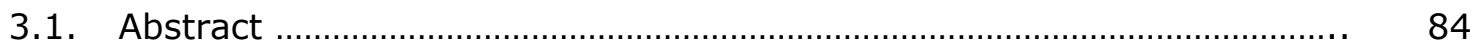

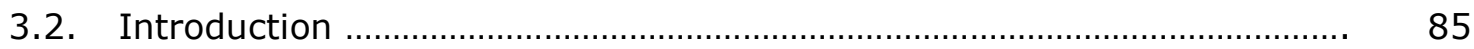

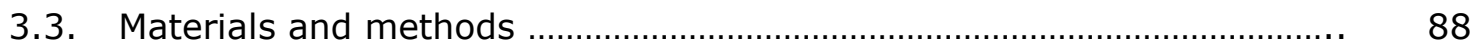

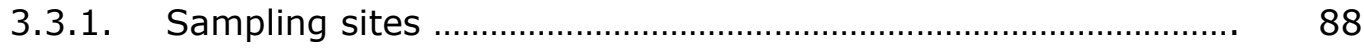

3.3.2. Sampling collection ……........................................................ 88

3.3.3. Bioinformatics ...................................................................... 91

3.3.4. Statistical analysis .............................................................. 92

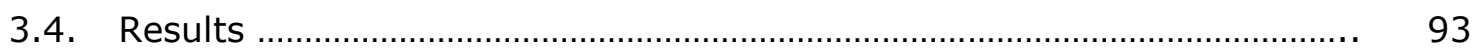

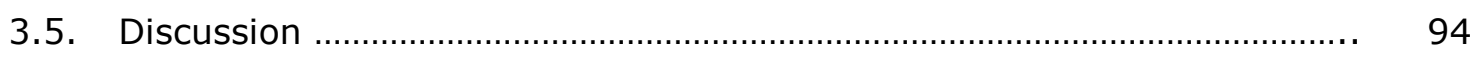

3.5.1. Implications for use of Glomeraceae native inoculum in

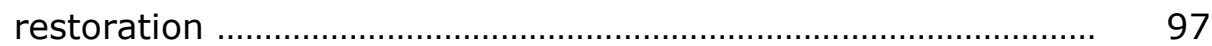

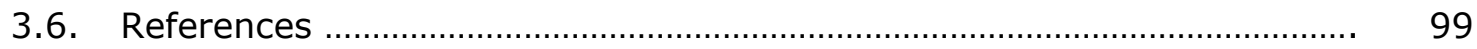

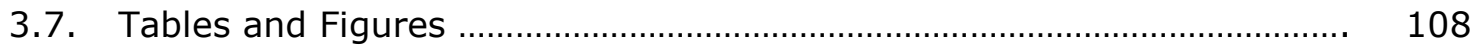




\section{Preface}

Chapter 1, Effects of mycorrhizal inoculation, fertilization, and liming on growth and nutrient acquisition of Thuja occidentalis L. seedlings on acidic peat soil; in preparation for submission to publish in a peer-reviewed journal. Guswarni Anwar conducted and designed the study, collected and analyzed the data, and wrote the manuscript. Dr. Erik A. Lilleskov and Dr. Rodney A. Chimner contributed to experimental design and edited the manuscript.

Chapter 2, Effect of arbuscular mycorrhizal inoculum, AM host proximity, and other environmental factors on growth and survival of Thuja occidentalis seedlings in a poor fen; in preparation for submission to a peer-reviewed journal. Guswarni Anwar conducted and designed the study, collected and analyzed the data, and wrote the manuscript. Dr. Erik A. Lilleskov and Dr. Rodney A. Chimner contributed to experimental design and to editing the manuscript.

Chapter 3, Structure and composition of arbuscular mycorrhizal community on Thuja occidentalis roots in peatland, mesic upland, and mine tailing habitat types; in preparation for submission to a peer-reviewed journal. Guswarni Anwar conducted and designed the study, collected the data, and wrote the manuscript. Dr. Louis J. Lamit performed the bioinformatic analysis and contributed to analysis of the data and wrote the bioinformatic methods. Dr. Erik A. Lilleskov and Dr. Rodney A. Chimner contributed to experimental design and to editing the manuscript. 


\section{Acknowledgements}

I am so blessed and grateful to the Almighty God for having a lot of kind people who supported and helped throughout my work to accomplish the doctoral program. Completion of this dissertation would not have been possible without their kindness. My deepest gratitude goes first to my advisors Dr. Erik A. Lilleskov and Dr. Rodney A. Chimner for their generous guidance, encouragement, consistent support, and abundance of patience to supervise and teach me to be a good scientist. They are the first people who introduced and invited me to learn and concern myself with wetlands, in particular peatlands, where I previously had no knowledge about such ecosystems. I would like to express my sincere thanks as well to my committee members, Dr. Molly A. Cavaleri and Dr. Noel R. Urban for their valuable feedback, encouragement, support, and kindness that made my work and this dissertation much better.

My great appreciation and deepest thanks goes to Dr. Louis J. Lamit, who supervised and taught me in working on DNA extraction, analyzed the data, and helped me a lot in many ways. I would like also to express my sincere thanks to Dr. James A. Bess, Dr. John A. Hribjan, and Dr. Evan Kane for their feedback and assistance to accomplish my work. I greatly appreciate and express my thanks to Lynette Potvin for her kind assistance and feedback to smooth my work.

Special thanks to Joe Plowe, my field assistant who worked very hard to help me collecting the samples under heavy weather and extreme sites. My big thanks to Karena Schmidt, Kayla Marie, Eryn Grupido, Tia Scarpelli, Sara Kelso, Sarah Hartung, Brandon Stimac, Greg Houle, Rose Schwarz, Sirikorn, Ahmad Sulaiman, and Justina Silva who helped me in the lab and the field. I really appreciate their 
assistance and kindness. I would like to thank all staff of the USDA Forest Service Northern Research Station, faculty and staff of School of Forest Resources and Environmental Science at Michigan Technological University, and many people who contributed a lot for helping and supporting my study.

My study would have not been possible without funding support by FulbrightDikti, Michigan Technological University, USDA Forest Service, and Dr. Rodney Chimner's projects. My big gratitude for their sponsorships.

Finally, my deepest thanks to my family for being patient to look forward to my completion and always pray for and support me. Likewise, my big thanks to all of my friends who helped, supported, and encouraged me that made my time in Houghton fun and memorable.

I dedicate my work and this dissertation to my beloved mom who always prayed for me and waited for my success and to my lovely son, my husband, my sister, and my brother who always encourage and increase my strength and spirit to accomplish my study. This success is dedicated also to my country, Indonesia. I wish I can contribute a lot to serve the nation and the people to share my knowledge and experience that I got during study in the USA. 


\section{Abstract}

The relationship of arbuscular mycorrhizal (AM) fungi with northern white cedar (NWC) was examined from the perspective of both fundamental questions about habitat specificity in the root fungal community, as well as applied questions regarding AM fungal efficacy in NWC restoration in peat soils. I performed two experiments testing the effects of AM fungi on survival, growth, and nutrition of NWC seedlings; and one molecular study to determine the habitat effects on community composition of NWC root-associated fungi. First, a greenhouse AM inoculation experiment was conducted in factorial combination with fertilization and liming to examine conditional effectiveness of AM fungal inoculation. Second, a field experiment in a poor fen was conducted to determine effectiveness of AM fungal inoculation, AM plant proximity, and environmental factors on survival, growth, and nutrition of NWC seedlings. Third, an observational study employed Illumina sequencing to determine habitat effects on diversity and composition of NWC rootassociated fungal communities in mine tailings, peatlands, and uplands. AM inoculation of NWC had different outcomes in the greenhouse and field experiments. In the greenhouse AM fungi significantly increased all plant growth and many nutrient metrics, whereas in the field there were no significant inoculum effects. This might be due to the differences in several experimental conditions. Seedlings in the greenhouse grew under high environmental control, higher $\mathrm{pH}$, using commercial inoculum, and with no competition. In contrast, the field experiment was conducted without environmental controls, with native inoculum under more acidic and competitive conditions. However, in addition to $\mathrm{pH}$ and light effects, we observed positive AM plant proximity effects on growth and nutrition, perhaps indicating a mycorrhizal role in NWC seedling success in poor fens. In the fungal community 
analysis, unidentified Glomeraceae were the dominant AM fungi across all habitats. Total fungal and AM fungal community richness was higher in bog and upland than in stamp sands. Fungal community composition within Glomeromycota and all fungal taxa were both significantly different between the mine tailing and the other two habitats. There were taxa with both broad and narrow habitat associations that are potential targets for general vs habitat-specific AM inoculum. 


\section{Summary}

Arbuscular mycorrhiza ( $\mathrm{AM}$ ) fungi colonize most terrestrial plant species and some wetland plants. These fungi assist plant growth and nutrition especially phosphorus mobilization in nutrient-poor soils. Therefore, AM fungi are an effective tool of restoration and reclamation projects in degraded lands, in both peatlands and uplands. In many cases, degraded lands exhibit reduced productivity due to mineral nutrient deficiency, soil drought, and increased heavy metals (soil toxicity). Such conditions potentially reduce or eliminate indigenous AM propagules. It is important to reintroduce AM fungi into the disturbed lands to support plant growth and accelerate restoration and reclamation programs. However, relatively little is known about AM fungi role in the establishment and growth of northern white cedar (Thuja occidentalis L.).

Northern-white cedar is an arbuscular mycorrhizal tree species that is common in the northeastern United States and Canada. This species occurs in both upland and wetland habitats. In wetlands it is predominantly found in rich swamps (forested rich fens) on soils with slightly acidic (5.5) to neutral $\mathrm{pH}$; but also occurs in more acidic peatlands. Northern-white cedar provides a variety of benefits, particularly related to wood products and wildlife habitat. In recent years, NWC have been negatively affected by white-tailed deer browsing, harvesting, low recruitment, and high competition with associated trees and shrubs.

Fens are a globally important peatland type, including in the northern Great Lakes region. At the most acidic and nutrient-poor end of the fen continuum (poor fens), not many tree species are able to occupy this habitat. Poor fens are predominantly covered by ericaceous shrubs and sphagnum mosses. Acidity, high water tables, and low nutrient availability cause these ecosystems to support low 
tree productivity. When these ecosystems are disturbed they can be subject to restoration or mitigation programs that include planting major trees such as Pinaceae and NWC. Success of these restoration efforts is variable, perhaps because the role of mycorrhizal fungi has not been considered as part of these efforts.

The main goal of our study was to improve understanding of the relationship of AM fungi with NWC. We approached this from the perspective of both basic questions about the community of fungi involved in the symbiosis in different habitats, as well as applied questions regarding the efficacy of AM fungi in improving success of NWC restoration in peat soils. This was conducted using two experimental series looking at the effects of AM fungi on survival and growth of NWC seedlings; and one molecular study to determine occurrence of AM fungi in association with NWC in three contrasting habitat types. To achieve this goal we had three primary objectives and associated activities.

The first objective was to determine efficacy of AM fungi to improve growth and nutrient acquisition of NWC in peat soils, as a low impact approach to peatland restoration without chemical additions (e.g., fertilization and liming). We conducted an AM inoculation greenhouse experiment in factorial combination with fertilization and liming to examine effectiveness of AM fungal inoculation under a range of environmental conditions. We also determined success of AM fungal colonization by quantifying occurrence of their structures in NWC roots. We germinated NWC seeds and treated the seedlings with commercial AM fungi inoculum, fertilization, and liming. We measured height, diameter, plant biomass, and nutrient acquisition $(\mathrm{N}, \mathrm{P}$, $\mathrm{Cu}$ ). Our findings showed AM inoculation without fertilization significantly increased all growth and nutrient metrics of the seedlings except $\mathrm{N}$ and $\mathrm{Cu}$ concentration. The positive impact of AM inoculation on plant growth and nutrient acquisition was similar to fertilizer. Our study showed liming alone did not improve NWC growth and 
nutrient acquisition. Fertilization, and to a lesser extent liming, reduced the efficacy of AM inoculum to improve plant growth and nutrient acquisition. We conclude that using AM inoculation alone effectively increased NWC growth and nutrient supply and reduced the need for fertilizer and lime in peatlands. AM inoculation could be an ecologically and economically favorable alternative to enhance the success of restoration of NWC in acid peatlands.

The second objective of our study was to determine effectiveness of AM fungal inoculation, AM plant proximity, and environmental factors on survival, growth, and nutrient uptake of NWC seedlings in a field study in a poor fen. We assessed whether native AM fungal inoculum, AM plant proximity, AM plant index (ordination of basal area and percentage of vegetation cover for the major mycorrhizal types), and other environmental factors (soil $\mathrm{pH}$, water table depth, peat bulk density, and light intensity) affected NWC survival and growth in a poor fen. We conducted the experiment in a poor fen dominated by ericaceous shrubs and sphagnum mosses with patchy distribution of ectomycorrhizal (ECM) and AM trees. We planted 396 NWC seedlings along 70-100 m long transects parallel to the peat margin located $10,50,100,150$ and $200 \mathrm{~m}$ from the peatland margin. We randomly established plots within each $5 \mathrm{~m}$ interval over the length of these transects. We placed four points within each plot in a crossed design with each axis $2 \mathrm{~m}$ in length. At planting, half of the seedlings were inoculated with native AM inoculum using fresh NWC fine roots taken from the study area, and half were left as un-inoculated control treatments. We applied a range of statistical analyses to determine treatment effects on NWC growth and nutrient acquisition. After 12 months from the initial planting, we found that AM inoculum had no significant effect on survival, plant growth, and nutrient acquisition (N, P, Ca) whether analyzed alone or in interaction with other environmental factors. Light was the only significant predictor of survival, 
with greater survival under higher light. AMF plant proximity significantly affected plant growth and nutrient acquisition, with NWC seedling growth and nutrient supply higher when closer to AM trees. Relationship of AM plant proximity with light and ERM (ericoid mycorrhizal) plants were significant, with lower light and Ericaceae cover near AM trees. We conclude that AM inoculant was not able to improve survival rate, growth and plant nutrition. However, the fact that AM plant proximity significantly increased the growth and nutrient supply indicates the need for further analysis to test whether enhanced AM colonization or other factors such as reduced competition from Ericaceae are the cause.

The third objective of our study was to determine effect of habitat type on diversity and composition of NWC root-associated fungal communities in three habitat types (peatland, mine tailings, upland), and to determine the effect of environmental factors and plant community as predictors of fungal community composition and structure. We assessed AM fungi that belong to the phylum Glomeromycota as predominant fungal species in all the habitats. We conducted a molecular study with DNA based next generation (Illumina) sequencing to identify structure and composition of fungal species especially Glomeromycota in the three habitats. We collected NWC root samples in each habitat type (14 sampling locations: 5 peatland, 3 stamp sand, 6 upland), and measured soil and foliar chemistry. We extracted DNA from the root samples to be used in high-throughput sequencing with the Illumina MiSeq. The resulting sequences were subjected to bioinformatics pipeline to cluster sequences into operational taxonomic units (OTUs). We statistically analyzed the data using PERMANOVA to test the effect of habitat on fungal community similarity. We also used non-metric multidimensional scaling (NMDS) to test habitat effects on the OTU composition. We determined indicator species from each habitat type and tested the effect of habitat, soil $\mathrm{pH}$, and plant 
community on rarefied OTU richness and evenness. Our finding showed Glomeromycota, mostly in the Glomeraceae, were common members of the fungal community across the habitats. Fungal community richness for all taxa and for Glomeromycota was significantly affected by habitat type. Stamp sands had the lowest richness across the habitats. Unidentified Glomeraceae OTUs were the most abundant Glomeromycota in this study. Fungal community composition within Glomeromycota and all fungal taxa were significantly affected by habitat type, perhaps mediated by differences in $\mathrm{pH}$ and $\mathrm{AM}$ plant index. Considering the consistent occurrence of Glomeraceae in the three habitats, this family may be the source of important inoculant in seedling planting program of land restoration projects.

In conclusion, AM inoculation on NWC in poor fen soils showed different results between the greenhouse and field experiment. The greenhouse experiment showed AM fungi significantly increased all plant growth and nutrient metrics. In contrast, the field experiment showed non-significant effects. This might be due to the differences in several experimental conditions. Seedlings in the greenhouse grew under high control of environmental factors, higher $\mathrm{pH}$, with commercial inoculum, and no competition with other plants. In contrast, the field experiment was conducted without environmental controls, with native inoculum, under more acidic conditions, and the seedlings faced high competition with neighboring plants. However, our positive AM plant proximity effects also suggest that there might be a mycorrhizal role in NWC seedling success in these habitats. Our positive growth and nutrition responses suggest it is possible to use AM fungi as an inoculum on NWC seedlings in restoration projects, at least on mildly acidic to circumneutral peat. More tests should be carried out on best practices in inoculation under field conditions, and to distinguish mycorrhizal from other influences on seedling success. Moreover, 
dominance of different AM OTUs in mine soils vs peatland and upland habitats suggests that inoculum sources with both narrow and broad habitat ranges are available, and should be tested for efficacy over a broad range of site conditions. 
Chapter 1. Effects of mycorrhizal inoculation, fertilization, and liming on growth and nutrient acquisition of Thuja occidentalis L. seedlings on acidic peat soil ${ }^{1}$

\subsection{Abstract}

Arbuscular mycorrhizal (AM) fungi are hypothesized to assist growth of northern white cedar (NWC) in acid peatlands, yet there is little direct evidence that they can provide sufficient resources, especially nitrogen, from unfertilized peat soils. Our objective was to determine mycorrhizal efficacy to support NWC growth and nutrient supply as part of a low-impact approach for ecological restoration of NWC in oligotrophic peatlands. We tested the effectiveness of AM inoculation in a greenhouse experiment in factorial combination with fertilization and liming. We also determined AM colonization rate in the different treatment combinations. We found that AM inoculation in the absence of fertilization significantly increased all growth and nutrient concentrations and content variables of the seedlings, except $\mathrm{N}$ and $\mathrm{Cu}$ concentration. Fertilizer alone had a similar impact on plant growth and nutrient acquisition when compared to unfertilized AM inoculation treatments. We also found that liming alone was ineffective at increasing NWC growth and nutrient uptake. There were many interactions of AM inoculation with liming and fertilization. Specifically, the effect of AM inoculation on many growth and nutrition metrics was reduced in the presence of both fertilization and liming. We conclude that using AM inoculation alone was able to improve NWC growth and its nutrient acquisition and reduce the need for fertilizer and lime in peatlands.

\footnotetext{
$\overline{1}$ The material contained in this chapter is in preparation for submission to a journal.
} 


\subsection{Introduction}

Northern white cedar (Thuja occidentalis L; NWC) is a dominant tree in forested wetlands in northeastern North America. It is most prominent in rich swamps or forested rich fens with pH ranging from 5.5 to 7.2 (Johnston, 1990; Fraver et al., 2009), however, is also found in acidic peatlands (poor fens of $\mathrm{pH} \sim$ 4.5).

Arbuscular mycorrhizal (AM) fungi colonize NWC (Brundrett et al., 1989, Matthes-Sears et al., 1992; Bainard et al., 2011) and may assist NWC colonization of these nutrient-poor soils by enhancing nutrient, especially P uptake. However, AM fungi are relatively uncommon in acidic peatlands. It is largely unknown whether arbuscular mycorrhizal fungi can play an important nutritional role for NWC colonization in these acidic peatlands. Understanding the role of AM fungi on NWC is important not only for expanding fundamental knowledge of AM fungi in peatlands, but also because NWC is the subject of intensive restoration efforts (e.g., Kangas et al., 2015, Palik et al., 2015). Therefore, it is necessary to develop economically feasible and environmentally sound techniques to enhance NWC ability to establish and grow in these marginal sites.

Historically, both fertilization and liming have been commonly used to improve seedling growth in marginal soils during restoration (Moore, 2000; Walker, 2002; Jonard et al., 2010; Pabian et al., 2012) However, fertilization and liming can be costly and lead to accumulation of heavy metals in soils, aquatic ecosystems, and plants (Braekke, 1999, Savci, 2012; van der Ent et al., 2013, Marchand et al., 2014).

Mycorrhizal inoculation effectively reduced fertilizer ( $N$ and $P$ ) use by enhancing capability of host plants to take up both nutrients from soil (Singh, 1998, Tawaraya et al., 2007). However, Hoeksema et al. (2015) found that AM fungi 
effectively overcame $\mathrm{P}$ limitation but not $\mathrm{N}$ limitation. Given that acid peatlands are commonly $\mathrm{N}$ limited, it is important to understand whether AM inoculation can reduce the need for fertilizer and lime additions in peatlands.

Both fertilization and liming could also reduce the efficacy and abundance of mycorrhizal fungi (Treseder, 2004). Fertilizers, through enhancing $\mathrm{N}$ and $\mathrm{P}$, generally eliminate nutritional benefits of mycorrhizas (Nijjer et al., 2010), and instead can potentially turn mycorrhizal symbiosis into a parasitic rather than mutualistic relationship (Johnson, 1993). A mutualism commonly occurs in high $\mathrm{N}$ and low $\mathrm{P}$, and vice versa for parasitism symbiosis (Johnson et al., 2014). Liming could also decrease the benefit of AM fungi because increasing $\mathrm{pH}$ from acid $\mathrm{pH}$ to about $\mathrm{pH}$ 7, increases availability of inorganic P (Schlesinger, 1997), and reduces amount of fungi (Ivarson, 1977). However, at higher $\mathrm{pH}, \mathrm{P}$ availability declines again and so mycorrhizal colonization and benefits could increase (Anderson et al., 1996; Borja and Nielsen, 2008).

Copper availability in peatlands or organic soils is generally low and can limit plant growth (Rehm, 2002). Cu uptake by AM fungi might be affected by availability of soil $\mathrm{P}$, where their activity will be hampered under high $\mathrm{P}$ concentration ( $\mathrm{P}$ fertilizer), which likely reduces absorption of Cu by plants (Lambert et al., 1979). However, their role in Cu acquisition is still unclear (Leyval et al., 1997). Some studies found increased Cu absorption by AM plants (Killham and Firestone, 1983; Weissenhorn and Leyval, 1995) whereas others showed the reverse (Leyval et al., 1991).

Given the paucity of information of the effect of AM fungi on NWC seedling growth and macro- and micronutrient uptake on poor peat soils, our objective was to fill this gap. The aims of the present greenhouse study were to 1) test if AM inoculation increased growth of NWC seedling on oligotrophic peat soil, and 2) 
quantify if fertilization and liming of the soil modified results of inoculation. We hypothesized that 1) AM inoculation would increase NWC growth and nutrient acquisition, especially $P$, and 2 ) the positive impact of AM inoculation of NWC would be reduced in fertilized and limed seedlings.

\subsection{Materials and methods}

\subsubsection{Study site}

A greenhouse study was conducted at the School of Forest Resources and Environmental Science, Michigan Technological University. Seeds of NWC were obtained from the USDA Forest Service (J.W. Toumey Nursery, Watersmeet, MI). The peat soil $(\mathrm{pH} 4.4)$ used for this study was obtained from a forested poor fen near Painesdale, Houghton County, MI (N 47.01349 $\left.{ }^{\circ}, \mathrm{W} 88.43082^{\circ}\right)$. The peatland is dominated by non-mycorrhizal mosses (Sphagnum and Polytrichum), dwarf shrubs belonging to Ericaceae colonized by ericoid mycorrhizal fungi, and trees dominated by black spruce and tamarack colonized by ectomycorrhizal fungi. To avoid contamination with native inoculum from sparsely distributed AM hosts, soil was collected under Ericaceae from an area with no NWC or other AM host species present within 100 meters.

\subsubsection{Experimental treatments}

Prior to sowing, NWC seeds were soaked overnight in cold water. The seeds were germinated on flats filled with a mixture of pasteurized $\left(70^{\circ} \mathrm{C}\right)$ vermiculite (Sunshine Vermicullite, Sun Gro Horticulture Canada Ltd) and potting soil (Sunshine Mix 1, Sun Gro Horticulture Canada Ltd) with a 1:2 ratio. The seeded flats were placed within a mist chamber in the greenhouse for approximately two months until the seeds germinated and grew to an average height of $2 \mathrm{~cm}$. 
The experiment was a full-factorial completely random experimental design consisting of three factors: mycorrhizal inoculation (M), fertilization (F), and liming (L), each with two levels (with and without the factor). Each treatment combination was replicated ten times. We used Osmocote Plus 15-9-12 (N-P-K) slow release fertilizer that included some micronutrients such as magnesium, sulfur, boron, copper, iron, manganese, molybdenum, and zinc (Everris NA, Inc., Dublin, OH). For lime, we used garden and lawn lime (Mayfille Limestone Inc, Mayfille, WI) consisting of $22 \%$ calcium ( $\mathrm{Ca}$ ) and $12 \%$ of magnesium $(\mathrm{Mg})$. Fertilizer and lime were mixed with the soils about a month prior to the initiation of the experiment, applied based on their manufacture's recommendation, with dosage $1.65 \mathrm{~g}$ fertilizer/500 $\mathrm{ml}$ soil and $1.15 \mathrm{~g}$ lime/500 $\mathrm{ml}$ soil. Arbuscular mycorrhizal inoculum consisted of Rhizophagus intraradices, Glomus mosseae, G. aggregatum, and Claroideoglomus etunicatum (Tri-C Enterprises, Chino, CA) that contained 120 propagules/cc. Control inoculum material for other effects of inoculum was pasteurized at $70^{\circ} \mathrm{C}$. Mycorrhizal inoculum was applied in the growing media when the seedlings were transplanted. The inoculum was placed around seedling roots at the rate of $3.4 \mathrm{~g}$ per seedling as recommended by the manufacturer. On un-inoculated treatments, the seedlings were given the same amount of pasteurized AM inoculum. On March 12, 2014 the previously germinated seedlings were transplanted into Deepots $7 \mathrm{~cm}$ in diameter by $25 \mathrm{~cm}$ tall (Stuewe and Sons, Inc. Tangent, OR) containing $500 \mathrm{ml}$ unsterilized- field collected peat soils treated as described above. The pots were randomly arranged in racks on greenhouse benches. Day length was set at 16 hours with supplemental lighting via Halco metal halide lamps (Prolume MP 400/BU), and temperature maintained at $22^{\circ}-24^{\circ} \mathrm{C}$. Seedlings were watered daily using tap wat 


\subsubsection{Data collection}

As a non-destructive measure of the effect of the treatments on growth, seedling height was measured monthly. Seedlings were harvested after 11 months from their transplanting time (February 7, 2015). At harvest, height and diameter of seedlings were measured. In addition, shoots and roots of the seedling were separated. Roots were washed with tap water, $0.3 \mathrm{~g}$ (wet weight) root subsamples were taken for assessment of mycorrhizal colonization (see below), then residual roots and shoots were placed into paper bags and oven dried $\left(65^{\circ} \mathrm{C}\right)$ until their weights were constant. After drying, we measured root and shoot dry weight. Healthy fine roots to be used in measurement of mycorrhizal colonization were subsampled from around the root collar where new roots emerged. To measure the effectiveness of mycorrhizal inoculum, we first cleared and stained the roots following the protocol of Vierheilig et al. (2005). Briefly, this entailed clearing the roots by submerging them in $30 \mathrm{ml} 10 \% \mathrm{KOH}$ solutions and placing them in a water bath at $90^{\circ} \mathrm{C}$. When $\mathrm{KOH}$ solution became colored, the solution was changed until it remained clear. Cleared roots were rinsed with DI water and stained overnight with the staining solution with concentration $0.06 \%$ Chlorazol E Black (CEB, Acros Organic $(0.3 \mathrm{~g})$, lactic acid $(100 \mathrm{ml})$, glycerol $(200 \mathrm{ml})$, and DI water $(200 \mathrm{ml})$. Finally, the roots were rinsed with DI water and placed in destaining solution consisting of lactic acid $(200 \mathrm{ml})$, glycerol $(100 \mathrm{ml})$, and DI water $(400 \mathrm{ml})$. The destaining solution was changed until solution remained clear. Roots were mounted on slides in PVLG gel (a mixed solution of DI water $(100 \mathrm{ml})$, lactic acid $(100 \mathrm{ml})$, glycerol $(100 \mathrm{ml})$, and polyvinyl alcohol (16.6 g) (van Diepen, 2008). Next we scored the percentage of fungal colonization on the stained roots under the microscope, based on presence of AM and other fungal structures including aseptate AM hyphae, septate non-AM 
hyphae, arbuscules, coils, and vesicles (van Diepen, 2008). We measured the percentage of colonized roots under 200x magnification, with a total of 100 root transects per slide. Photos of mycorrhizal structure on colonized roots were taken using a microscope-mounted 5.0 megapixel digital camera (Leica DFC480, Cambridge, UK).

We measured leaf nutrient concentration and content $(\mathrm{N}, \mathrm{P}, \mathrm{C}$, and $\mathrm{Cu})$ in dried NWC leaves. The leaves were ground use a mortar and pestle, and analyzed at Laboratory of Forest Ecology Stable Isotope, SFRES, at Michigan Tech. For \%C and $\% \mathrm{~N}$ we used a Costech 4010 elemental analyzer (Costech Analytical Technologies Inc, Valencia, CA, USA) calibrated with atropine. For $\% \mathrm{P}$ and $\% \mathrm{Cu}$, we used inductively coupled plasma optical emission spectrometry on a Perkin Elmer Optima 7000DV ICP-OES (PerkinElmer Inc, Waltham, MA, USA) using the dry ash method (Miller 1998). Foliar nutrient content was derived from dry mass and concentration data. To determine the efficacy of the liming treatment, we measured soil $\mathrm{pH}$ of each treatment at the termination of the experiment on pooled, $2 \mathrm{~mm}$ sieved soils. We measured soil pH use a pH conductivity meter (Denver Instrument Model 220, Denver Instrument, Arcada, CO, USA).

\subsubsection{Data analysis}

The effect of treatment factors on NWC growth metrics (height, diameter, biomass, and biomass allocation) and nutrient status (concentration and content of $\mathrm{N}, \mathrm{P}$, and $\mathrm{Cu} ; \mathrm{N}: \mathrm{P}$ ), and percentage of mycorrhizal colonization were statistically tested using SAS program (SAS Institute Inc., Cary, NC, USA) using generalized linear models. We accounted for lack of normality using transformations when needed, and lack of homogeneity of variance was accounted for using an appropriate "group" term that permitted analysis under heterogeneous variance. There was no 
transformation needed for the variables height, total biomass, $\mathrm{P}$ and $\mathrm{Cu}$ content, $\% \mathrm{Cu}$, and NP ratio. We transformed other variables as following: square root (diameter, root biomass, root shoot ratio, N content) and log 10 (shoot biomass, $\% \mathrm{~N}, \% \mathrm{P})$.

\subsection{Results}

\subsubsection{AM structures presence}

AM fungal structures such as aseptate hyphae, vesicles, and arbuscules were more abundant in inoculated than uninoculated treatments (Table 1.1). The most common structures were aseptate AM hyphae, which appeared in all inoculated treatments and no inoculated treatments. Few arbuscules were observed in this experiment, and those that were observed appeared to be degraded. Vesicles were also found in limited number. Septate hyphae, indicating non-mycorrhizal root endophytes, were highest in the fertilized + inoculated treatment combination (Fig 1.1).

\subsubsection{Seedling Growth}

For virtually all growth metrics, there was a significant and roughly equivalent positive effect of both fertilization and inoculation. However, these effects were mostly non- additive: the positive effect of both treatments was much stronger alone than when in combination, resulting in many significant treatment interactions (Table 1.2; Fig 1.4; Fig. 1.8).

In comparison with the other two treatments, the liming main effects were weaker, and its interactions with inoculation and fertilization differed. There were significant negative main effects of liming on shoot and total biomass. In the presence of fertilization, the negative effects of liming were reversed, leading to 
significant interactions for root biomass, shoot biomass, and total biomass (Table 1.2; Fig 1.4; Fig 1.6). In contrast, the negative effects of liming were enhanced in the presence of mycorrhizal inoculation, leading to large reductions in root, shoot and total biomass in the mycorrhizal limed treatment relative to the mycorrhizal unlimed treatment, which manifested as significant liming $\mathrm{x}$ inoculation interactions for root biomass and total biomass (Table 1.2; Fig 1.4; Fig 1.7).

\subsubsection{Nutrient acquisition}

For almost all nutrient metrics, both fertilization and mycorrhizal inoculation showed the same positive effects, except on $\% \mathrm{~N}$ and $\% \mathrm{Cu}$. When in combination, fertilization and inoculation had a smaller or no additive effect, leading to significant fertilization $\mathrm{x}$ inoculation interactions for all variables except \%P (Table 1.3; Fig 1.4; Fig 1.8).

Liming showed different effects from both fertilization and inoculation. There were significant negative main effects of liming on \%, $\mathrm{P}$ content, and $\mathrm{N}$ content, and significant positive main effects of liming on NP ratio. Liming had a weak significant interaction with inoculation for both \%N and \%P (Table 1.3; Fig 1.5; Fig 1.8). In both cases this resulted from a positive effect of inoculation in combination with liming vs. negative $(\% \mathrm{~N})$ or non-significant $(\% \mathrm{P})$ effect in the absence of liming.

\subsection{Discussion}

1.5.1. Mycorrhizal inoculation effects on growth and nutrient acquisition

Overall, eleven months after treating the NWC seedlings with the experimental treatments, AM inoculation positively affected all growth metrics of NWC seedlings and nutrient measurements except $\mathrm{N}$ concentration. These results supported our hypothesis that on unfertilized acid peat soil AM fungi inoculation was 
able to improve NWC growth and nutrient supply, especially $P$, reducing the need for fertilizer and liming. Our results also show that AM inoculum that consisted of fungi of Rhizophagus intraradices, Glomus mosseae, G. aggregatum, and Claroideoglomus etunicatum, successfully colonized NWC seedlings.

Many studies have exhibited that benefits of AM fungi for plants are predominantly obtained in sites with limited nutrients, especially P (Liu et al., 2000; Tawaraya, 2003; Smith \& Read, 2008; Smith \& Smith, 2011). This is consistent with their importance in enhancing plant $\mathrm{P}$ uptake, whereas their role in $\mathrm{N}$ uptake is less clear (Smith and Smith, 2011). Our study shows that mycorrhizal growth response (MGR) was very strong, positive and significantly greater on inoculated seedlings (M) than that of on uninoculated seedlings (control). Likewise, we found mycorrhizal inoculation resulted in positive effects to plant growth in absence of fertilization and liming. Even, these treatments hindered efficacy of AM fungi (Fig 1.4; Fig 1.5; Fig 1.7, Fig 1.8).

Enhanced plant growth was likely caused by increasing nutrient availability especially P. Analysis of foliar N : P ratio shows that mycorrhizal inoculation was able to reduce the ratio, which is a good indicator of increasing $\mathrm{P}$ availability to the plants ( $\mathrm{P}$ concentration and content). These results suggest that availability of the limiting resource $(\mathrm{P})$ as a major driver to control plant growth with an assumption that other resources were not limiting. Liebig's law of the minimum state that plant growth is predominantly determined by the most limiting resource, although plant growth is mostly controlled by co-limited factors by multiple resources (Harpole et al., 2011; Johnson et al., 2014). Although AM fungi are capable of $\mathrm{N}$ acquisition from either inorganic or organic forms (Smith and Smith, 2011), many studies report that AM fungi do not increase $\mathrm{N}$ availability as much as $\mathrm{P}$ availability (Liu et al., 2000; Valentine et al., 2001; Jin et al., 2012). In acid peatlands, where $\mathrm{N}$ is often limiting 
(Bayley et al., 2005) and other species have specific adaptations to increase $\mathrm{N}$ uptake (Smith and Read, 2008), this could reduce the efficacy of AMF of NWC relative to competitors. Tissue $\mathrm{N}$ concentration, $\mathrm{P}$ concentration, and $\mathrm{N}: \mathrm{P}$ ratios in our study reveal that mycorrhizal inoculation successfully alleviated $\mathrm{P}$ deficiency, but not $\mathrm{N}$ limitation (Fig 1.6). Tissue N:P >16 indicates $\mathrm{P}$ limitation (Koerselman and Meuleman, 1996; Johnson et al., 2014), where AM fungi act as a mutualistic symbiont where they supply surplus $P$ for plant photosynthate. Meanwhile, tissue N:P $<14$ depicts limitation in $\mathrm{N}$ availability where AM fungi may act as commensal or parasitic symbiont (Johnson et al., 2014). Under $\mathrm{N}$-limited systems, AM fungi may be incapable of providing $\mathrm{N}$ surplus for host plants since their $\mathrm{N}$ demand (per unit biomass) is higher than their hosts (Johnson et al., 2014; Hodge \& Storer, 2015). It is assumed that AM fungi used $\mathrm{N}$ to fulfill their own nutritional needs before supplying it to host plants. Hodge and Fitter (2010) found that the AM extraradical hyphae had $\mathrm{N}$ concentration seven- to ten-fold higher than that of plant shoots and roots. Under limited soil $\mathrm{N}$ availability, AM fungi cannot supply $\mathrm{N}$ to their hosts (Hoeksema et al., 2015). In addition, in pot experiments AM external hyphae and plant root systems have to compete using the same soil volume so it is less likely AM external hyphae would explore different soil resources (Hodge, 2000; Hodge, 2001).

Our findings indicate that AM fungi reduced foliar $\mathrm{Cu}$ concentration, although all treatments were several-fold above the deficiency threshold of $\sim 4 \mathrm{ppm}$ for other conifers (Schmitt \& White 1988). Reduction of Cu concentration in the roots and shoots has been reported by several authors (Zhang et al., 2009; Latef, 2011 ; Meier et al., 2015). It is possible that reduction of copper concentration in the plants is related to AM fungi benefits in protecting the plants from $\mathrm{Cu}$ toxicity and increasing $\mathrm{P}$ availability. Latef (2011) suggested AM plants had protection from Cu exposure by enhancing availability of phosphorus and improving plant growth. Timmer and 
Leyden (1980) reported there was negative correlation between $\mathrm{P}$ availability and $\mathrm{Cu}$ uptake by plants, where increasing $\mathrm{P}$ supply led to diminished copper acquisition by plants. In addition, increasing copper uptake is also influenced by nitrogen where a soluble organic $\mathrm{N}$ will associate with $\mathrm{Cu}$ compound to translocate copper throughout the plant from the xylem and phloem saps (Singh and Swarup, 1982). Hence, if reduction of $\mathrm{N}$ uptake occurred, it would affect alleviation of copper uptake. Nevertheless, mechanisms of AM fungi in $\mathrm{Cu}$ accumulation have not still been clear. Glomalin produced by AM fungi could be a major consideration in decreasing $\mathrm{Cu}$ concentration where this glycoprotein can support sequestration of $\mathrm{Cu}$ and other heavy metals (Gil-Gardeza et al., 2014). Several studies about copper-binding capacity of AM hypae revealed that AM fungi become a biological barrier in $\mathrm{Cu}$ translocation in plant tissues where glomalin will prevent $\mathrm{Cu}$ transfer from the roots to shoots (Joner and Leyval., 1997; Joner et al., 2000; Toler et al., 2005; Zhang et al., 2009).

Presence of AM fungi structures such as arbuscules and vesicles mirrors AM colonization in the roots, although presence of hypha alone can be evidence of their association with the roots. Our study showed limited arbuscules and vesicles in AMcolonized roots. We assumed that it was affected by soil pH status. Duke et al. (1994) suggested that lack of arbuscules might indicates plant roots are in nutrientrich conditions and the plant is less responsive to P supply by AM fungi. Abbot et al. (1984) and Braunberger et al. (1991) stated that proportion of arbuscules to vesicles might be used to understand relative benefit of mycorrhizal fungi to the plant. However, Brundrett and Kendrick (1988) suggested that arbuscules are ephemeral structures, sometimes they are not present in the samples particularly when the sample roots are collected in active forms. 
1.5.2. Interaction of mycorrhizal inoculation with fertilization and liming Fertilization and liming have generally been applied to increase plant growth, improve soil fertility, and reduce soil acidity in peatland restoration (Huotari et al., 2007; Bjork et al., 2010; Caporn et al., 2007). Their ability to supply some essential nutrients and increase soil $\mathrm{pH}$ in short term are the major consideration to use them to restore the degraded peatlands, even though there are economic and ecological costs of these practices. Both of these practices appear to reduce plant response to mycorrhizal inoculation. Our study showed benefits of inoculation are greatest in the absence of fertilization (Fig 1.7; Fig 1.8). These results indicate that mycorrhizal inoculation is an important alternative to fertilization of NWC, and might be beneficial under liming to a high soil $\mathrm{pH}$.

In conclusion, AM inoculation successfully improved nutrient status and growth of NWC seedlings in acidic peat soils, with benefits similar to those of fertilization. This indicates that AM fungi might be an alternative to enhance success of NWC restoration projects without the need for additional liming and fertilization. AM inoculation would sustain in the plant roots under the favor environments. However, two factors might limit our ability to infer success in acid peatland soil. Firstly, our study was a greenhouse experiment, hence eliminating plant competition. Presence of other plants might restrict NWC growth because all the plants require the same basic factors to support their growth such as nutrient, light, water, space, and other factors, and other species have adaptations that might favor them for competition for limited N (Johnston, 1990; Weber et al., 2005). Secondly, AM efficacy is determined by environmental factors (e.g., more acidic field pH) and AMF species compatibility with the host plants. Therefore tests of the efficacy of mycorrhizal inoculation in the field are needed to confirm practical utility. 


\subsection{References}

Abbott. L.K., A.D. Robson, G.D. Boer. 1984. The effect of phosphorus on the formation of hyphae in soil by the vesicular-arbuscular mycorrhizal fungus, Glomus fasciculatum. The New Phytologist 97 (3): 437-446

Andersson, S., P. Jensen, B. Soderstrom. 1996. Effects of mycorrhizal colonization by Paxillus involutus on uptake of Ca and $\mathrm{P}$ by Picea abies and Betula pendula grown in unlimed and limed peat. New Phytologist 122: 695-704

Bainard, L. D., J. N. Klironomos, A. M. Gordon. 2011. The mycorrhizal status and colonization of 26 tree species growing in urban and rural environments. Mycorrhiza 21(2): 91-96.

Bayley, S. E., M. N. Thormann, A. R. Szumigalski. 2005. Nitrogen mineralization and decomposition in western boreal bog and fen peat. Ecoscience 12: 455_465.

Bjork, R. G., M. Ernfors, U. Sikstrom, M. B. Nilsson, M. X. Andersson, T. Rutting, L. Klemedtsson, 2010. Contrasting effects of wood ash application on microbial community structure, biomass and processes in drained forested peatlands. FEMS Microbiol. Ecol. 73(3): 550-562.

Børja, I. \& P. Nilsen. 2008. Long term effect of liming and fertilization on ectomycorrhizal colonization and tree growth in old Scots pine (Pinus sylvestris L.) stands. Plant and Soil, 314 (1-2): 109-119.

Brække, F. H. 1999. Drainage, Liming and Fertilization of Organic Soils. I. Long-term Effects on Acid/Base Relations. Scandinavian Journal of Forest Research 14(1): 51-63.

Braunberger, P.G., M.H. Miller, R.L. Peterson. 1991. Effect of phosphorous nutrition on morphological characteristics of vesicular-arbuscular mycorrhizal colonization of maize. The New Phytologyst 119 (1): 107-113 
Brundrett M.C. and W.B. Kendrick. 1988. The mycorrhizal status, root anatomy, and phenology of plants in a sugar maple forest. Canadian Journal of Botany 66: 1153-1173.

Brundrett, M., G. Murasea, \& B. Kendrick. 1989. Comparative anatomy of roots and mycorrhizae of common Ontario trees. Can. J. Bot. 68: 551-578.

Caporn, S., R. Sen, C. Field, E. Jones, J. Carroll, \& N. Dise. 2007. Consequences of lime and fertiliser application for moorland restoration and carbon balance. Research report to Moors for the Future. May 2007. Department of Environmental and Geographical Sciences, Faculty of Science and Engineering. Manchester Metropolitan University. Chester StreetManchester M1 5GD

Duke, S.E., R.B. Jackson, M.M. Caldwell. 1994. Local reduction of mycorrhizal arbuscule frequency in enriched soil microsites. Can. J. Bot. 72: 998-1001

Fraver, S., A. S. White, R. S. Seymour. 2009. Natural disturbance in an old-growth landscape of northern Maine, USA. Journal of Ecology 97: 289-298

Gil-Cardeza, M.L., A. Ferri, P. Cornejo, E. Gomez. 2014. Distribution of chromium in a Cr-polluted soil: presence of $\mathrm{Cr}$ (III) in glomalin related protein fraction. Sci. Total Environ 493: 828-833

Harpole W.S., J.T. Ngai, E.E. Cleland, E.W. Seabloom, E.T. Borer, M.E.S. Bracken, J.J. Elser, D.S. Gruner, H. Hillebrand, J.B. Shurin, J. E, Smith. 2011. Nutrient co-limitation of primary producer communities. Ecology Letters 14: 852-862. Hodge, A. 2000. Microbial ecology of the arbuscular mycorrhiza. FEMS Microbiology Ecology 32:91-96 
Hodge, A. 2001. Arbuscular mycorrhizal fungi influence decomposition of, but not plant nutrient capture from, glycine patches in soil. New Phytol 151:725-734

Hodge, A. and A.H. Fitter 2010. Substantial nitrogen acquisition by arbuscular mycorrhizal fungi from organic material has implications for $\mathrm{N}$ cycling. Proc Natl Acad Sci USA 107: 13754-13759

Hodge, A. and K. Storer. 2015. Arbuscular mycorrhiza and nitrogen: implications for individual plants through to ecosystems. Plant and Soil 286 (1): 1-19

Hoeksema, J.D., V.B. Chaudhary, C.A. Gehring, N.C. Johnson, J.Karst, R.T. Koide, A.Prinle, C.Zabinski, J.D.Bever, J.C. Moore. G.W. T. Wilson, J.N. Klironomos, J. Umbanhowar. 2015. A meta-analysis of context-dependency in plant response to inoculation with mycorrhizal fungi. Ecology Letters 13: 394-407

Huotari, N., E.T. Sutela, A. Kauppi, E. Kubin. 2007. Fertilization ensures rapid formation of ground vegetation on cut-away peatlands. Canadian Journal of Forest Research 37: 874-883

Ivarson, K.C. 1977. Changes in decomposition rate, microbial population and carbohydrate content of an acid peat bog after liming and reclamation. Canadian Journal of Soil Science 57(2): 129-137

Jin, H., J. Liu, J. Liu, X.W. Huang. 2012. Forms of nitrogen uptake, translocations, and tranbsfer via arbuscular mycorrhizal fungi: A review. Science China Life Sciences 55 (6): 474-482

Johnson, N.C. 1993. Can fertilization of soil select less mutualistic mycorrhizae? Ecological applications 3(4): 749-757

Johnson, N.C., G.W.T. Wilson, J.A. Wilson, R.M. Miller, M.A. Bowker. 2014. Mycorrhiza: phenotypes and the Law of the Minimum. New Phytologyst: 1-12 
Johnston, W.F. 1990. Thuja occidentalis L. northern-white cedar. In: Burns, R.M.; Honkala, B.H., eds. Silvics of North America. Vol. 1. Agric. Hndbk. 654. Washington, DC: U.S. Department of Agriculture, Forest Service: 580-589.

Jonard, M., F. Andre, P. Giot, F. Weissen, R.V. der Perre, Q. Ponette. 2010. Thirteenyear monitoring of liming and PK fertilization effects on tree vitality in Norway spruce and European beech stands. European Journal of Forest Research 129 (6): 1203-1211

Joner E.J. and C. Leyval. 1997. Uptake of $109 \mathrm{Cd}$ by roots and hyphae of a Glomus mosseae/Trifolium subterraneum mycorrhiza from soil amended with high and low concentrations of cadmium. New Phytol 135:353-360

Joner, E.J., R. Briones, C. Leyval. 2000. Metal-binding capacity of arbuscular mycorrhizal mycelium. Plant Soil 226: 227-234

Kangas, L. C., R. Schwartz, M. Rennington, C. R. Webster, R. A. Chimner. 2015. Artificial microtopography and herbivory protection facilitates wetland tree (Thuja occidentalis L.) survival and growth in created wetlands. New Forests: $1-14$

Killham K. and M.K. Firestone. 1983. Vesicular arbuscular mycorrhizal mediation of grass response to acidic and heavy metal depositions. Plant Soil 72: 39-48 Koerselman W. and A.F.M. Meuleman. 1996. The vegetation N: P ratio: a new tool to detect the nature of nutrient limitation. Journal of Applied Ecology 33: $1441-1450$.

Lambert, D. H., D. E. Baker, H. Cole Jr. 1979. The role of mycorrhizae in the interactions of phosphorus with zinc, copper, and other elements. Soil Sci. Soc. Am. J. 43:976-980. 
Latef, A.A.H.A. 2011. Influence of arbuscular mycorrhizal fungi and copper on growth, accumulation of osmolyte, mineral nutrition and antioxidant enzyme activity of pepper (Capsicum annum L.). Mycorrhiza 21: 495-503

Leyval C, J. Berthelin, D. Schontz, I. Weissenhorn, J.L. Morel. 1991. Influence of endomycorrhizas on maize uptake of $\mathrm{Pb}, \mathrm{Cu}$ and $\mathrm{Cd}$ applied as mineral salts or sewage sludge. In: Farmer J.G. (ed) Heavy metals in the environment. CEP Consultants, Edinburgh: 204-207

Leyval, C., K. Turnau, K. Haselwandter. 1997. Effect of heavy metal pollution on mycorrhizal colonization and function: physiological, ecological, and applied aspects. Mycorrhiza 7: 139-153

Liu, A., C. Hamel, R.I. Hamilton, B.L. Ma, D.L. Smith. 2000. Acquisition of Cu, Mn, and Fe by mycorrhizal maize (Zea mays L.) grow in soil at different $\mathrm{P}$ and micronutrient levels. Mycorrhiza 9: 331-336

Matthes-Sears, U., C. Neeser \& D.W. Larson. 1992. Mycorrhizal colonization and macronutrient status of cliff-edge Thuja occidentalis and Acer saccharum. Ecography 15 (3): 262-266

Marchand, L., Nsanganwimana, F., Lamy, J. B., Quintela Sabaris, C., Gonnelli, C., Colzi, I., Mench, M. 2014. Root biomass production in populations of six rooted macrophytes in response to $\mathrm{Cu}$ exposure: Intra-specific variability versus constitutive-like tolerance. Environmental pollution 193: 205-215

Meier, S., P. Cornejo, P. Cartes, F. Borie, J. Medina, R. Azcon. 2015. Interactive effect between Cu-adapted arbuscular mycorrhizal fungi and biotreated agrowaste residue to improve the nutritional status of Oenothera picensis growing in Cu-polluted soils. J. Plant Nutr. Soil Sci. 178: 126-135 
Miller, R. O. 1998. High temperature oxidation: dry ashing. In: Kalra, Y. P, (Ed) Handbook of Reference Methods for Plant Analysis. Taylor \& Francis, Boca Raton, USA: 53-56

Moore, D. J., C. Camiré, R. Ouimet. 2000. Effects of liming on the nutrition, vigor, and growth of sugar maple at the Lake Clair Watershed, Québec, Canada. Can. J. For. Res. 30: 725-732

Nijjer, S., W.E. Rogers, E. Siemann. 2010. The Impacts of fertilization and mycorrhizal production and investment in Western Gulf Coast grasslands. The American Midland Naturalist 163 (1): 124-133

Pabian, S.E., S.M. Rummel, W.E. Sharpe, M.C. Brittingham. 2012. Terrestrial liming as a restoration technique for acidic forest ecosystem. International Journal of Forestry Research Volume 2012, Article ID 976809:1-11

Palik, B. J., B. K. Haworth, A. J. David, \& R. K. Kolka. 2015. Survival and growth of northern white-cedar and balsam fir seedlings in riparian management zones in northern Minnesota, USA. Forest Ecology and Management 337: 20-27.

Rehm, G. 2002. Copper for crop production. University of Minnesota Extension.

Savci, S. 2012. An agricultural pollutant: Chemical fertilizer. International Journal of Environmental Science and Development 3 (1): 77-80

Schlesinger, W.H. 1997. Biogeochemistry. An analysis of global change. 2nd Edn. Academic Press, San Diego, 588 p.

Schmitt, M.D.C. and E.H. White. 1988. Conifer growth on residual organic soils: A greenhouse study. Plant Soil 108:253-261

Sing, D.V. and C. Swarup. 1982. Copper nutrition of wheat in relation to nitrogen and phosphorus fertilization. Plant and Soil 65: 433-436 
Singh, S. 1998. Role of mycorrhiza in the tree nurseries. Part 1. Evaluation of mycorrhizal effieciency with and without application of fertilizers. Mycorrhiza News 10: 2-11

Smith, S.E. and D.J. Read. 2008. Mycorrhizal symbiosis. $3^{\text {rd }}$ Edition. Academic Press.

Smith, S.E. and F.A. Smith. 2011. Roles of arbuscular mycorrhizas in plant nutrition and growth: New paradigms from cellular to ecosystem scales. Annual Review of Plant Biology 62: 227-250

Tawaraya, K. 2003. Arbuscular mycorrhizal dependency of different plant species and cultivars. Soil Sci. Plant Nut. 49 (5): 655-668.

Tawaraya, K., M. Turjaman, \& H. A. Ekamawanti. 2007. Effect of arbuscular mycorrhizal colonization on Nitrogen and Phosphorus uptake and growth of Aloe vera L. Hortscience 42 (7):1737-1739

Timmer, L.W. and R.F. Leyden. 1980. The relationship of mycorrhizal infection to phosphorus-induced copper deficiency in sour orange seedlings. The New Phytologyst 85 (1): 15-23

Toler, H.D., J.B. Morton, J.R. Cumming. 2005. Growth and metal accumulation and arbuscular mycorrhizal colonization of pennycrees Thlaspi praecox Wulf. (Brasiccaceae) from the vincinity of a lead mine and smelter in Slovenia. Environ. Pollut. 133: 233-242

Treseder, K.K. 2004. A meta-analysis of mycorrhizal responses to nitrogen, phosphorous, and atmospheric $\mathrm{CO}_{2}$ in field studies. New Phytologyst 164 : 347-355

Valentine, A.J., B.A. Osborne, D.T. Mitchell. 2001. Interactions between phosphorus supply and total nutrient availability on mycorrhizal colonization growth and photosynthesis of cucumber. Sci. Horti. 88: 177-189. 
van der Ent, A., Baker, A. J., Reeves, R. D., Pollard, A. J., \& Schat, H. 2013. Hyperaccumulators of metal and metalloid trace elements: Facts and fiction. Plant and Soil $362(1-2): 319-334$.

van Diepen, L. 2008. The role and diversity of arbuscular mycorrhizal fungi in Acer saccharum dominated forest ecosystems under natural and $\mathrm{N}$-amended conditions. Dissertation at Michigan Technological University.

Vierheilig, H., P. Schweiger, M. Brundrett. 2005. An overview of methods for the detection and observation of arbuscular mycorrhizal fungi in roots. Physiologia Plantarum 125 (4): 393-404

Walker, R.F. 2002. Response of Jeffrey pine on a surface mine site to fertilizer and lime. Restoration Ecology 10 (2): 204-212

Weber, A., J. Karst, B. Gilbert. 2005. Thuja plicata exclusion in ectomycorrhizaldominated forests: testing the role of inoculum potential of arbuscular mycorrhizal fungi, Oecologia 143: 148-156

Weissenhorn, I., C. Leyval, J. Berthelin. 1995. Bioavailability of heavy metals and abundance of arbuscular mycorrhiza in a soil polluted by atmospheric deposition from a smelter. Biol. Fertil. Soils. 19: 22-28

Zhang, X.H. A.J. Lin, Y.L. Gai, R. J. Reid, M.H. Wong, Y.G. Zhu. 2009. Arbuscular mycorrhizal colonization increases copper binding capacity of root cell walls of Oryza sativa L. and reduces copper uptake. Soil Biology and Biochemistry 41: 930-935 


\subsection{Tables and Figures}

Table $1.1 . \%$ root length with AM structures (aseptate hyphae, vesicles, arbuscules) and non-AM fungal structures (septate hyphae) in the NWC stained roots with 200x magnification

\begin{tabular}{lrrrr}
\hline Treatment & \multicolumn{1}{c}{$\begin{array}{c}\text { Aseptate } \\
\text { hyphae }\end{array}$} & $\begin{array}{c}\text { Septate } \\
\text { hyphae }\end{array}$ & Vesicles & Arbuscules \\
\hline Control & $0 \pm 0.0$ & $1.9 \pm 1.1$ & $0 \pm 0.0$ & $0 \pm 0.0$ \\
$\mathrm{M}^{1}$ & $9.9 \pm 1.9$ & $5.2 \pm 2.3$ & $0.8 \pm 0.8$ & $4 \pm 1.9$ \\
$\mathrm{~F}^{1}$ & $0 \pm 0.0$ & $1.3 \pm 0.9$ & $0.1 \pm 0.1$ & $1.2 \pm 0.9$ \\
$\mathrm{~F}+\mathrm{M}$ & $2.7 \pm 1.1$ & $15.3 \pm 9.9$ & $0.4 \pm 0.4$ & $2.4 \pm 0.8$ \\
$\mathrm{~L}^{1}$ & $0 \pm 0.0$ & $0 \pm 0.0$ & $0 \pm 0.0$ & $0 \pm 0.0$ \\
$\mathrm{~L}+\mathrm{M}$ & $11.7 \pm 2.6$ & $0 \pm 0.0$ & $0.8 \pm 0.3$ & $5.5 \pm 1.9$ \\
$\mathrm{~L}+\mathrm{F}$ & $0 \pm 0.0$ & $0.3 \pm 0.3$ & $0 \pm 0.0$ & $0 \pm 0.0$ \\
$\mathrm{~L}+\mathrm{F}+\mathrm{M}$ & $2.7 \pm 0.9$ & $1.2 \pm 0.7$ & $0 \pm 0.0$ & $1.1 \pm 0.7$ \\
\hline
\end{tabular}

${ }^{1} \mathrm{M}$ : mycorrhizal inoculation; F: fertilization; L: liming

Table 1.2. $P$ values for treatment effects on $A M$ and non-AM fungal structures in the NWC stained roots. Abbreviations as in Table 1.1.

\begin{tabular}{lcccc}
\hline Treatment & $\begin{array}{c}\text { Aseptate } \\
\text { Hyphae }\end{array}$ & $\begin{array}{c}\text { Septate } \\
\text { Hyphae }\end{array}$ & Vesicles & Arbuscules \\
\hline L & 0.6708 & $\mathbf{0 . 0 3 7 3}$ & 0.6037 & 0.7154 \\
F & $<.0001$ & 0.3031 & 0.2552 & 0.1073 \\
M & $<.0001$ & $\mathbf{0 . 0 8 9 3}$ & 0.0514 & $\mathbf{0 . 0 0 0 2}$ \\
L*F & 0.5520 & 0.4434 & 0.6037 & 0.1766 \\
L*M & 0.6708 & 0.1208 & 0.7553 & 0.6666 \\
F*M & $<.0001$ & 0.2775 & 0.1795 & $\mathbf{0 . 0 1 7 6}$ \\
L*F*M & 0.5520 & 0.3493 & 0.7553 & 0.5733 \\
\hline
\end{tabular}




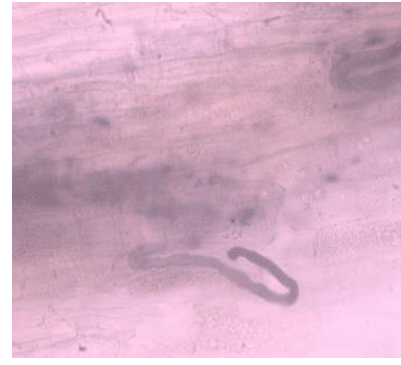

a)

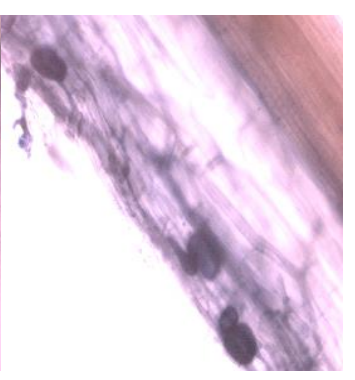

b)

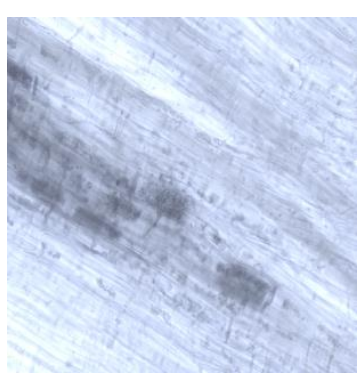

c)

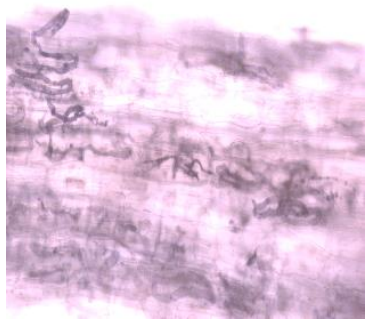

d)

Fig 1.1. The principles structures of AM fungi (a-c) and other root fungi (d), observed by clearing the roots tissues then staining roots with Chlorazol E. Black with 200X magnification: a) aseptate hyphae; b) vesicles; c) arbuscules; d) septate hyphae (non-AM fungi).

Table 1.3. P values of growth variables of the NWC seedlings. Abbreviations as in Table 1.1.

\begin{tabular}{|c|c|c|c|c|c|c|}
\hline Treatments & $\begin{array}{l}\text { Height } \\
(\mathrm{cm})\end{array}$ & $\begin{array}{l}\text { Diameter } \\
\quad(\mathrm{cm})\end{array}$ & $\begin{array}{c}\text { Root } \\
\text { Biomass } \\
(\mathrm{g})\end{array}$ & $\begin{array}{c}\text { Shoot } \\
\text { Biomass } \\
(\mathrm{g})\end{array}$ & $\begin{array}{c}\text { Total } \\
\text { Biomass } \\
(\mathrm{g})\end{array}$ & $\begin{array}{l}\text { Root } \\
\text { Shoot } \\
\text { Ratio }\end{array}$ \\
\hline $\mathrm{L}$ & 0.1508 & 0.6537 & 0.1807 & 0.0100 & 0.0021 & 0.2006 \\
\hline$F$ & $<.0001$ & $<.0001$ & $<.0001$ & $<.0001$ & $<.0001$ & $<.0001$ \\
\hline M & $<.0001$ & $<.0001$ & $<.0001$ & $<.0001$ & $<.0001$ & 0.0331 \\
\hline $\mathrm{L}^{*} \mathrm{~F}$ & 0.0309 & 0.4070 & 0.0072 & 0.0465 & 0.0178 & 0.1451 \\
\hline$L^{*} M$ & 0.1998 & 0.8217 & 0.0034 & 0.3693 & 0.0005 & 0.0335 \\
\hline $\mathrm{F}^{*} \mathrm{M}$ & $<.0001$ & $<.0001$ & $<.0001$ & $<.0001$ & $<.0001$ & 0.0431 \\
\hline $\mathrm{L} * \mathrm{~F} * \mathrm{M}$ & 0.1334 & 0.8036 & 0.4054 & 0.6211 & 0.3414 & 0.2828 \\
\hline
\end{tabular}


Table 1.4. P values of foliar nutrient variables of the NWC seedlings. Abbreviations as in

Table 1.1.

\begin{tabular}{lccccccc}
\hline Treatment & $\% \mathrm{~N}$ & $\% \mathrm{P}$ & $\% \mathrm{Cu}$ & $\mathrm{N}$ Content & $\mathrm{P}$ Content & $\begin{array}{c}\mathrm{Cu} \\
\text { Content }\end{array}$ & $\begin{array}{c}\mathrm{N}: \mathrm{P} \\
\text { Ratio }\end{array}$ \\
\hline $\mathrm{L}$ & 0.0942 & $\mathbf{0 . 0 1 7 9}$ & 0.0570 & $\mathbf{0 . 0 0 7 2}$ & $\mathbf{0 . 0 2 6 3}$ & 0.4620 & 0.6272 \\
$\mathrm{~F}$ & $\mathbf{0 . 0 0 0 4}$ & $<.0001$ & $\mathbf{0 . 0 2 0 8}$ & $<.0001$ & $<.0001$ & $<.0001$ & $<.0001$ \\
$\mathrm{M}$ & 0.9393 & $\mathbf{0 . 0 0 1 7}$ & 0.0552 & $<.0001$ & $<.0001$ & $<.0001$ & $\mathbf{0 . 0 1 3 9}$ \\
L*F & 0.3606 & 0.3818 & 0.2655 & 0.8996 & 0.5896 & 0.7241 & 0.0869 \\
L*M & $\mathbf{0 . 0 4 4 9}$ & $\mathbf{0 . 0 3 3 7}$ & 0.7406 & 0.3874 & 0.1655 & 0.4648 & 0.5446 \\
F*M $^{*}$ & $\mathbf{0 . 0 1 7 2}$ & 0.6661 & $<.0001$ & $<.0001$ & $\mathbf{0 . 0 0 2 5}$ & $\mathbf{0 . 0 0 0 9}$ & $\mathbf{0 . 0 1 4 5}$ \\
LFFM $^{*}$ & 0.1702 & 0.4349 & 0.1025 & 0.3030 & 0.5844 & 0.9190 & 0.9490 \\
\hline
\end{tabular}

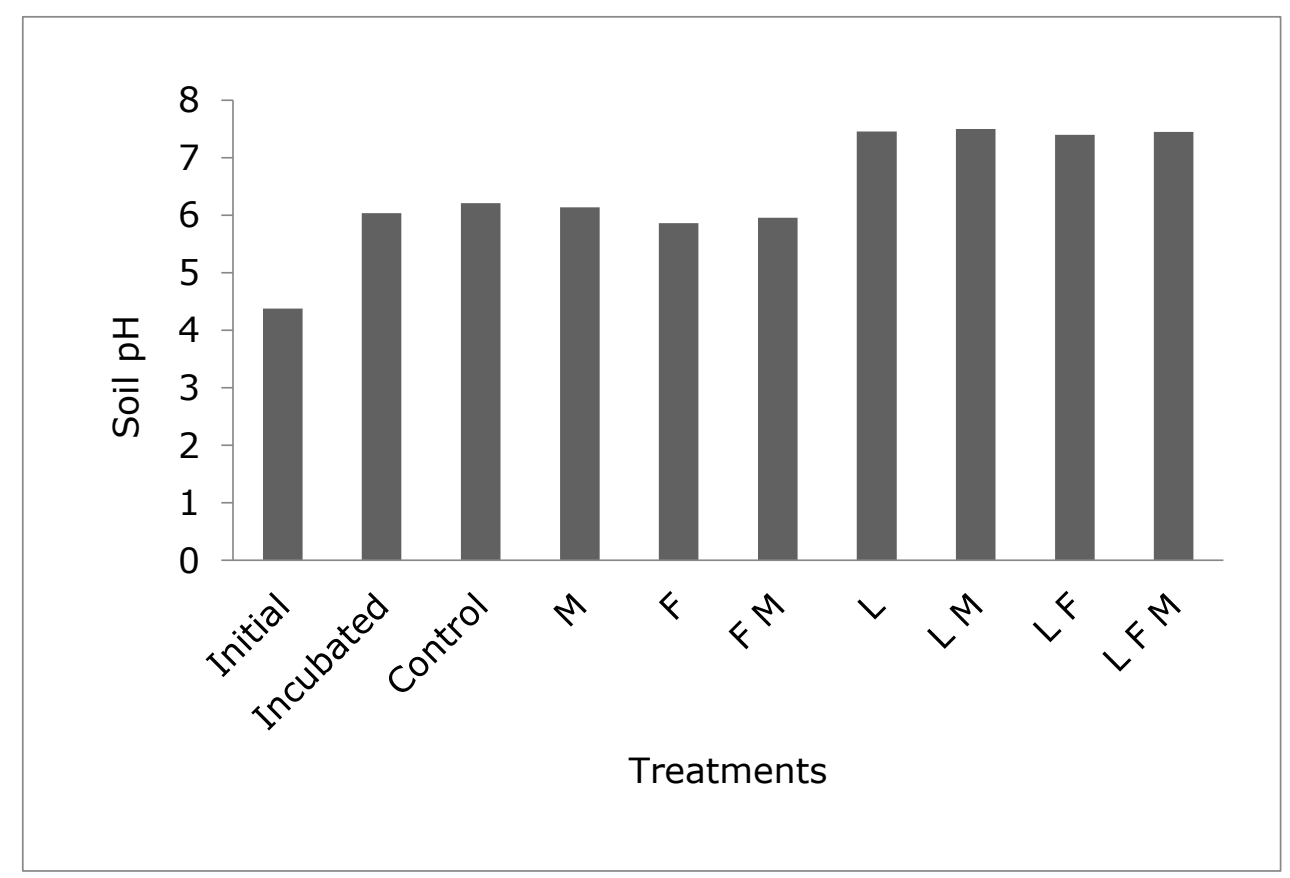

Fig 1.2. $\mathrm{pH}$ of pooled samples of the growth media used in the experiment(Control: no treatment. Initial $=$ prior to experiment. Incubated $=$ limed prior to the experiment. Others represent final $\mathrm{pH}$ of pooled soil samples. $\mathrm{pH}$ of peat increased over the course of the experiment. Abbreviations as in Table 1.1. 


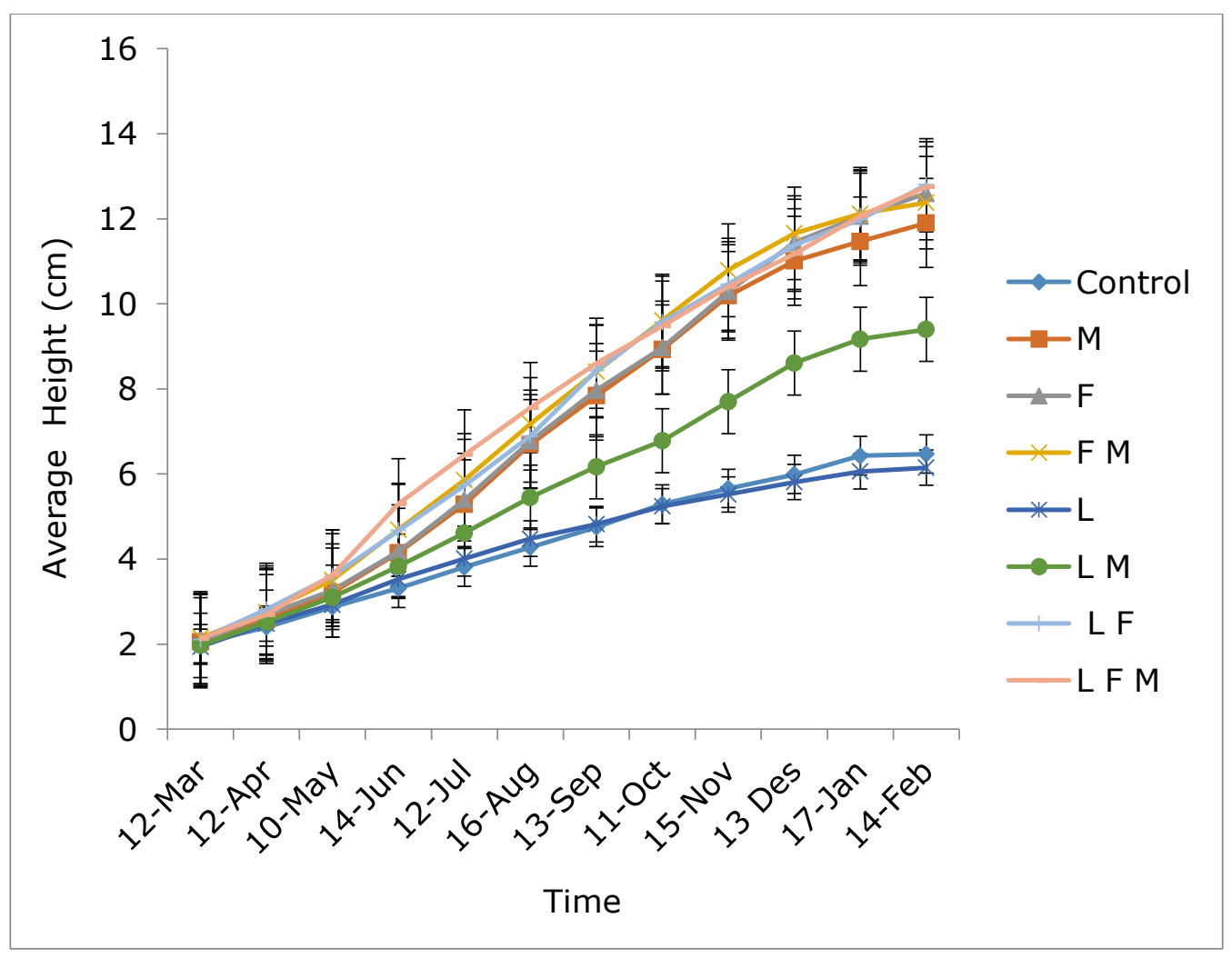

Fig. 1.3 Average height of the NWC seedlings within 11 months (Control: no treatment, M: mycorrhizal inoculation, F: fertilizer, FM: fertilization*mycorrhizal inoculation, L: liming, LM: liming*mycorrhizal inoculation,LF: liming*fertilization, FM:liming*fertilization*mycorrhizal inoculation). Error bars indicate standard error. 

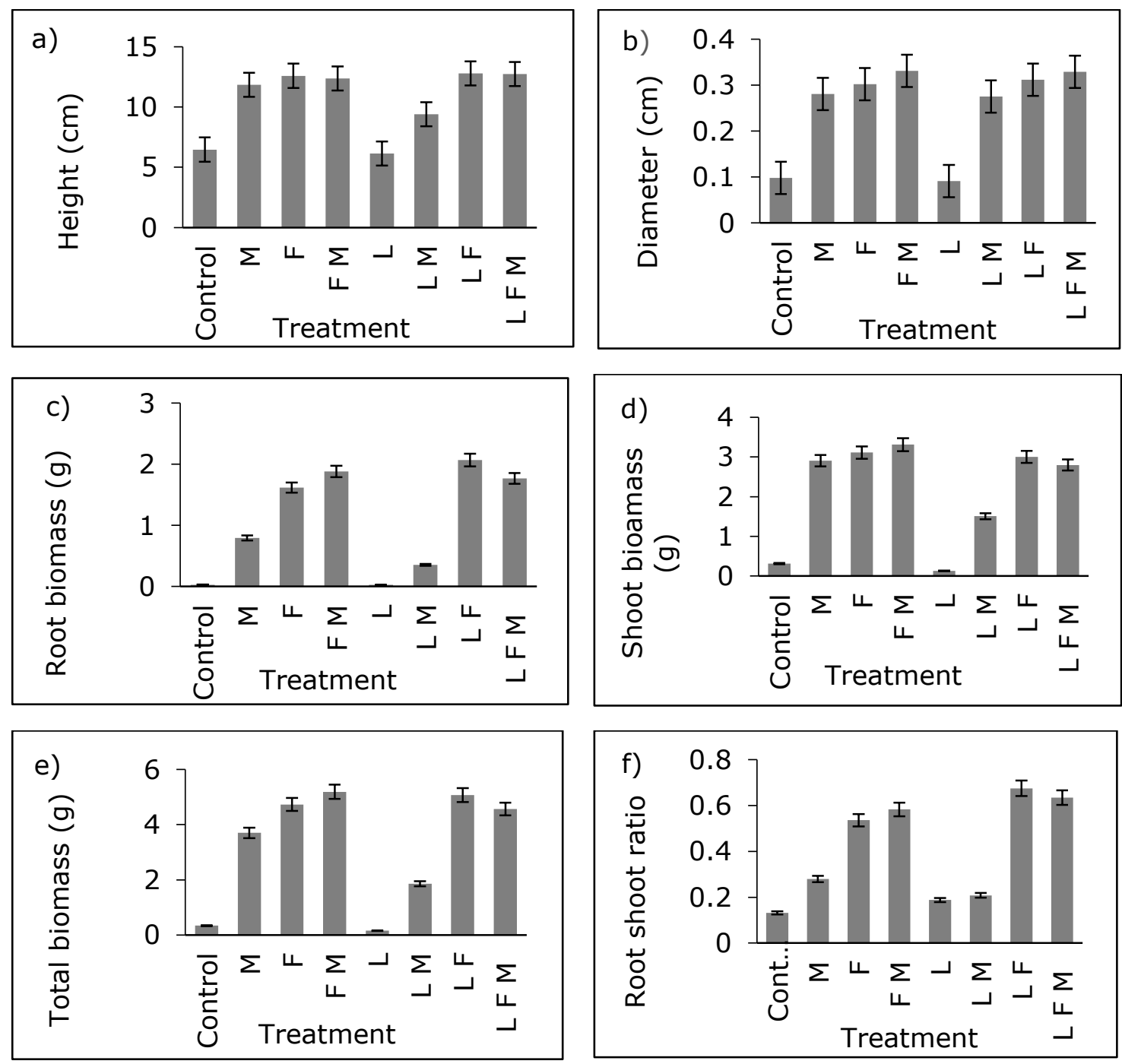

Fig 1.4. Effect of mycorrhizal inoculation, liming, and fertilization on growth of the NWC seedlings on: a) height; b) diameter; c) root biomass; d) shoot biomass; e) total biomass; f) root shoot ratio. See Table 1.3 for significance tests. Abbreviations as in Table 1.1. Error bars indicate standard error. 

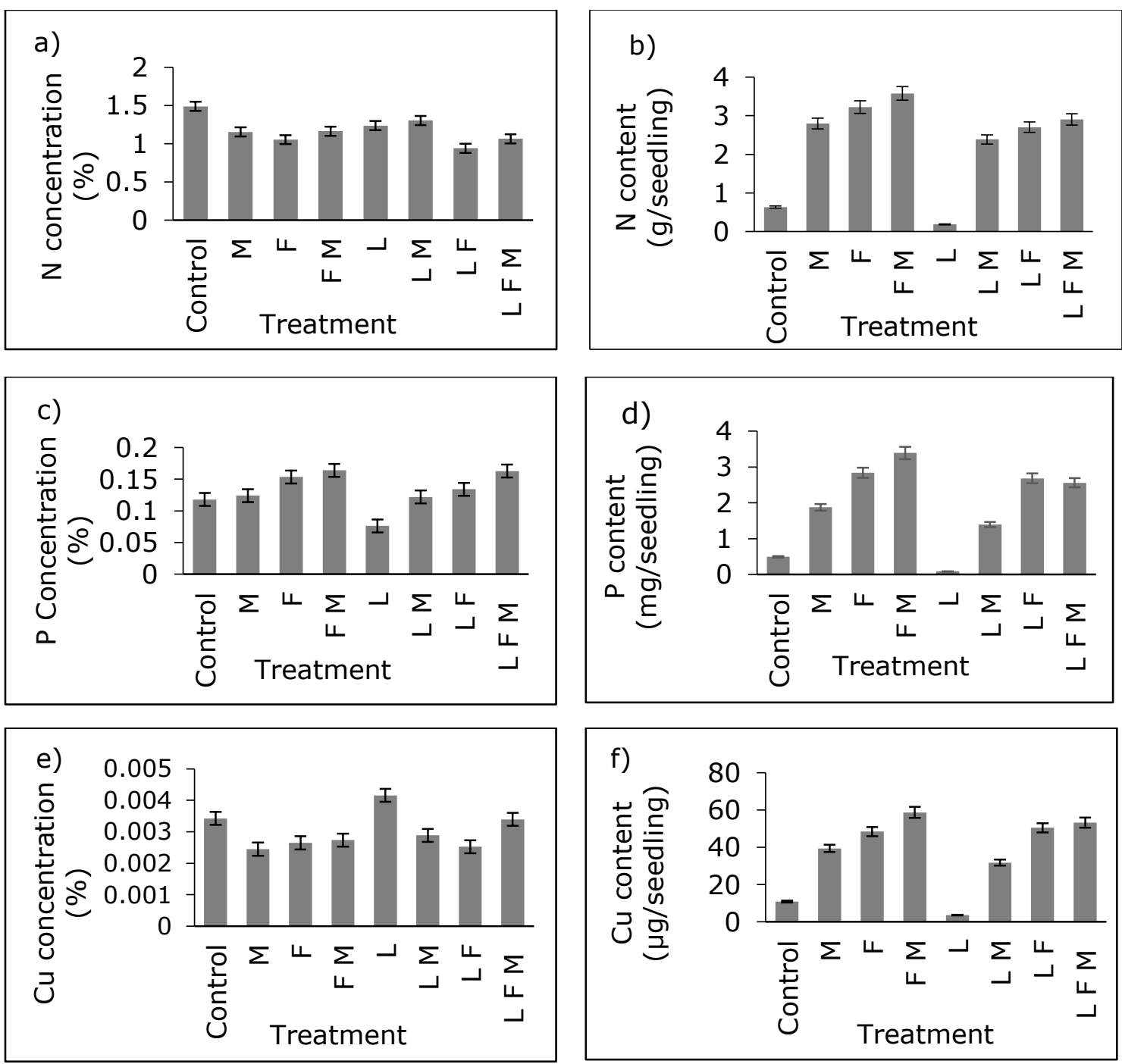

Fig 1.5. Average nutrient status of the NWC foliage: a) $N$ concentration; b) $N$ content; c) P concentration; d) P content; e) $\mathrm{Cu}$ concentration; f) Cu content. See Table 1.4 for significance tests 


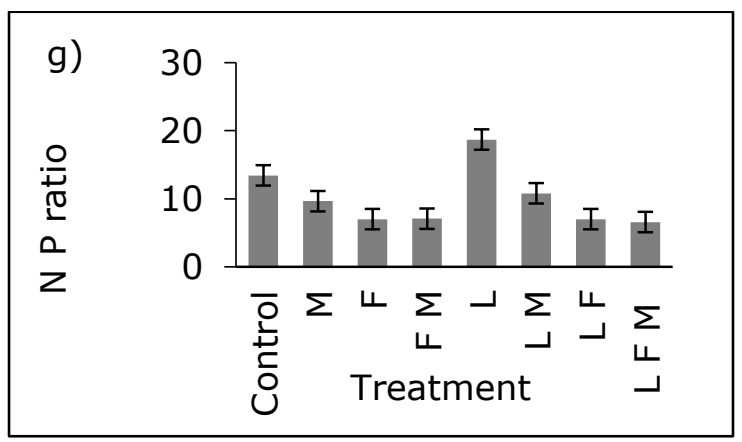

Fig 1.5 (cont'd). Average NP ratio of the NWC foliage. See Table 1.4 for significance tests.
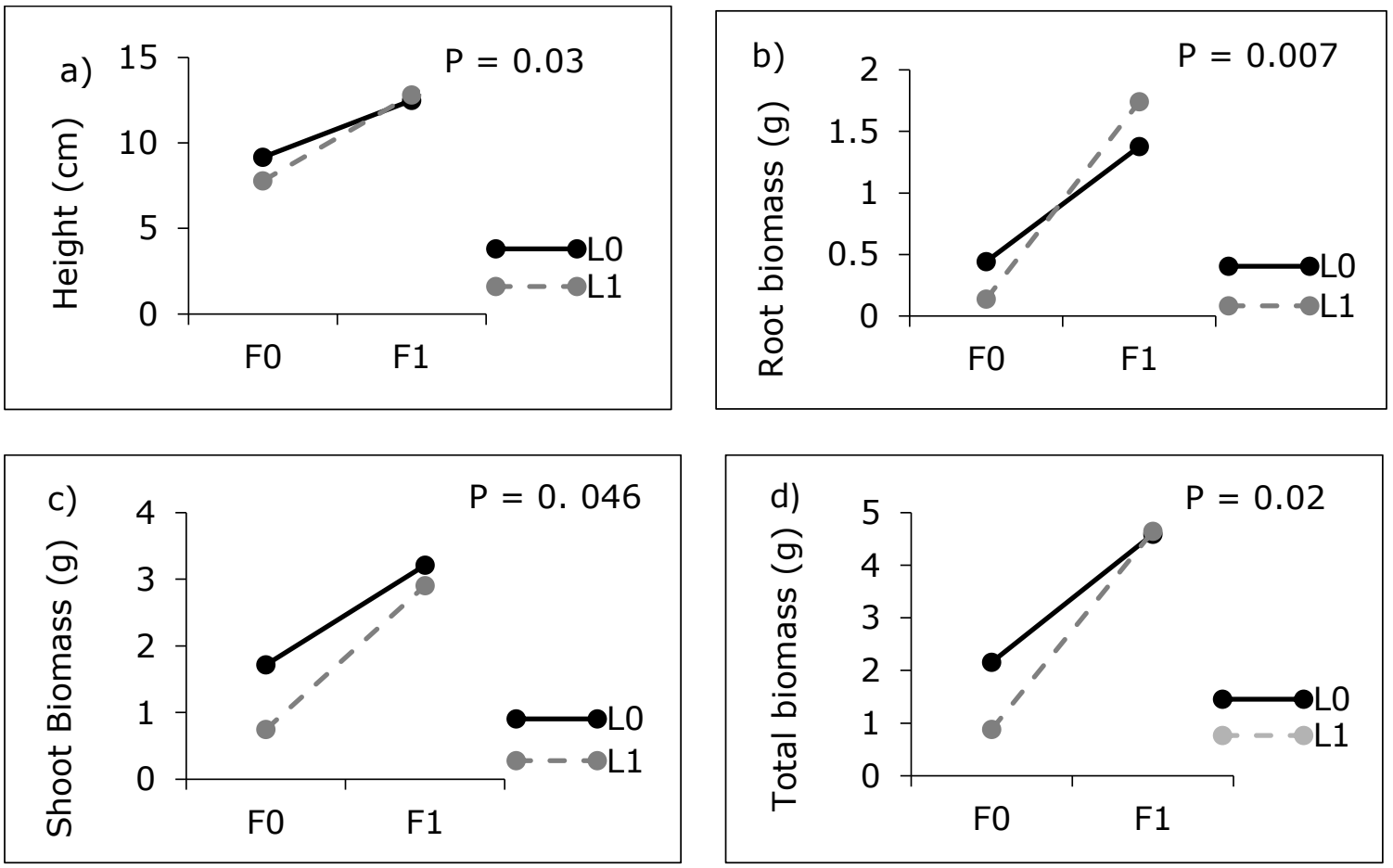

Fig 1.6. Interaction plots between fertilization and liming on height (a); root biomass (b); shoot biomass (c); and total biomass (d) (LO: unlimed, L1: limed, F0: unfertilized, F1: fertilized) 

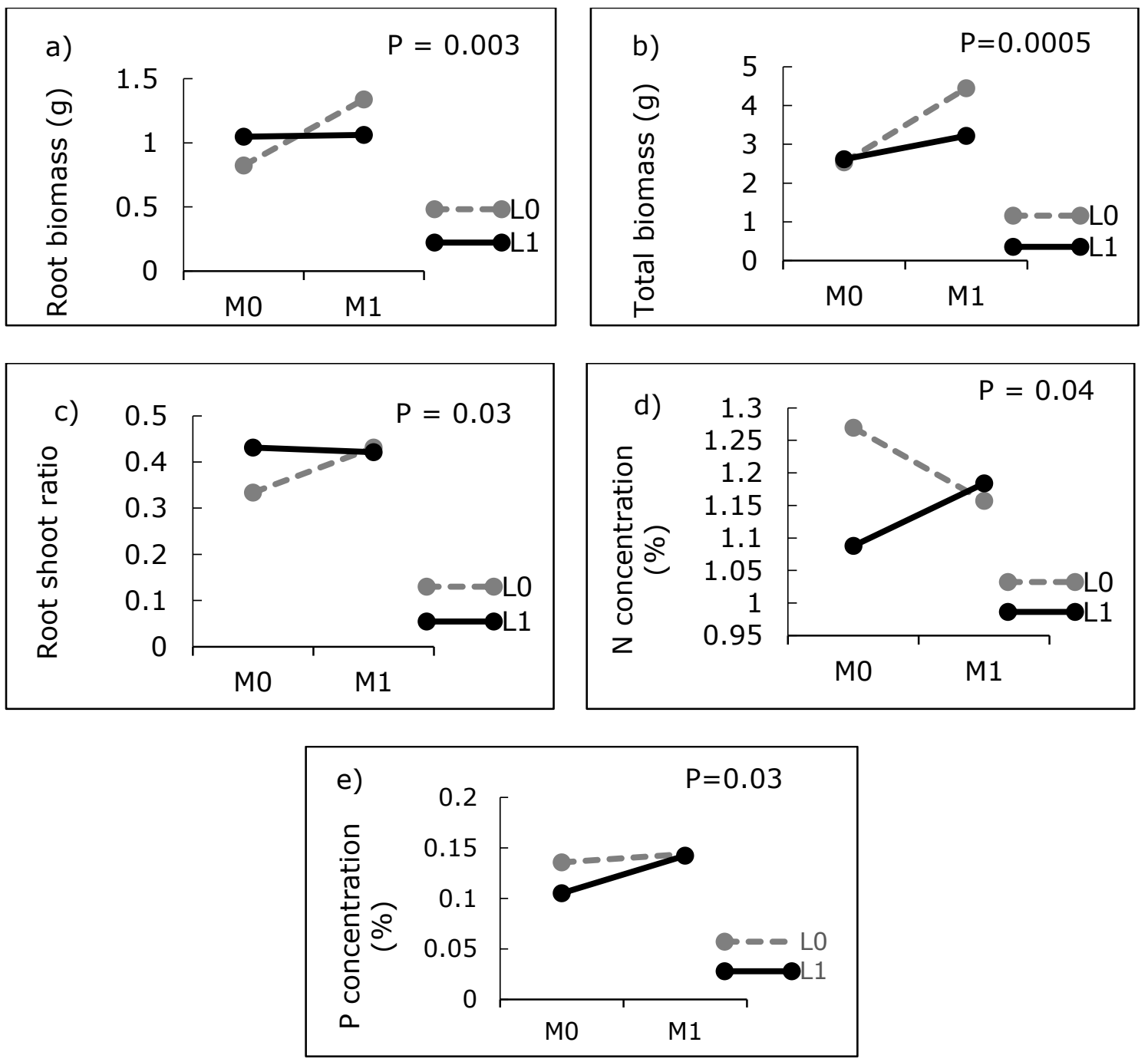

Fig 1.7. Interaction of liming with inoculation on : a) root biomass; b) total biomass; c) root shoot ratio; d) $\mathrm{N}$ concentration, and e) P concentration. (L0: unlimed, L1: limed, M0: uninoculated, M1: inoculated) 

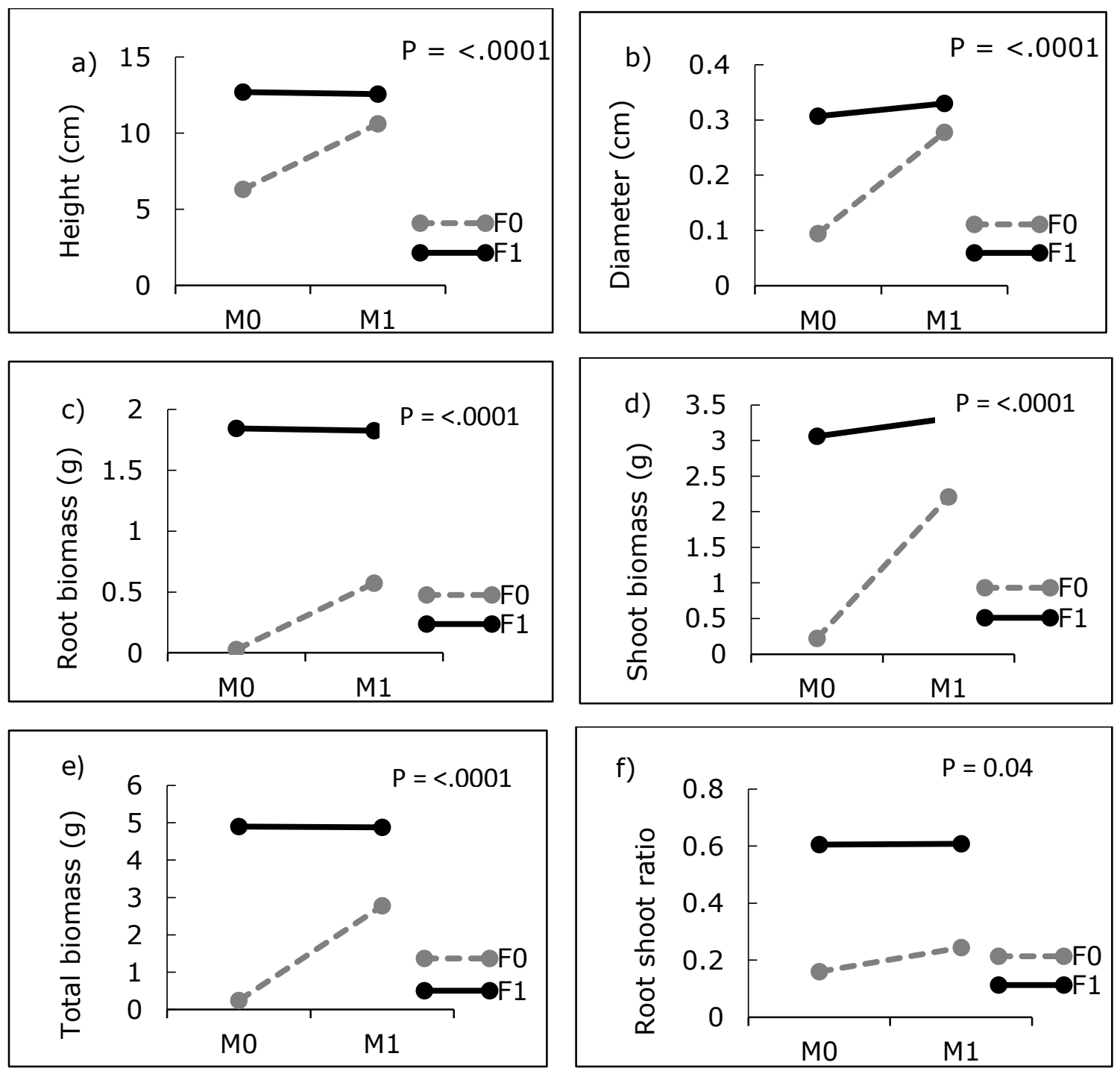

Fig 1.8. Interaction of fertilization with mycorrhizal inoculation on the seedling growth: a) height; b) diameter; c) root biomass; d) shoot biomass; e) total biomass; f) root shoot ratio. (M0: uninoculated, M1: inoculated, F0: unfertilized, F1: fertilized) 

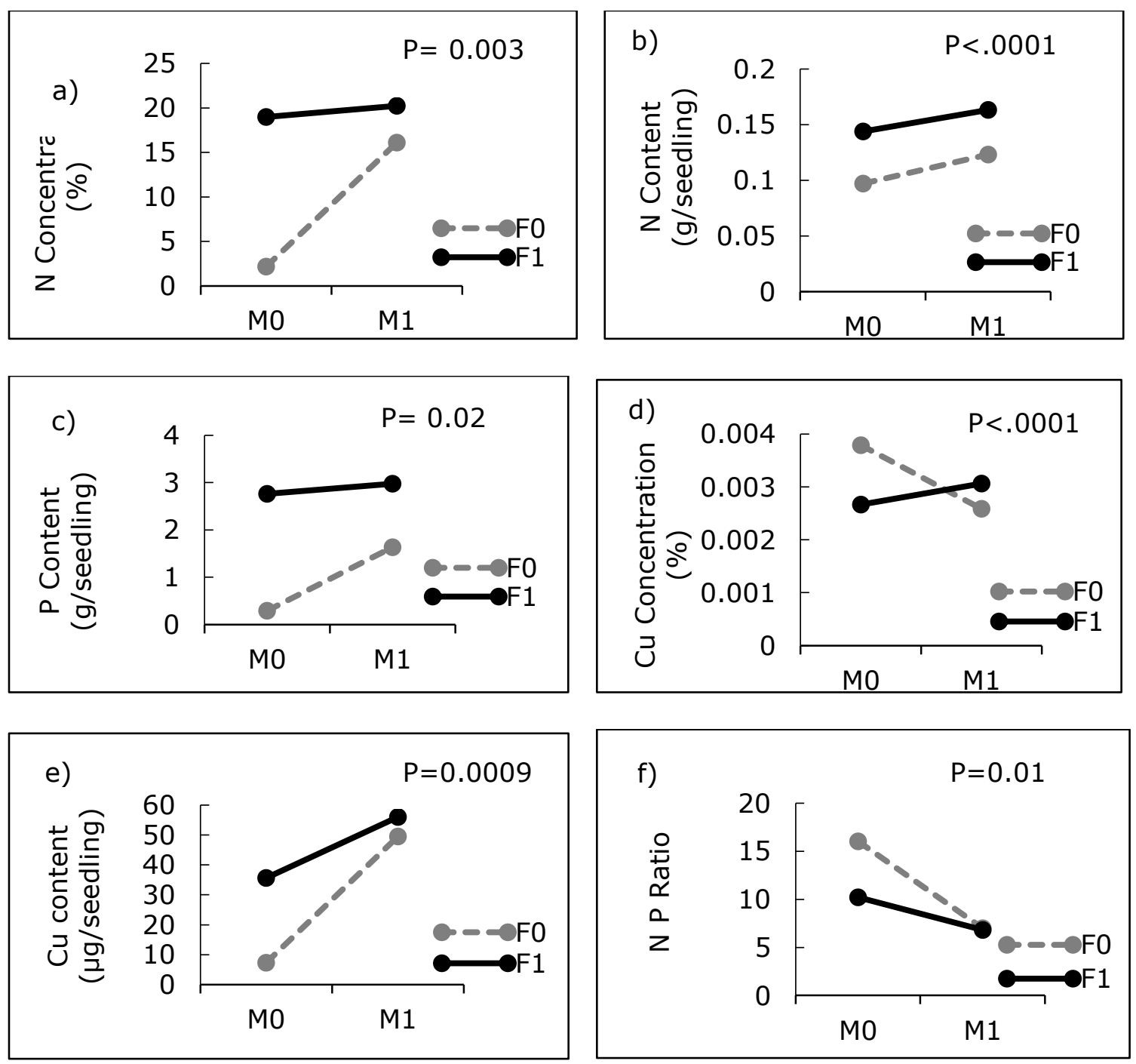

Fig 1.9. Interaction of fertilization with mycorrhizal inoculation on nutrient acquisition of the seedling foliar: a) N concentration; b) $\mathrm{N}$ content; c) P content; d) Cu concentration; d) Cu content, (k), and N P ratio (I). (M0: uninoculated, M1: inoculated, F0: unfertilized, F1: fertilized) 
Chapter 2. The effect of arbuscular mycorrhizal inoculum, AM host proximity, and other environmental factors on growth and survival of Thuja occidentalis seedlings in a poor fen ${ }^{2}$

\subsection{Abstract}

Northern white-cedar (NWC) is occasionally found in acidic peatlands. As an arbuscular mycorrhizal (AM) plant, its establishment in such ecosystems could be mediated by limiting inoculum of AM fungi. We predicted that several factors play important roles to support NWC survival and growth, such as native AM inoculum, AM plant proximity, and several environmental factors (light, $\mathrm{pH}$, water table depth, peat bulk density). We conducted a field study to examine the effect of these factors on the survival and growth of NWC seedlings. Our findings indicated that AM inoculant had no significant effect on survival. Light was the only significant predictor of survival, with higher light associated with greater seedling survival. Inoculation treatment had no significant effect on seedling growth and nutrient concentrations, either in single treatment or in interaction with other abiotic factors except with water table depth on relative growth rate. However, seedlings closer to AM trees showed higher growth and increased foliar nutrient concentration. Reduction of water table depth and higher $\mathrm{pH}$ were associated with greater plant growth and nutrient concentration. Higher light correlated with greater plant growth but reduced nutrient concentrations. The best model predicting plant growth and nutrient concentration involved light intensity, metrics of AM plant proximity (distance to hosts, PCA of plant community), soil $\mathrm{pH}$, and water table depth. We conclude that using AM

\footnotetext{
$\overline{2}$ The material contained in this chapter is in preparation for submission to a journal.
} 
inoculant did not improve survival rate, growth or nutrition of NWC seedlings, yet proximity to living AM host plants was associated with improved growth and nutrition. Further analysis is needed to determine whether the latter was due to mycorrhizal or other environmental factors. It may be important to consider proximity to AM hosts in peatland restoration projects.

\subsection{Introduction}

Northern white-cedar (NWC; Thuja occidentalis L.) is an important tree species in the northeastern United States and eastern Canada due to its various economic, social, spiritual, and ecological values (Johnston, 1990, Boulfroy et al., 2012). It occurs commonly as pure stands or mixtures in uplands (mesic mineral soils) and poorly drained lowlands (organic soils) (Johnston, 1990; Hannah, 2004; Hofmeyer et al., 2009, Larouche et al., 2011; Boulfroy et al., 2012; Man et al., 2013). In lowland peatlands, this species is generally found in association with black spruce (Picea mariana), balsam fir (Abies balsamea), and tamarack (Larix laricina) (Hofmeyer et al., 2009; Man et al., 2013).

Despite the fact that NWC is commonly found in high $\mathrm{pH}$, nutrient rich peatlands, often called peat swamps (Hannah, 2004), it can sometimes be found in oligotrophic peatlands (forested poor fens) with organic soil, low pH and low nutrient availability. The nutrient impoverishment of poor fens limits the vascular plant species able to grow and survive, such as dwarf shrubs in the Ericaceae, some small insectivorous species, and few trees in the Pinaceae (Thornmann et al., 1999; Nordbakken et al., 2003; Thormann, 2006).

NWC is symbiotic with arbuscular mycorrhizal (AM) fungi (Brundrett et al., 1989, Matthes-Sears et al., 1992; Bainard et al., 2011; this dissertation Chapter 1). 
AM fungi play an important role in nutrient poor soils (Smith et al., 2011). Generally, vascular plants hosting ericoid mycorrhizal fungi (Ericaceae) and ectomycorrhizal fungi (Pinaceae) are prevalent in acidic peatlands, whereas arbuscular mycorrhizal hosts are not abundant in northern acid peatlands (Thormann, 2006). AM plants are commonly found in mild climates with phosphorus poor soils in the northern hemisphere, in contrast to ectomycorrhizal that predominantly occurs in colder climates with low nitrogen soils (Allen et al., 1995; Smith and Read, 2008). Both ericoid and ectomycorrhizal fungi are thought to be especially good at mobilizing organic nitrogen, which can be critically important in these often $\mathrm{N}$-limited peatlands. Extracellular enzymes produced by ericoid and selected ectomycorrhizal fungi promote their abilities to degrade and decompose proteins and chitins to provide nitrogen (Read et al., 2003). Meanwhile, AM fungi have conventionally been recognized to be exclusively able to mobilize inorganic nutrients (Smith and Read, 2008). However, recent studies reveal that AMF were able to take up organic nitrogen from organic sources (Nasholm et al., 1998; Whiteside et al., 2009; Hodge and Fitter, 2010; Talbot \& Treseder, 2010) and some species can use several organic nitrogen derivates (amino acids) (Hawkins et al., 2000; Cappellazzo et al., 2007). Whiteside et al. (2010) confirmed that AMF gained organic nitrogen in recalcitrant and labile forms.

AM fungi are very important in the earliest stage of AM plant life cycles, especially in nutrient impoverished sites and disturbed ecosystems. Absence of propagules of AM fungi potentially reduces nutrient supply for the plants in such environments. Lack of AMF inoculum triggers reduction of AM plant survival and growth, particularly where ectomycorrhizal and ericoid plants dominate (Weber et al., 2005). 
Environmental factors that influence plant growth in peatlands might also affect $\mathrm{AM}$ effectiveness. Soil $\mathrm{pH}$, fertility, water table depth, bulk density, and light intensity might have effects on mycorrhizal functions where AM fungi increases their benefits under limited soil nutrients and reduce their benefit under limited light (Johnson, 2010). For instance, root colonization by AM fungi declined under shading, and abundance of hypha in soil decreased with fertilizer addition (Shi et al., 2014). Likewise, increasing water availability reduced AM colonization (Miller, 2000; Escudero and Mendoza, 2005).

Understanding the required conditions for $\mathrm{AM}$ colonization and the factors affecting the AM fungi functions in the earliest stage of NWC establishment is crucial for peatland restoration with NWC. Currently, NWC is undergoing restoration trials in several states to try and reestablish populations (e.g., Kangas et al., 2015). To determine the importance of AM fungi in colonizing NWC seedlings, we examined several factors that potentially affect NWC growth and survival including AMF inoculant and environmental factors. The objectives of our study were: 1 ) to determine effect of native AM inoculant, 2) to test effect of measures of AM plant proximity (distance to, basal area of, and \% cover of AM host species), and 3) to determine effect of environmental factors (soil $\mathrm{pH}$, water table depth, bulk density, and light intensity).

We hypothesized that; 1 ) native AM inoculant would increase growth and survival of NWC seedlings, 2) higher AM host plant abundance would positively affect growth, nutrition, and survival of NWC seedlings, and 3) Light, water table depth, soil $\mathrm{pH}$, and cover of Ericaceae would affect growth and survival of the NWC seedlings. 


\subsection{Materials and Methods}

\subsubsection{Study site}

The study took place in a peatland near Painesdale, Houghton County, MI (N $47.01349^{\circ}, \mathrm{W} 88.43082^{\circ}$ ). Cumulative precipitation during the study period (from 1 September 2013 to 1 November 2014) was $679 \mathrm{~mm}$ (NOAA, 2015). The site is a partially forested poor fen with hummock and hollow microtopography, covered mainly by dwarf shrubs in the Ericaceae and Sphagnum mosses. The peatland margin was dominated by NWC, tamarack (Larix laricina (Du Roi) K. Koch) and tag alder (Alnus spp), and NWC and other trees extended out partway into the peatland from one margin. Soil pH range of the site ranged between 3.7 and 5.0 (Appendix Table 2.1).

\subsubsection{Experimental treatment}

Our goal was to set up plots over the range of conditions in the peatland, including areas with and without NWC and other AM hosts present (Appendix Table 2.1). We established a $200 \mathrm{~m}$-long transect set perpendicular from to the edge of the peatland toward its center. This transect extended from the forested margin of the peatland to the open fen in the center dominated by Sphagnum and Ericaceae. At $10,50,100,150$, and $200 \mathrm{~m}$ along this transect we established several $100 \mathrm{~m}$-long secondary perpendicular transects, with exception the $10 \mathrm{~m}$ transect, which was only $70 \mathrm{~m}$-long because of the shape of the peatland. Over the length of these secondary transects we randomly placed replicate plots within each $5 \mathrm{~m}$ interval. Each plot had four points in a crossed design with the length of each axis $2 \mathrm{~m}$. At each point we dug a $15 \times 15 \times 20 \mathrm{~cm}$ hole to plant each NWC seedling. In total, there were 396 NWC 
seedlings (99 plots $\times 4$ seedlings per plot). One year old NWC seedlings were obtained from the J.W. Toumey Nursery, MI, and maintained until time of planting in the greenhouse at the School of Forest Resources and Environmental Science for 6 months prior to planting. The seedlings were watered daily using tap water and temperature setting was $22^{\circ}-24^{\circ} \mathrm{C}$. The greenhouse conditions were 16 hours day length using supplemental lighting via Halco metal halide lamps (Prolume MP 400/BU.

We planted the seedlings on October 29, 2013. At planting seedlings had an average height and diameter of $26.7 \mathrm{~cm}(\mathrm{SE}=0.28 \mathrm{~cm})$ and $3.5 \mathrm{~mm}(\mathrm{SE}=0.1 \mathrm{~mm})$, respectively. Two of the seedlings in each plot were treated with native mycorrhizal inoculum and two were uninoculated. Native mycorrhizal inoculum was obtained by collecting NWC fine roots from rhizospheres of NWC trees in the site. Fresh fine roots $(20 \mathrm{~g})$ added to the planting hole at time of planting was used as inoculum for each NWC seedling, and as a control, $20 \mathrm{~g}$ of pasteurized fine roots were added into the holes of the uninoculated seedlings. The fine roots were pasteurized in an oven at $80^{\circ} \mathrm{C}$ for 30 minutes. The seedlings were grown in the field for $\sim 12$ months.

\subsubsection{Data collection}

Pre-harvest.

Height and diameter were measured three times: at planting, in June ( $~ 8$ months after planting), and at the end of the experiment ( $\sim 12$ months after planting). Seedling survival was measured at the end of the experiment.

To estimate percent of full sunlight reaching each seedling, we measured photosynthetically active radiation using an Apogee Quantum Flux MQ-200 PAR Meter at five points at the top of the canopy of each seedling, and simultaneously 
measured full sunlight at an open location using an AccuPAR model LP-80 Ceptometer. Water table depth was measured using a perforated PVC pipe inserted into the hole at the center of each plot. Percent cover classes of mosses, herbaceous plants, dwarf shrubs and seedlings were measured using a PVC quadrat frame $\left(1 \mathrm{~m}^{2}\right)$ centered on the seedling. Percent cover was grouped into 6 classes $(1=<1 \%, 2=1$ $5 \%, 3=5-25 \%, 4=25-50 \%, 5=50-75 \%, 6=>75 \%)$ based on ocular estimate of the percentage of coverage of the species in the frame.

\section{Post-harvest}

In September of 2014 half of the seedlings (one inoculated and one uninoculated; 198 total) from each sampling plot were harvested. A subsample of the fine roots $(0.3 \mathrm{~g})$ from each seedling sample were picked and weighed fresh and used to estimate mycorrhizal colonization. Root, stem and leaf biomass were determined separately after oven drying at $65^{\circ} \mathrm{C}$ to a constant weight.

Soils from each seedling planting location were sampled by coring at three points around the seedling planting holes to $20 \mathrm{~cm}$ depth using a $4 \mathrm{~cm}$ diameter steel corer. Bulk density was estimated with drying soils and calculating mass per unit volume of soil samples. Soil pH was measured with a mass ratio of 1 (dry peat):40 ( $\left.\mathrm{DI} \mathrm{H}_{2} \mathrm{O}\right)$ using a $\mathrm{pH}$ meter (Denver Instrument Model 220, Denver Instrument, Arvada, CO, USA).

Dried foliage was ground to a fine powder, and foliar nutrients consisted of $\mathrm{N}$, $\mathrm{C}, \mathrm{P}$, and $\mathrm{Ca}$ were measured at the Soil Laboratory of SFRES, Michigan Tech. N and C were analyzed on Costech 4010 Elemental analyzer (Costech Analytical Technologies Inc., Valencia, CA, USA) that calibrated with atropine. $\mathrm{P}$ and $\mathrm{Ca}$ analysis were 
performed using a Perkin Elmer Optima 7000DV ICP-OES (PerkinElmer Inc., Waltham, MA, USA).

\subsubsection{Data analysis}

Survival (class response variable) by inoculation (class treatment) was analyzed using ChiSquare test in JMP Statistical Discovery (Version 12, SAS, Campus Drive, Cary, NC, USA). Survival vs. continuous independent variables was tested using logistic regression. Continuous dependent variables (growth and nutrient concentration) vs. continuous independent variables (light, $\mathrm{pH}$, bulk density, water table depth, distance to AM hosts, and cover/basal area of mycorrhizal sources) were analyzed using regression methods (simple and all possible subsets multiple regression), and PCA (Principle Component Analysis) was run analyzed using JMP Statistical Discovery Version 12 (SAS Campus Drive Cary, NC, USA). PCA scores were rotated using Factor Analysis to align with primary axes, resulting in an output of factor scores that could be used as predictors in multiple regression. We ran a species-level PCA only to describe the community-level patterns, and one based on cover and basal area of different mycorrhizal types to use in regressions predicting NWC success.

\subsection{Results}

\subsubsection{PCA of plant cover}

To reduce the dimensionality of ground cover and tree community data as a predictor of seedling performance, a PCA was performed (Fig 2.1 and 2.2). Ground cover of AM hosts T. occidentalis, Symphoricarpos albus, Drosera spp., and Nemopanthus were clustered and had positive scores along the Factor 1 axis that accounted $14.8 \%$ of total variance (Fig 2.1). In a second PCA on mycorrhizal and 
other cover classes and basal area of different mycorrhizal trees, measures of AM cover and basal area had positive scores on Factor 1, whereas ERM cover had negative scores (Fig. 2.2, Table 2.2 ). This axis accounted $33.4 \%$ of total variance (Fig 2). PCA factor 1 was used as a predictor of seedling performance in the regression models.

\subsubsection{Survival rate}

Inoculated seedlings had slightly higher survival rate than uninoculated seedlings, but this effect was not significant $(P=0.405)$ where 154 inoculated seedlings (76\%) and 147 uninoculated seedlings (72\%) survived through the end of the observation. In logistic regression analysis, light was the only significant predictor of survival ( $P<0.001$; Table 2.3 ), with greater amount of light correlated with greater seedling survival (Fig 2.3).

\subsubsection{Seedling growth and nutrient acquisition}

Paired t-tests and Wilcoxon Signed Rank Tests showed no significant effect of inoculation on any of the seedling responses (Table 2.4). Stepwise analysis resulted in no significant effect of inoculation alone and the interaction of inoculation with the proximity AMF tree, environmental factors and plant community, except for a weak interaction with water table depth (WTD) on the relative growth rate (RGR) (Table 2.7). Meanwhile, distance to the nearest AMF tree (logdistAM+1), plant community factor 1 scores, and all abiotic environmental factors except bulk density (BD), showed significant relationship on the response variables when they were analyzed with inoculation treatment (Tables $2.5-2.10$ ). Seedlings closer to AM trees had higher growth and nutrient concentrations (Table 2.5, Fig 2.4). Soil pH had a positive 
relationship with seedling growth increment, foliar \%N, \%P, and N:P ratio (Fig 2.5). Increasing water table depth had a negative relationship with $\mathrm{N} \& \mathrm{P}$ concentrations (Table 2.7, Fig 2.6). Increasing light was a predictor of increased growth but reduced $\mathrm{N}, \mathrm{P}$, and Ca concentrations (Table 2.9, Fig 2.8). Factor 1 of the PCA of plant communities (positively related to AM host cover and negatively to Ericaceae cover) was associated with greater plant nutrient concentrations (Table 2.10, Fig 2.9).

Using multiple regression, the best models (lowest AICc value) predicting growth and nutrient acquisition most commonly included light intensity, metrics of AM plant proximity (distance to the closest AM tree and Factor 1 of the PCA of plant communities), soil $\mathrm{pH}$, and to a lesser extent depth to water table (Table 2.12, Fig 2.10).

\subsubsection{Relationship between AM plant proximity and other predictors}

AM plant proximity had significant relationship with light intensity and ERM cover $(P=0.0002)$, whereas no significant relationship with soil $\mathrm{pH}$, water table depth, and bulk density (Table 2.11).

\subsection{Discussion}

\subsubsection{AM Fungi: inoculation success and effectiveness}

Our AM inoculation results lead to the rejection of the hypothesis that native AM inoculant increased growth and survival of the NWC seedlings. There are two possible reasons for this. First, the inoculation might have been unsuccessful. Second, the inoculation might have been successful but the mycorrhizas might have been ineffective under the environmental conditions encountered. 
Regarding the first possibility, there may have been no AM colonization. Results on the success rate using native inoculum vary. While many studies reported that native AM fungi are more effective than non-native in plant colonization due to their adaptation to the plant site condition (Caravaca et al., 2003; Oliveira et al., 2005; Querejeta et al., 2006), other studies found the opposite (Trent et al., 1993; Calvente et al., 2004). Schreiner (2007) suggested that the relative effectiveness of native vs. non-native AM inoculant is still poorly understood. Moreover, Afek et al. (1990) and Werner \& Kiers (2014) suggested that AM colonization in the field might be less successful than under greenhouse condition due to AMF density and environmental factors.

Regarding the second possibility, that the AM fungi were ineffective under the study conditions, Fitter (1985) found that AM fungi field studies showed considerable divergence in the effectiveness results. Since AM fungi effectiveness may vary depending on the plant and fungal condition, it is possible that plant, AM fungi, or environmental factors could contribute to the non-significant results. Given that we used inoculum from NWC it is unlikely that there was a host-fungal incompatibility. However, it is possible that under the nutrient stresses of acidity and low nutrient availability in the Ericaceae-dominated areas of the peatland the AM fungi were unable to provide significant benefit to the NWC seedlings. If that is the case, then AM inoculum might be ineffective in invasion of acid peatlands. Our greenhouse experiment (Chapter 1 ) indicated that AM fungi were effective under somewhat acidic conditions. However, although the initial $\mathrm{pH}$ was quite acidic (4.4), $\mathrm{pH}$ increases caused by watering with tap water led to a final $\mathrm{pH}$ of around 6 , so it is unclear whether benefit would have accrued under more acidic conditions. Furthermore, the greenhouse experiment took place in the absence of Ericaceae or 
other plant competitors. Further manipulative experiments teasing apart $\mathrm{pH}$ and competitor impacts on seedling success would be informative.

In addition to the above factors that could influence the experimental outcome, different size of seedlings (height, diameter, root condition) and length of time of the seedlings in the nursery prior to inoculation might also determine AM fungi effectiveness. We used un-inoculated seedlings that originated from the nursery with various sizes. The seedlings were regularly fertilized in the nursery, although not in the 6 months prior to outplanting. John (1996) advocated that greatest benefits of AM inoculation will be found in the earliest stage of the plant development. Werner \& Kiers (2014) found that it is likely host plants have space limitation in their roots where AM fungi are not able to invade the roots due to occupation from the previous colonizer. Meanwhile, Cano \& Bago (2005) and Bennett \& Bever (2009) found that there was profound competition across AM fungi for root space.

AM fungi have are associated with stressful environment and their efficacy is strongly affected by environmental factors (Smith and Read, 2008). Our finding showed there was no significant effect between AM inoculation and other environmental factors except perhaps on water table depth. However, this result was so weak, especially in the context of multiple tests, that we are cautious in its interpretation, even though based on the correlation graphs showed AM inoculated plants performed greater than un-inoculated plants.

\subsubsection{AM host proximity and plant community effects}

In contrast with our result on AM inoculation, we found that proximity to AM host plants was positively associated with growth and nutrient acquisition. The 
distance effect was non-linear, with much greater effects within $10 \mathrm{~m}$ of AM host plants. There are two likely alternative explanations for this pattern. First, it is possible that the NWC seedlings benefited from access to the common mycorrhizal network and high inoculum density near other AM host species. Alternatively, it is also possible that the environmental conditions near $\mathrm{AM}$ hosts $(\mathrm{pH}$, nutrients, light, others unmeasured factors) are more favorable to NWC compared to conditions farther away.

Regarding the first alternative, it is possible AM fungi on AM hosts near the NWC seedlings infected and colonized their roots, leading to a positive AMF-mediated interaction by proximity to AMF host plants. Jastrow and Miller (1993) suggested that presence of neighbor-plants led to mycorrhizal network formation between the plants. Dickie et al. (2005) reported that seedlings showed the best performance within $15.7 \mathrm{~m}$ of host trees of the same mycorrhizal type, where high mycorrhizal infection and high nitrogen uptake occurred. Ronsheim \& Anderson (2001) stated that association with neighbor AMF plants benefit. Lyford (1980) suggested that increasing mycorrhizal infection occurred in the root zones of AMF trees.

Much of our study peatland was dominated by ericoid mycorrhizal and ectomycorrhizal plants which do not share mycorrhizal fungi with AM plants. Presence of other AM plants could therefore play a pivotal role on seedling growth. Our finding showed other AM plants were positively associated with NWC growth and nutrient acquisition. It is possible the NWC seedlings roots were colonized by hyphae or fungal propagules of other AM plants located near the NWC seedlings. On the other hand, AM hyphae of the NWC seedlings were not able to connect with mycorrhizal network of other mycorrhizal types (ErMF and ECMF). Molina et al. (1992) suggested that compatibility within a single host species commonly occurs 
with a specific mycorrhizal type, and this appears to be true for NWC (Brundrett et al., 1989; Sears et al., 1992; Bainard et al., 2011). Limited number of NWC trees in the study site may be caused by insufficient dispersal of AM fungi where their availability was restricted by presence of the appropriate hosts. This interpretation is only likely if our inoculations were successful, or if subsidy of the mycorrhizal network via common mycorrhizal networks is necessary for benefit. Similar condition occurred in red cedar seedlings where deficiency of dispersal AM trees among ectomycorrhizal plants may have restricted red cedar establishment (Weber et al., 2005).

Regarding the second alternative, we found there was a significant relationship between AM plant proximity with light and ERM (ericoid mycorrhizal) plant cover $\left(\mathrm{R}^{2}=0.1982 ; \mathrm{P}=0.0002\right.$ for each). Increasing distance from the nearest AM plant was associated with greater light and greater ERM cover. However, it seems unlikely that the light environment closer to the AM trees was favorable for seedling growth, because of our previous finding that seedlings grew faster in higher light. Meanwhile, ERM cover was lower near AM hosts. This condition could have high benefit for the NWC seedlings since less ERM cover potentially reduced competition for limited nutrients, particularly N. We also found that increasing ERM cover was associated with lower nitrogen concentration in NWC seedlings $\left(R^{2}=0.0284, P=\right.$ 0.0187). Therefore, it is possible that AM plants were able to maximize their functions in mobilizing nutrients for the NWC seedling with less competition with ERM plants. Hence, we cannot rule out possibility that the increase growth of the NWC seedlings near AM plant might be associated with ERM cover. Of course, these two alternative explanations (greater benefit from common mycorrhizal networks and less competition) are not mutually exclusive. 


\subsubsection{Other environmental effects}

Our finding showed light intensity had a positive relationship with plant growth. Light intensity will increase photosynthetic rates and supply more carbon to the roots. Increasing shading in the nearest AM trees potentially reduced plant growth and nutrient acquisition. Weber et al. (2005) reported increasing growth of red cedar seedlings under high light treatments. High light is very important for seedling development and establishment, where their shoots and roots will be greater under full light in wet sites. It is likely that capillarity brought sufficient moisture to the roots of all seedlings in the present study. Meanwhile, reduction of nutrient availability under high light occurred possibly because there was nutrient pool dilution via greater growth.

Soil $\mathrm{pH}$ contributed positively to reducing $\mathrm{N}: \mathrm{P}$ ratio. Increasing $\mathrm{pH}$ from 3.8 to 5.0 led to decrease N:P ratio that indicated increasing P availability. Johnston (1990) stated that NWC commonly occur on soils with pH 5.5-7.2. Bolan et al. (2003) reported that soil $\mathrm{pH}<4$ potentially impair plants and soil microorganisms where it may stimulate toxic elements. Sumner et al. (1991) stated that some essential nutrients such as $\mathrm{P}, \mathrm{Mo}, \mathrm{Ca}$, and $\mathrm{Mg}$ become less available in low $\mathrm{pH}$ soils.

We conclude that occurrence of AM fungi might be a crucial factor in peatland restoration especially in plant succession with NWC. Presence of AM plants may play an important role in seedling establishment, and so might determine success of seedling planting programs in peatland restoration projects. 


\subsection{References}

Afek, U., E. Rinadelli, J.A. Menge, E.L.V. Johnson, E. Pond. 1990. Mycorrhizal species, root age and position of mycorrhizal inoculum influence colonization of cotton, onion and pepper seedlings. Journal of the American Society for Horticultural Science 115: 938-942.

Allen, E.B., M.F. Allen, D.J.Helm, J.M.Trappe, R. Molina, E. Rincon. 1995. Patterns and regulation of mycorrhizal plant and fungal diversity. Plant Soil 170: 47-62

Bainard, L. D., Klironomos, J. N., \& Gordon, A. M. 2011. The mycorrhizal status and colonization of 26 tree species growing in urban and rural environments. Mycorrhiza 21(2), 91-96.

Bennet, A.E. \& J. D. Bever. 2009. Trade-offs between arbuscular mycorrhizal fungal competitive ability and host growth promotion in Plantago lanceolata. Oecologia $160(4): 807-816$

Bolan, N.S., D.C. Adriano, P.A. Mani, A. Duraisamy. 2003. Immobilization and phytoavailability of cadmium in variable charge soils. II. Effect of lime addition. Plant and Soil 251 (2): 187-198

Boulfroy, E., E. Forget, P. V. Hofmeyer, L. S. Kenefic, C. Larouche, G. Lessard, J.Martin Lussier, F. Pinto, J.-Claude Ruel, \& A. Weiskittel. 2012. Silvicultural Guide for Northern White-Cedar (Eastern White Cedar). U.S. Department of Agriculture, Forest Service

Brundrett, M., G. Murasea, \& B. Kendrick. 1989. Comparative anatomy of roots and mycorrhizae of common Ontario trees. Can. J. Bot. 68: 551-578 
Calvente, R., C. Cano, N. Ferrol, C. Azcon-Aguilar, J.M. Barea. 2004. Analyzing natural diversity of arbuscular mycorrhizal fungi in olive trees (Olea europaea L.) plantation and assessment of the effectiveness of native fungal isolates as inoculants for commercial cultivars of olive plants. Applied Soil Ecology26: 1119

Cano, C. \& A. Bago. 2005. Competition and substrate colonization strategies of three polyxenically grown arbuscular mycorrhizal fungi. Mycologia 97 (6): 12011214

Cappellazzo, G., L. Luisa, B. Paola. 2007. A limiting source of organic nitrogen induces specific transcriptional responses in the extraradical structures of the endomycorrhizal fungus Glomus intraradices. Current Genetics 51 (1): 59-70

Caravaca, F., J.M. Barea. J. Palanzuela. D. Figueroa., M.M. Alguacil, A. Roldan. 2003. Establishment of shrub species in a degraded semiarid site after inoculation with native or allochthonous arbuscular mycorrhizal fungi. Applied Soil Ecology 22: 103-111.

Dickie, I.A, S.A. Scnitzer, P.B. Reich, S.E. Hobbie. 2005. Spatially disjunctive effects on co-occurring competition and facilitation. Ecology Letters 8: 1191-1200

Escudero V.G. \& R.E. Mendoza. 2005. Seasonal variation of arbuscular mycorrhizal fungi in temperate grasslands along a wide hydrologic gradient. Mycorrhiza 15: 291-299.

Fitter, A.H. 1985. Functioning of vesicular-arbuscular mycorrhizas under field conditions. New Phytologist 99:257-265

Hannah, P.R. 2004. Stand structures and height growth patterns in northern-white cedar stands on wet sites in Vermont. Northern Journal of Applied Forestry 21(4):173-179 
Hawkins, H.J., A. Johansen, E. George. 2000. Uptake and transport of organic and inorganic nitrogen by arbuscular mycorrhizal fungi. Plant and Soil 226 (2): $275-285$

Hodge, A. \& A.H. Fitter. 2010. Substantial nitrogen acquisition by arbuscular mycorrhizal fungi from organic material has implications for $\mathrm{N}$ cycling. Proceedings of the National Academy of Sciences 107: 13754-13759

Hofmeyer, P.V., R.S. Seymour, \& L.S. Kenefic. 2009. Influence of soil site class on growth and decay of northern white cedar and two associates in Maine. Northern Journal of Applied Forestry 26 (2):68-75

Jastrow, J.D. \& R, M. Miller. 1993. Neighbor influences on root morphology and mycorrhizal fungus colonization in tallgrass prairie plants. Ecology 74: 561569

John, T. St. 1996. Arbuscular mycorrhizal inoculation in nursery practice. In: Landis, T.D. \& D.B. South. Tech.Coords. National proceedings, forest and conservation nursery associations. Gen. Tech. Rep. PNW-GTR-389. Portland, OR: U.S. Department of Agriculture, Forest Service. Pacific Northwest Research Station: 52-58

Johnson, N.C. 2010. Tansley review: resource stoichiometry elucidates the structure and function of arbuscular mycorrhizas across scales, The New Phytologist 185 (3): 631-647

Johnston, W.F. 1990. Thuja occidentalis L. - northern White-Cedar. In: Burns, R.M. ; Honkala, B.H., eds. Silvics of North America. Vol. 1. Agric. Hndbk. 654. Washington, DC: U.S. Department of Agriculture, Forest Service: 580-589. 
Kangas, L.C., R. Schwartz, M.R. Pennington, C. R. Webster, R.A. Chimner. 2015. Artificial microtopography and herbivory protection facilitates wetland tree (Thuja occidentalis L.) survival and growth in created wetlands. New Forests: $1-14$

Larouche, C., J.C. Ruel, J.M. Lussier. 2011. Factors affecting northern white-cedar (Thuja occidentalis) seedling establishment and early growth in mixedwood stands. Canadian Journal of Forest Research, 41(3), 568-582.

Lyford, W.H. 1980. Development of the root system of northern-red oak (Quercus rubra L.). Harv. Forest. Pap. 21: 1-30

Man, R., P. Lu, W. C. Parker, G. J. Kayahara, Q.L. Dang. 2013. Light-use efficiency and photosynthetic capacity of northern white-cedar (Thuja occidentalis L.) cuttings originated from layering and seed. Northern Journal of Applied Forestry, 30(2), 53-57

Matthes-Sears, U.M., C. Neeser \& D.W. Larson. 1992. Mycorrhizal colonization and macronutrient status of cliff-edge Thuja occidentalis and Acer saccharum. Ecography 15 (3): 262-266

Miller, S.P. 2000. Arbuscular mycorrhizal colonization of semi aquatic grasses along a wide hydrologic gradient. New Phytol 145:145-155

Molina, R., H. Massicotte, J.M.Trappe. 1992. Specificity phenomena in mycorrhizal symbiosis: community-ecological consequences and practical implications, In: Allen MF (ed) Mycorrhizal Functioning. Chapman \& Hall, New York, USA: 301302

Nasholm, T., A. Ekblad, A. Nordin, R. Glester, M. Hogberg, P. Hogberg. 1998. Boreal forest plants take up organic nitrogen. Nature 392: 914-916. 
Nordbakken, J. F., M. Ohlson, P. Högberg. 2003. Boreal bog plants: nitrogen sources and uptake of recently deposited nitrogen. Environmental pollution, 126(2), 191-200 Northern Research Station, Newtown Square, PA. General Technical Report NRS-98

Oliveira, R.S., M.Votsaka, J.C. Dodd, P.M.L. Castro. 2005. Studies on the diversity of arbuscular mycorrhizal fungi and the efficacy of two native isolates in highly alkaline anthropogenic sediment. Mycorrhiza 16: 23-31

Querejeta, J.I., M.F. Allen, F. Caravaca, A. Roldan. 2006. Differential modulation of host plant $\delta^{13} \mathrm{C}$ and $\delta^{18} \mathrm{O}$ by native and nonnative arbuscular mycorrhizal fungi in a semiarid environment. New Phytol. 169" 379-387

Read, D.J., .R. Leake \& J.P Moreno. 2003. Mycorrhizal fungi as drivers of ecosystems processes in heathland and boreal forest biomes. Can. Bot. 82: 1243-1263

Ronsheim, M.L. \& S.E. Anderson. 2001. Population-level specificity in the plantmycorrhizae association alters intraspecific interactions among neighboring plants. Oecologia 128: 77-84

Schreiner, R. P. 2007. Effects of native and nonnative arbuscular mycorrhizal fungi on growth and nutrient uptake of 'Pinot noir' (Vitis vinifera L.) in two soils with contrasting levels of phosphorus. Applied Soil Ecology 36 (203): 205-215 Shi, G., Y. Liu, N. C. Johnson, P. A. Olsson, L. Mao, G. Cheng, S. Jiang, L. An, G. Du, H. Feng. 2014. Interactive influence of light intensity and soil fertility on rootassociated arbuscular mycorrhizal fungi. Plant Soil 378:173-188

Smith, S.E. and D.J. Read. 2008. Mycorrhizal symbiosis. $3^{\text {rd }}$ Edition. Academic Press. Smith, S.E., I. Jakobsen, M. Grenlund, F.A. Smith. 2011. Roles of Arbuscular Mycorrhizas in Plant Phosphorus Nutrition: Interactions between Pathways of Phosphorus Uptake in Arbuscular Mycorrhizal Roots Have Important 
Implications for Understanding and Manipulating Plant Phosphorus Acquisition. Plant Physiology 156 (3): 1050-1057

Sumner. M.E., M.V. Fey, A.D. Noble. 1991. Nutrient Status and Toxicity Problems in Acid Soils. Soil Acidity: 149-182

Talbot, J.M. \& K.K. Treseder. 2010. Controls over mycorrhizal uptake of organic nitrogen. Pedebiologia 53: 169-179

Thorrnann, M.N, R.S. Currah, S.E. Bayley. 1999. The mycorrhizal status of the dominant vegetation along a peatland gradient in southern boreal Alberta, Canada. Wetlands 19 (2): 438-450

Thormann, M.N. 2006. Diversity and function of fungi in peatlands: A carbon cycling perspective. Can J. Soil. Sci.86:281-293. Wetlands 19 (2): 438-450

Trent, J.D., A.J. Svejar, G.J. Bethlenfalvay. 1993. Growth and nutrition of combination of native and introduced plants and mycorrhizal fungi in a semiarid range. Agric. Ecosyst. Environ. 45: 13-23

Weber, A., J. Karst, B. Gilbert. 2005. Thuja plicata exclusion in ectomycorrhizaldominated forests: testing the role of inoculum potential of arbuscular mycorrhizal fungi, Oecologia 143: 148-156

Werner, G.D.A. \& E.T. Kiers. 2014. Order of arrival structures arbuscular mycorrhizal colonization of plants. New Phytologist: 1-9

Whiteside. M.D., K.K. Treseder, P.R. Atsatt. 2009. The brighter side of soils: Quantum dots track organic nitrogen through fungi and plants. Ecology 90: $100-108$ 
2.7. Tables and Figures

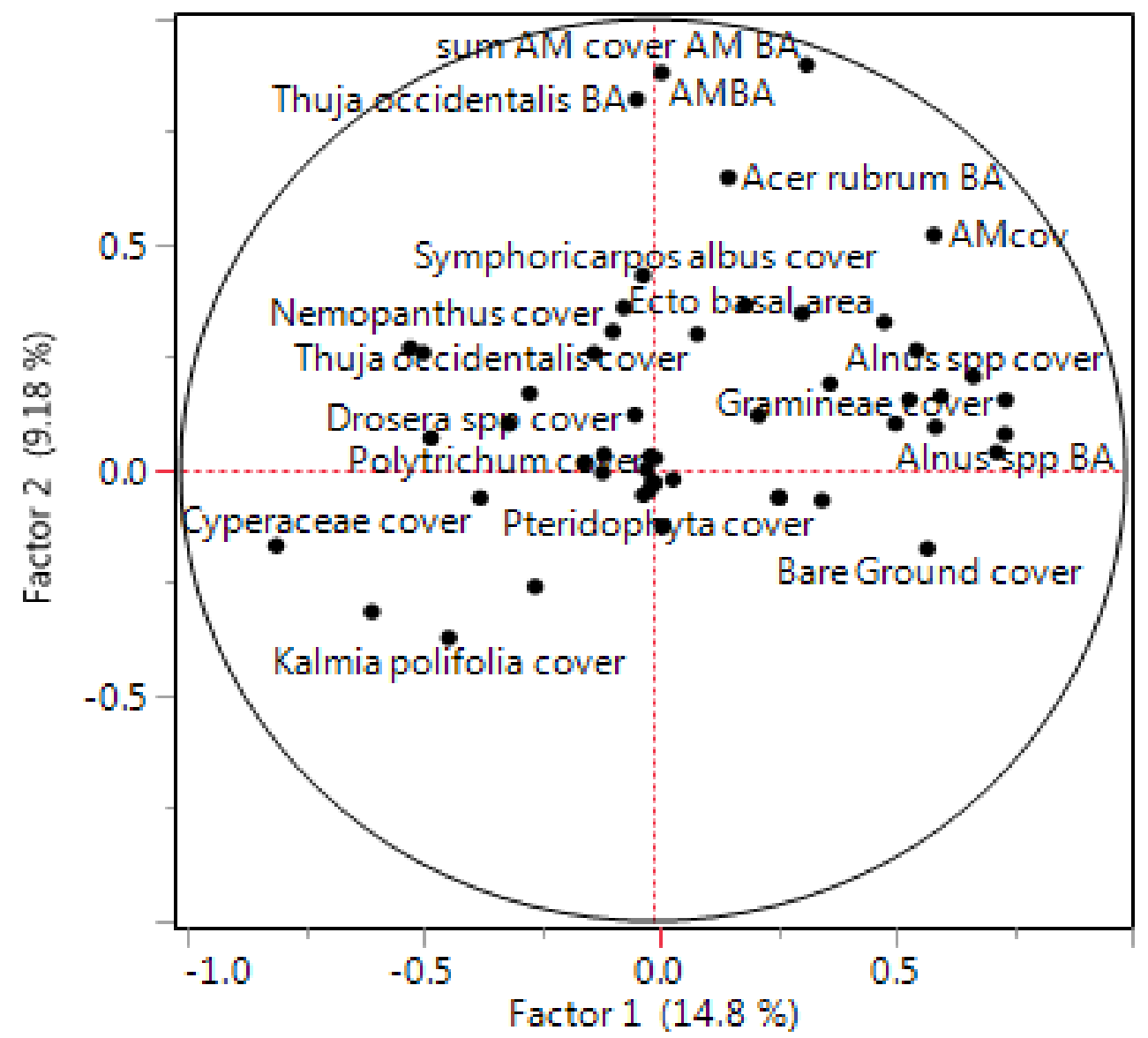

Fig 2.1. PCA of ground cover and basal area of plant community. Symols represent cover classes or basal area of species. 
Table 2.1. Cover class loadings on the first two axes of the rotated species-level factor analysis of the plant community. $B A=$ basal area

\begin{tabular}{|c|c|c|}
\hline Species & Factor 1 & Factor 2 \\
\hline Acer rubrum cover & 0.196 & 0.365 \\
\hline Alnus spp cover & 0.678 & 0.207 \\
\hline Amelanchier cover & 0.042 & -0.020 \\
\hline Andromeda polifolia cover & -0.249 & -0.258 \\
\hline Bare Ground cover & 0.581 & -0.173 \\
\hline Betula papyrifera cover & -0.013 & 0.001 \\
\hline Betula allegheniansis cover & 0.266 & -0.060 \\
\hline Bryophyta cover & 0.598 & 0.095 \\
\hline $\begin{array}{l}\text { Chamaedaphne calyculata } \\
\text { cover }\end{array}$ & -0.594 & -0.313 \\
\hline Cyperaceae cover & -0.365 & -0.061 \\
\hline Cypripedium acaule cover & -0.145 & 0.016 \\
\hline Decomposed CWD cover & -0.001 & -0.023 \\
\hline Drosera spp cover & -0.038 & 0.123 \\
\hline Gramineae cover & 0.746 & 0.156 \\
\hline Kalmia polifolia cover & -0.432 & -0.371 \\
\hline Larix laricina cover & -0.106 & -0.005 \\
\hline $\begin{array}{l}\text { Ledum groenlandicum } \\
\text { cover }\end{array}$ & -0.261 & 0.170 \\
\hline Lichen cover & 0.020 & -0.124 \\
\hline Litterfall cover & 0.558 & 0.265 \\
\hline Nemopanthus cover & -0.085 & 0.307 \\
\hline Open Water cover & 0.513 & 0.103 \\
\hline Orchideceae cover & -0.005 & 0.030 \\
\hline Picea mariana cover & -0.020 & -0.054 \\
\hline Polytrichum cover & 0.004 & 0.0271 \\
\hline Pteridophyta cover & 0.357 & -0.066 \\
\hline Quercus rubra cover & 0.266 & -0.060 \\
\hline Sphagnum cover & -0.514 & 0.270 \\
\hline $\begin{array}{l}\text { Symphoricarpos albus } \\
\text { cover }\end{array}$ & -0.021 & 0.431 \\
\hline Thuja occidentalis cover & 0.094 & 0.301 \\
\hline Typha latifolia cover & 0.542 & 0.156 \\
\hline Undecomposed CWD cover & -0.008 & -0.045 \\
\hline Vaccinium oxycoccos cover & -0.470 & 0.071 \\
\hline Vaccinium uliginosum & -0.124 & 0.259 \\
\hline cover & & \\
\hline AMcov & 0.594 & 0.521 \\
\hline ECM cover & 0.609 & 0.163 \\
\hline ERM cover & -0.797 & -0.167 \\
\hline OM cover & -0.104 & 0.034 \\
\hline NM cover & -0.486 & 0.260 \\
\hline lichen cover & 0.020 & -0.124 \\
\hline
\end{tabular}


Table 2.1. ( cont'd) $^{\prime}$

\begin{tabular}{lrr} 
Acer rubrum BA & 0.159 & 0.649 \\
Alnus spp BA & 0.745 & 0.080 \\
Betula papyrifera BA & 0.223 & 0.121 \\
Betula allegheniansis BA & 0.374 & 0.191 \\
Larix laricina BA & -0.305 & 0.103 \\
Picea mariana BA & -0.061 & 0.360 \\
Pinus strobus BA & 0.002 & -0.029 \\
Thuja occidentalis BA & -0.034 & 0.821 \\
Tsuga canadiensis BA & 0.315 & 0.347 \\
AMBA & 0.018 & 0.880 \\
Ecto basal area & 0.489 & 0.328 \\
sum AM cover AM BA & 0.3252 & 0.898 \\
\hline
\end{tabular}

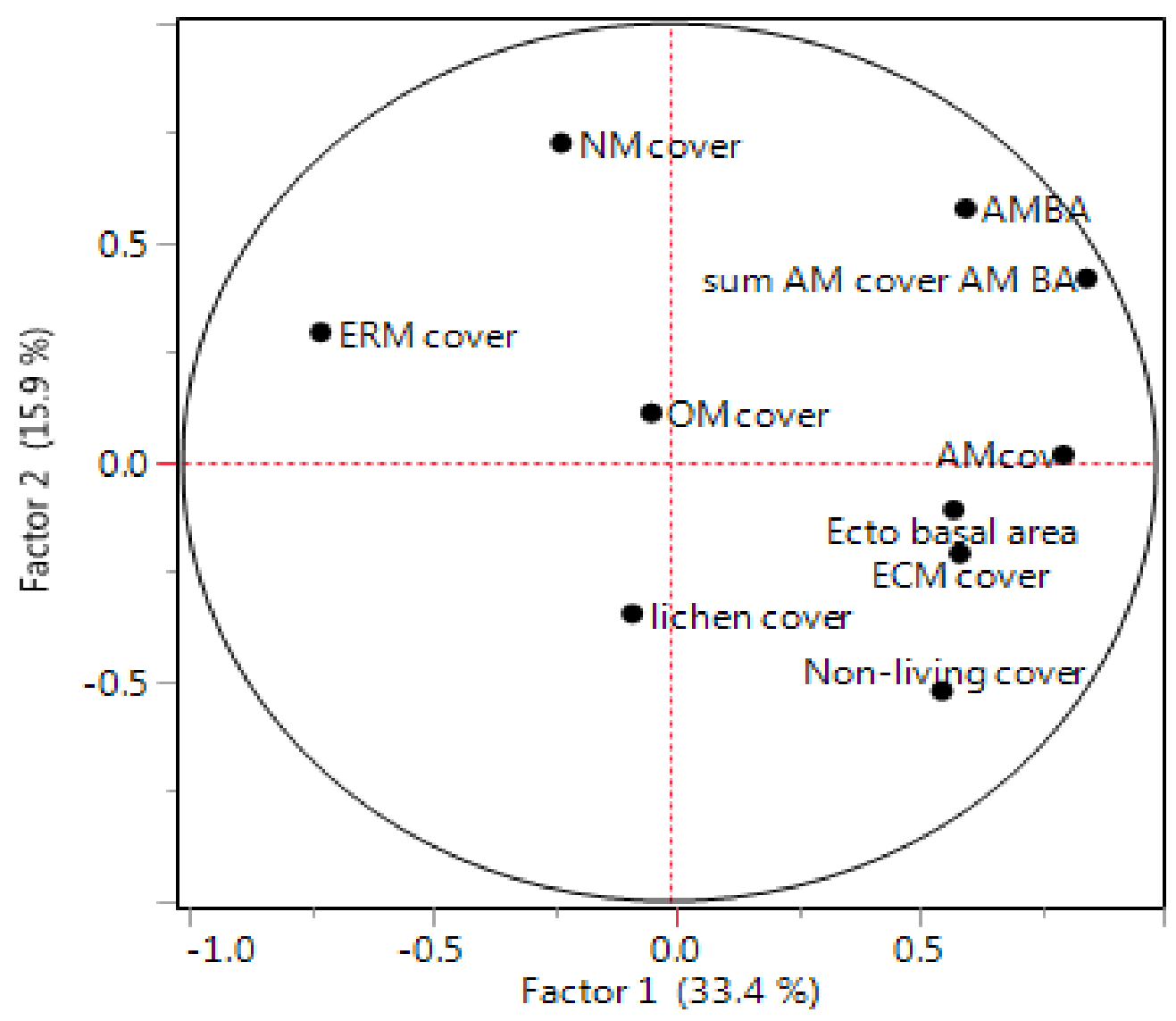

Fig 2.2. PCA of cover and basal area classes 
Table 2.2. The loading of mycorrhizal type and other cover and basal area classes on the two axes of the rotated factor analysis.

\begin{tabular}{lrr}
\hline Cover type & Factor 1 & Factor 2 \\
\hline Arbuscular Mycorrhizal cover & 0.809264 & 0.018045 \\
Ectomycorrhizal cover & 0.595983 & -0.207510 \\
Ericoid mycorrhizal cover & -0.716490 & 0.296521 \\
Orchid mycorrhizal cover & -0.037057 & 0.112754 \\
Non-mycorrhizal cover & -0.222074 & 0.727849 \\
lichen cover & -0.076313 & -0.344531 \\
Non-living cover & 0.559586 & -0.520112 \\
Arbuscular mycorrhizal BA* & 0.608565 & 0.578145 \\
Ectomycorrhizal basal area & 0.583554 & -0.108014 \\
Sum AM cover AM BA & 0.856789 & 0.419627 \\
\hline BA $=$ basal area & &
\end{tabular}

Table 2.3. Effect of inoculation and abiotic factors on survival of the seedlings

\begin{tabular}{lcc}
\hline Variables & ChiSquare & P Value \\
\hline Inoculation & 0.6935 & 0.405 \\
Soil pH & 3.6766 & 0.055 \\
Water Table Level (WTL) & 0.6256 & 0.429 \\
Bulk Density (BD) & 0.1712 & 0.679 \\
\% Light & 10.695 & $\mathbf{0 . 0 0 1}$ \\
AM Plant Index & 0.6314 & 0.429 \\
AM Plant Proximity & 2.5357 & 0.111 \\
ERM cover & 2.5501 & 0.110
\end{tabular}

$\mathrm{P}$ value $<0.05$ : null hypothesis rejected, chi square $<\mathrm{P}$ value: null hypothesis accepted 


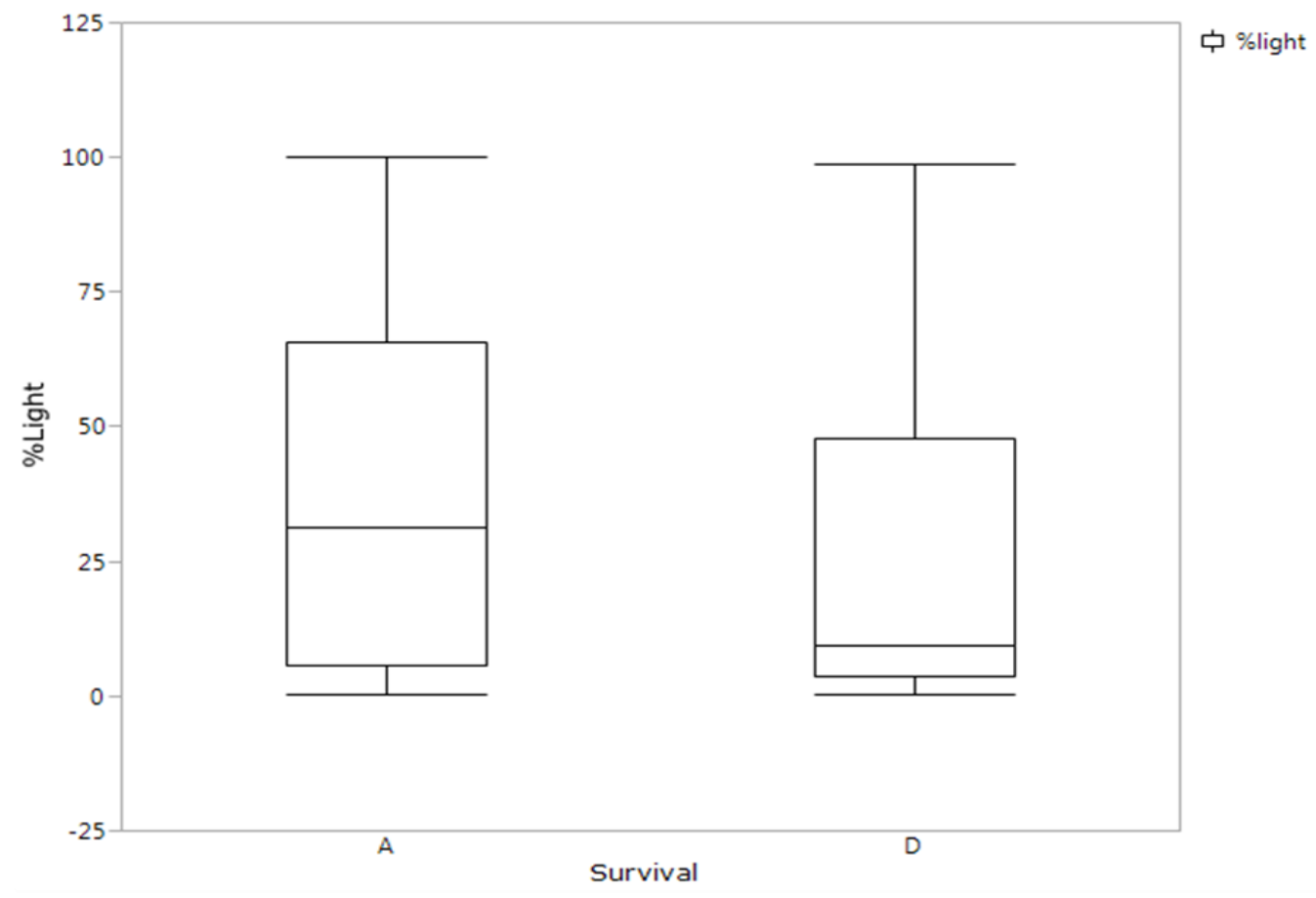

Fig 2.3. One way analysis of light intensity ( $\%$ full sunlight) by survival ( $A=$ alive, $D=$ dead). Boxes represent $25 \%$ quantiles, bars represent range.

Table 2.4. Summary of $P$ value of effect of inoculation on the seedling response variables. T tests were used unless the data did not meet the assumptions of the test, in which case Wilcoxon Signed Rank Tests were used.

\begin{tabular}{lcc}
\hline \multicolumn{1}{c}{ Seedling Trait } & t-test & $\begin{array}{c}\text { Wilcoxon Signed } \\
\text { Rank Test }\end{array}$ \\
\hline Growth $\left(\Delta \mathrm{D}^{2} \mathrm{H}\right)$ & 0.237 & $\mathrm{ND}$ \\
RGR & $\mathrm{ND}$ & 0.317 \\
$\% \mathrm{~N}$ & $\mathrm{ND}$ & 0.586 \\
$\% \mathrm{P}$ & 0.393 & $\mathrm{ND}$ \\
$\% \mathrm{Ca}$ & 0.087 & $\mathrm{ND}$ \\
$\mathrm{N}:$ P ratio & $\mathrm{ND}$ & 0.598 \\
\hline
\end{tabular}

* ND: No Data 
Table 2.5. Summary of $P$ value of effect of inoculation, AM plant proximity, and their combination on the seedling response variables.

\begin{tabular}{lcclllc}
\hline $\begin{array}{l}\text { Seedling } \\
\text { trait }\end{array}$ & \multicolumn{2}{c}{ Inoculation } & \multicolumn{2}{c}{ AM Plant Proximity } & \multicolumn{2}{l}{$\begin{array}{l}\text { Inoc*AM Plant } \\
\text { Proximity }\end{array}$} \\
& Estimate & $\mathrm{P}$ & Estimate & $\mathrm{P}$ & Estimate & $\mathrm{P}$ \\
\hline $\begin{array}{c}\text { Growth } \\
\left(\Delta \mathrm{D}^{2} \mathrm{H}\right)\end{array}$ & 0.1173 & 0.5341 & -0.5555 & $\mathbf{0 . 0 1 8 7}$ & 0.0085 & 0.9712 \\
RGR & & & & & & \\
\%N & -0.0001 & 0.2877 & -0.0001 & 0.5469 & -0.0001 & 0.3990 \\
$\% \mathrm{P}$ & 0.0150 & 0.6003 & -0.1263 & $\mathbf{0 . 0 0 0 4}$ & -0.0196 & 0.5767 \\
$\%$ Ca & 0.0009 & 0.5317 & -0.0084 & $\mathbf{< . 0 0 0 1}$ & -0.0015 & 0.3979 \\
N:P ratio & 0.0179 & 0.2260 & -0.0661 & $\mathbf{0 . 0 0 0 3}$ & -0.0093 & 0.6087 \\
\hline
\end{tabular}

Table 2.6. Summary of $\mathrm{P}$ value of effect of inoculation, $\mathrm{pH}$, and their combination on the seedling response variables.

\begin{tabular}{llllllc}
\hline Seedling & \multicolumn{2}{c}{ Inoculation } & \multicolumn{2}{c}{ Soil pH } & \multicolumn{2}{c}{ Inoc*Soil pH } \\
trait & Estimate & \multicolumn{1}{c}{$\mathrm{P}$} & \multicolumn{1}{c}{ Estimate } & \multicolumn{1}{c}{$\mathrm{P}$} & Estimate & $\mathrm{P}$ \\
\hline Growth & -0.0069 & 0.9755 & 2.5822 & $\mathbf{0 . 0 1 3 6}$ & 0.3859 & 0.7100 \\
$\left(\Delta \mathrm{D}^{2} \mathrm{H}\right)$ & & & & & & \\
RGR & $<-.0001$ & 0.7199 & 0.0009 & 0.2383 & 0.0011 & 0.1594 \\
$\% \mathrm{~N}$ & 0.0167 & 0.5571 & 0.5271 & $\mathbf{< . 0 0 0 1}$ & 0.0336 & 0.7984 \\
$\% \mathrm{P}$ & 0.0011 & 0.4487 & 0.02634 & $\mathbf{0 . 0 0 0 2}$ & -0.0084 & 0.2273 \\
$\%$ Ca & 0.0193 & 0.2038 & 0.1206 & 0.0873 & 0.02234 & 0.7504 \\
$\mathrm{~N}: \mathrm{P}$ ratio & 0.1865 & 0.2071 & 3.3314 & $\mathbf{< . 0 0 0 1}$ & -1.0473 & 0.1265 \\
\hline
\end{tabular}

Table 2.7. Summary of $P$ value of effect of inoculation, water table level in $\mathrm{cm}(\mathrm{WTL})$, and their combination on the seedling response variables

\begin{tabular}{llllllc}
\hline $\begin{array}{l}\text { Seedling } \\
\text { trait }\end{array}$ & \multicolumn{2}{c}{ Inoculation } & \multicolumn{2}{c}{ WTL } & \multicolumn{3}{c}{ Inoc*WTL } \\
\hline Growth & -0.0135 & 0.9531 & -0.0233 & 0.4150 & -0.0157 & 0.5809 \\
$\left(\Delta \mathrm{D}^{2} \mathrm{H}\right)$ & & & & & & \\
$\mathrm{RGR}$ & $<-.0001$ & 0.6752 & $<-.0001$ & 0.1549 & $<-.0001$ & $\mathbf{0 . 0 4 4 6}$ \\
$\% \mathrm{~N}$ & 0.0053 & 0.8505 & -0.0131 & $\mathbf{0 . 0 0 0 3}$ & -0.0019 & 0.5886 \\
$\% \mathrm{P}$ & 0.0009 & 0.5677 & -0.0007 & $\mathbf{0 . 0 0 0 3}$ & $<-.0001$ & 0.8201 \\
$\%$ Ca & 0.0192 & 0.2122 & -0.0012 & 0.5450 & -0.0007 & 0.7244 \\
$\mathrm{~N}: \mathrm{P}$ ratio & 0.0784 & 0.5580 & -0.0663 & $\mathbf{< . 0 0 0 1}$ & -0.0208 & 0.2127 \\
\hline
\end{tabular}


Table 2.8. Summary of $P$ value of effect of inoculation, peat bulk density (BD), and their combination on the seedling response variables

\begin{tabular}{llllllc}
\hline Seedling & \multicolumn{2}{c}{ Inoculation } & \multicolumn{2}{c}{ Soil BD } & \multicolumn{2}{c}{ Inoc*BD } \\
trait & Estimate & $\mathrm{P}$ & Estimate & $\mathrm{P}$ & Estimate & $\mathrm{P}$ \\
\hline Growth & -0.0312 & 0.8905 & -25.8079 & 0.3606 & - & 0.0964 \\
$\left(\Delta \mathrm{D}^{2} \mathrm{H}\right)$ & & & & & 47.0589 & \\
RGR & $<-.0001$ & 0.6543 & -0.0174 & 0.3900 & -0.0240 & 0.2349 \\
$\% \mathrm{~N}$ & 0.0162 & 0.5854 & 0.5347 & 0.8848 & -2.4095 & 0.5140 \\
$\% \mathrm{P}$ & 0.0009 & 0.5728 & -0.2952 & 0.1319 & -0.1748 & 0.3715 \\
\%Ca & 0.0174 & 0.2554 & -2.5612 & 0.1828 & 0.9229 & 0.6305 \\
$\mathrm{~N}: \mathrm{P}$ ratio & 0.1736 & 0.2701 & -5.3936 & 0.7849 & 24.7174 & 0.2120 \\
\hline
\end{tabular}

Table 2.9. Summary of $P$ value of effect of inoculation, percent of full sunlight at the seedling canopy (\%light), and their combination on the seedling response variables

\begin{tabular}{llllllc}
\hline Seedling & \multicolumn{2}{c}{ Inoculation } & \multicolumn{2}{c}{ \%light } & \multicolumn{3}{c}{ Inoc*\%light } \\
trait & Estimate & $\mathrm{P}$ & Estimate & $\mathrm{P}$ & Estimate & $\mathrm{P}$ \\
\hline Growth & 0.1327 & 0.4815 & 0.0144 & $\mathbf{0 . 0 1 4 8}$ & 0.0061 & 0.3008 \\
$\left(\Delta \mathrm{D}^{2} \mathrm{H}\right)$ & & & & & & \\
$\mathrm{RGR}$ & $<-.0001$ & 0.2951 & $<.0001$ & 0.6836 & $<.0001$ & 0.3752 \\
$\% \mathrm{~N}$ & 0.0055 & 0.8475 & -0.0037 & $\mathbf{< . 0 0 0 1}$ & -0.0004 & 0.6334 \\
$\% \mathrm{P}$ & 0.0003 & 0.8217 & 0.0003 & $\mathbf{< . 0 0 0 1}$ & -0.0001 & 0.3967 \\
$\% \mathrm{Ca}$ & 0.0121 & 0.3964 & -0.0024 & $\mathbf{< . 0 0 0 1}$ & 0.02234 & 0.7504 \\
$\mathrm{~N}: \mathrm{P}$ ratio & 0.1865 & 0.2071 & 3.3314 & $\mathbf{< . 0 0 0 1}$ & 0.0001 & 0.9749 \\
\hline
\end{tabular}

Table 2.10. Summary of $P$ value of effect of inoculation, first axis of PCA of mycorrhizal host type cover and basal area (AM Plant Index), and their combination on the seedling traits. Higher values of AM plant index indicate greater AM host cover and basal area.

\begin{tabular}{lllllll}
\hline Seedling & \multicolumn{2}{c}{ Inoculation } & \multicolumn{2}{c}{ AM Plant Index } & \multicolumn{2}{c}{ Inoc*AM Plant Index } \\
trait & Estimate & $\mathrm{P}$ & Estimate & $\mathrm{P}$ & Estimate & $\mathrm{P}$ \\
\hline Growth & 0.1220 & 0.5206 & 0.1568 & 0.4097 & -0.0116 & 0.9513 \\
$\left(\Delta \mathrm{D}^{2} \mathrm{H}\right)$ & & & & & & \\
$\mathrm{RGR}$ & -0.0001 & 0.2903 & -0.00003 & 0.8088 & 0.0001 & 0.3024 \\
$\% \mathrm{~N}$ & 0.0189 & 0.5025 & 0.1442 & $<.0001$ & 0.0118 & 0.7246 \\
$\% \mathrm{P}$ & 0.0012 & 0.3912 & 0.0091 & $\mathbf{< . 0 0 0 1}$ & -0.0009 & 0.6052 \\
$\% \mathrm{Ca}$ & 0.0198 & 0.1912 & 0.0381 & $\mathbf{0 . 0 3 2 8}$ & 0.0141 & 0.4275 \\
$\mathrm{~N}: \mathrm{P}$ ratio & 0.1924 & 0.2010 & 0.7411 & $<.0001$ & 0.1714 & 0.3324 \\
\hline
\end{tabular}



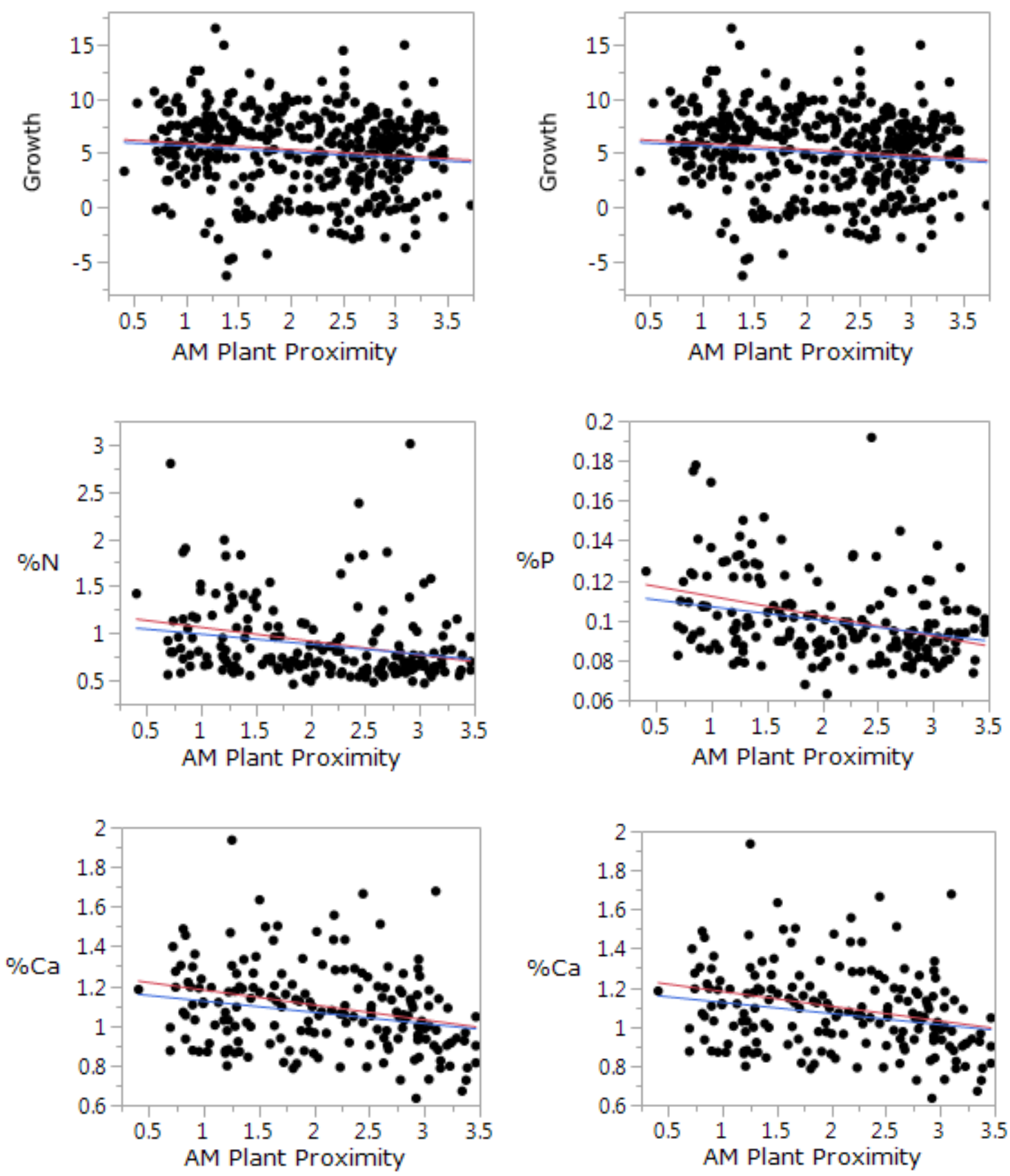

Fig 2.4. Effect of log transformed distance to the nearest AM tree (AM plant proximity) on NWC seedling growth and nutrient acquisition (inoculated with red line and uninoculated with blue line) 

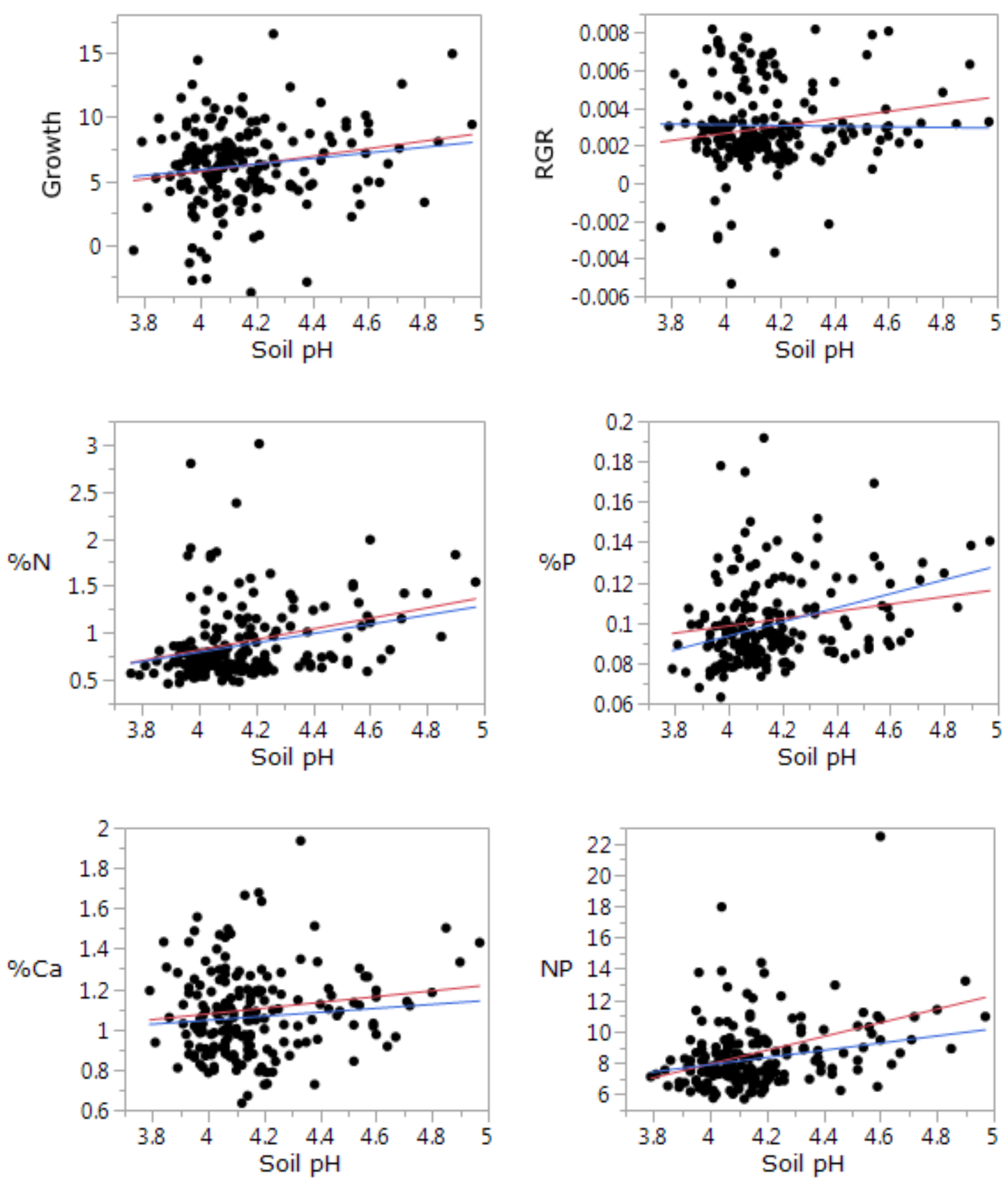

Fig 2.5. Effect of soil pH on NWC seedling growth and nutrient acquisition (inoculated with red line and uninoculated with blue line). 

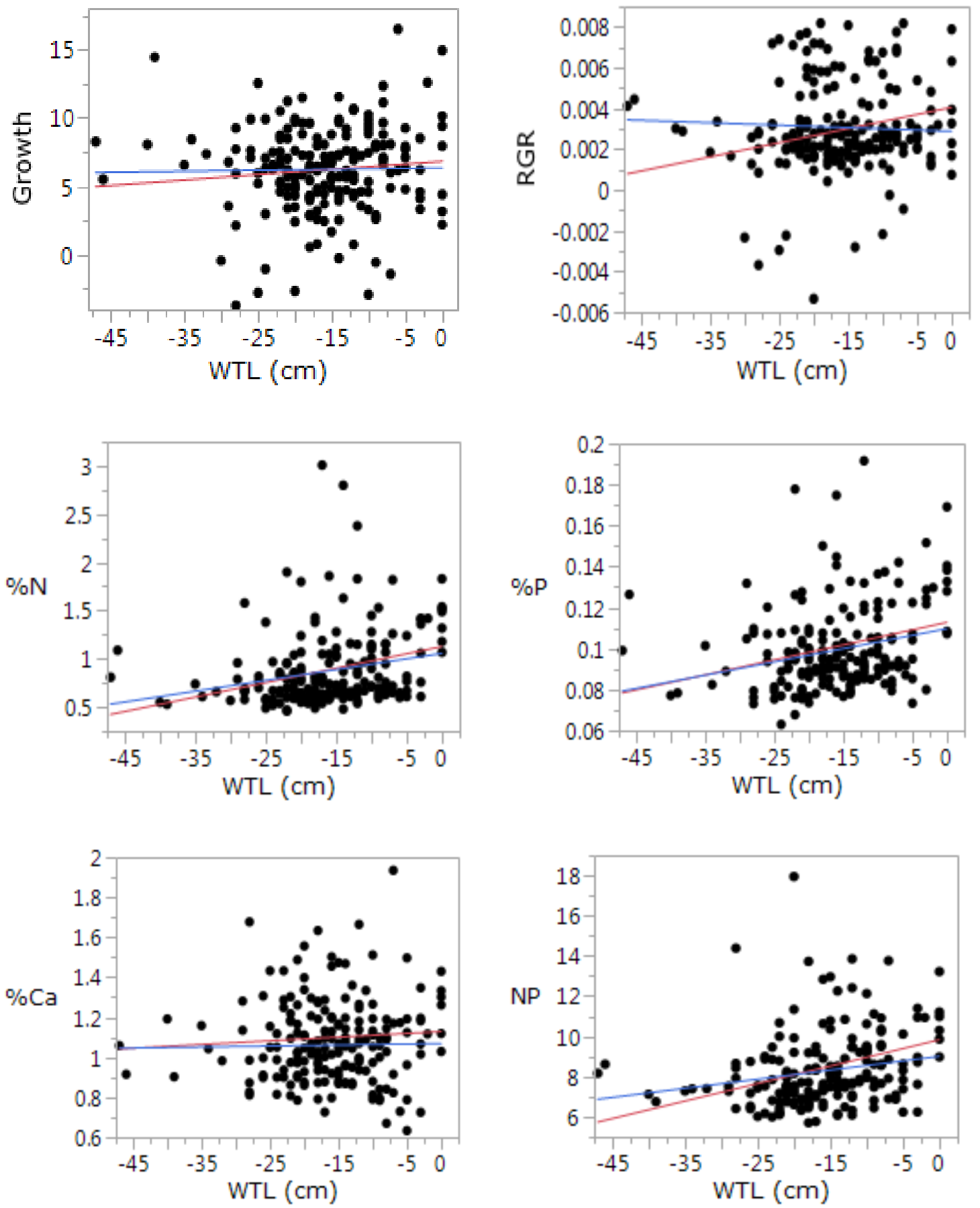

Fig 2.6. Effect of water table depth (WTD) on NWC seedling growth and nutrient acquisition (inoculated with red line and uninoculated with blue line). 

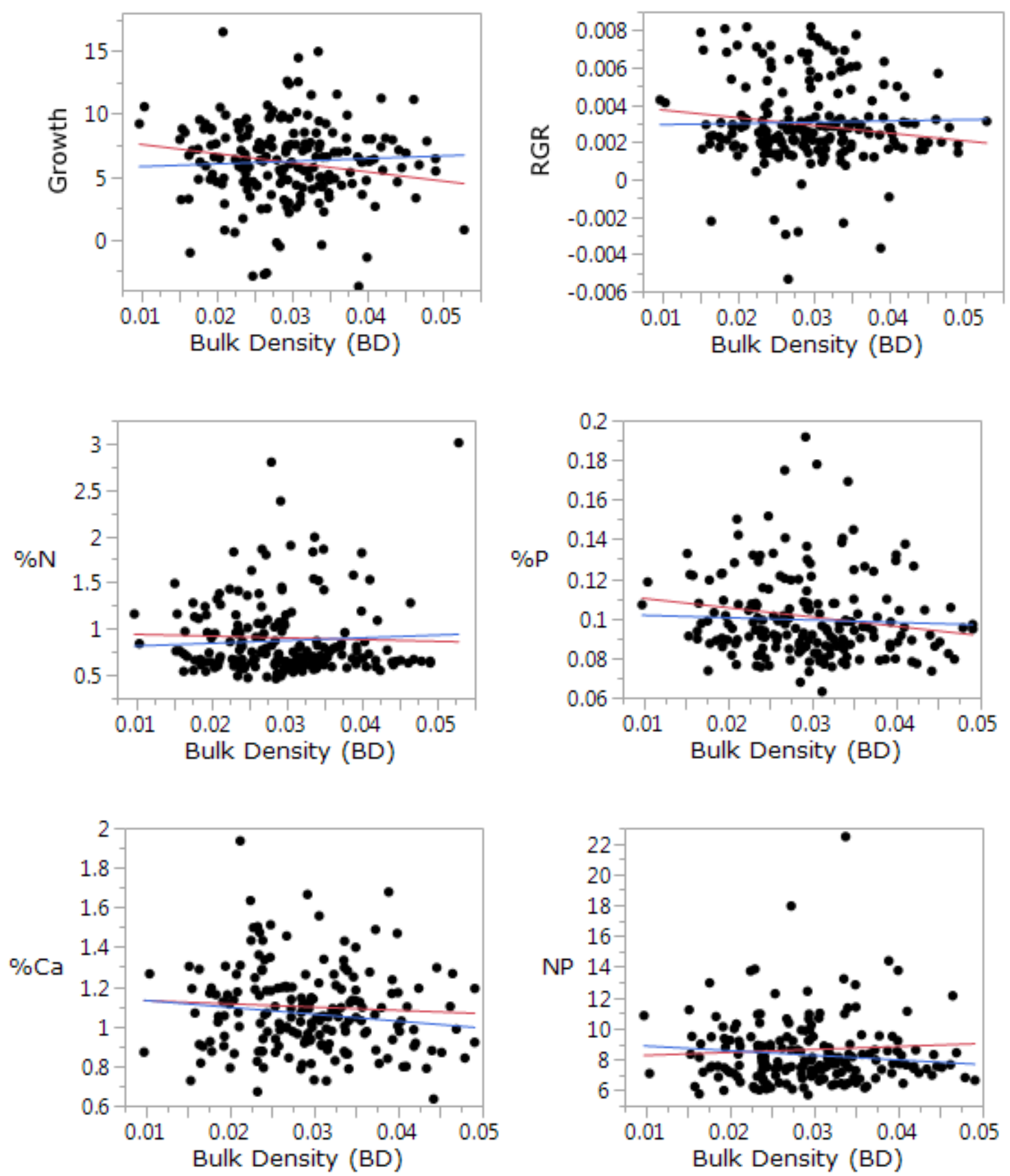

Fig 2.7. Effect of soil bulk density (BD) on NWC seedling growth and nutrient acquisition (inoculated with red line and uninoculated with blue line). 

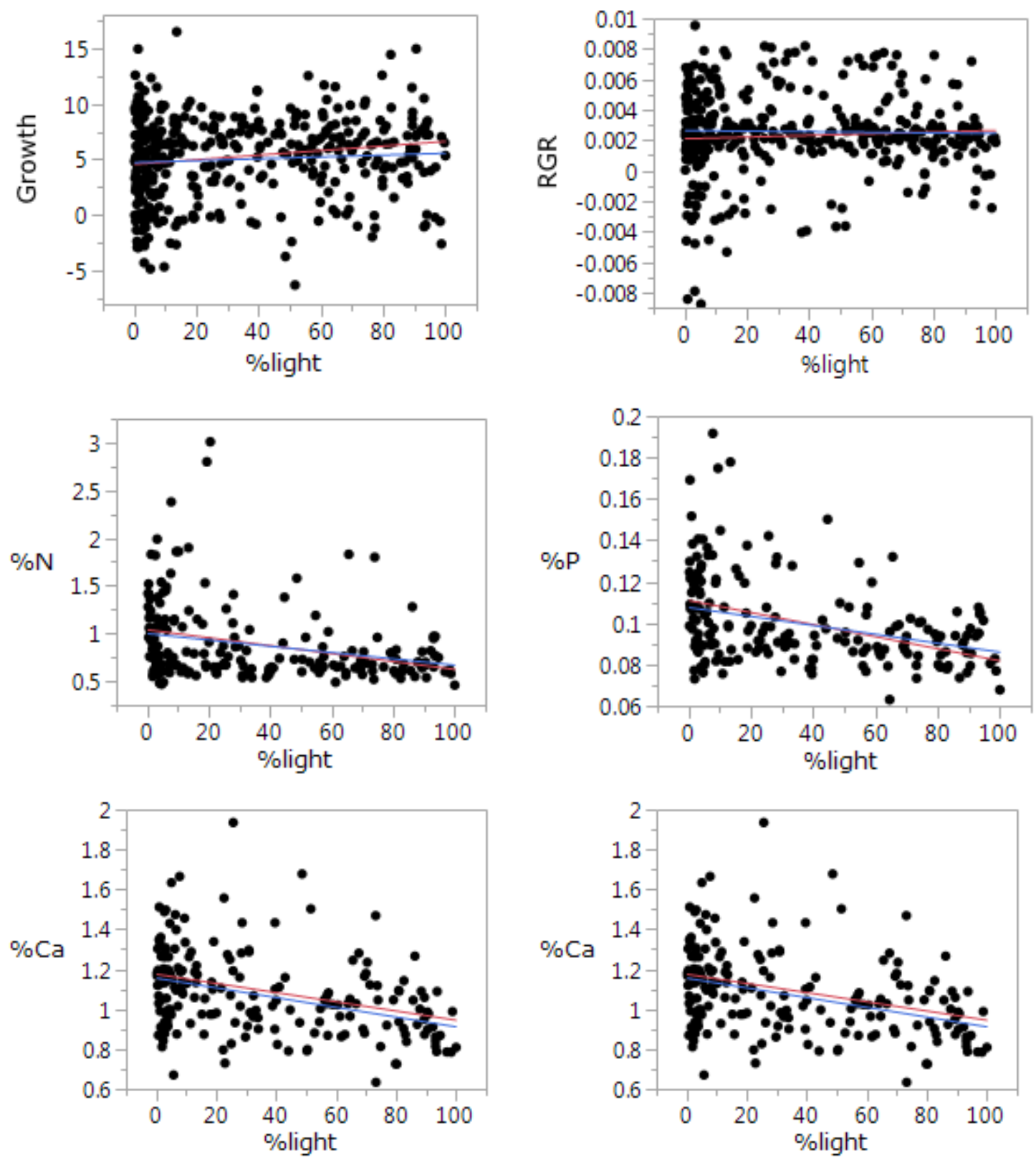

Fig 2.8. Effect of light intensity on NWC seedling growth and nutrient acquisition (inoculated with red line and uninoculated with blue line). 

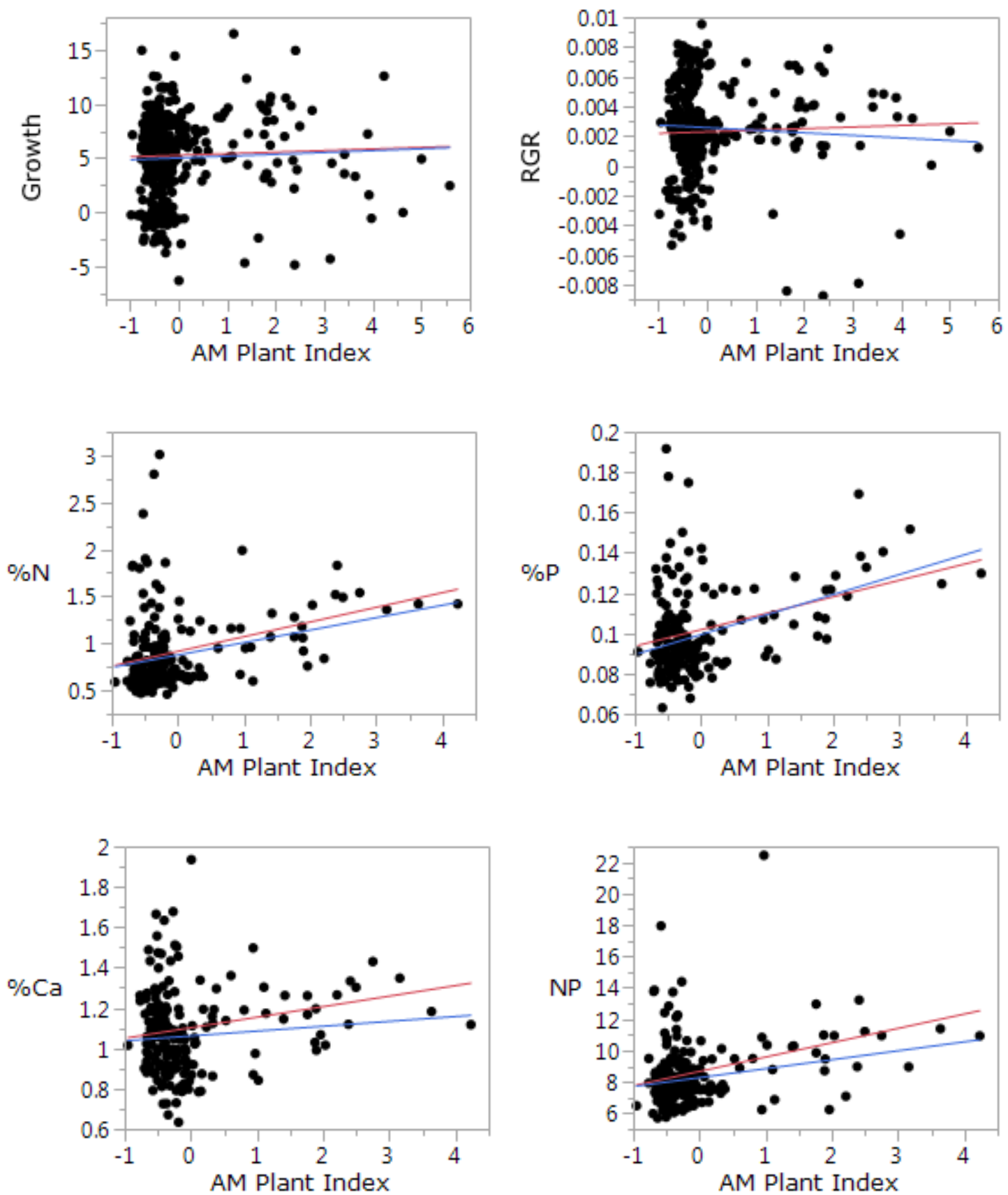

Fig 2.9. Effect of the AM plant index (first axis of the cover and basal area PCA for the different mycorrhizal types) on NWC seedling growth and nutrient acquisition (inoculated with red line and uninoculated with blue line). 
Table 2.11. Relationship between distance to the nearest AM tree (AM plant proximity) and other predictors

\begin{tabular}{lll}
\hline \multicolumn{1}{c}{ Other Predictors } & $\mathrm{R}^{2}$ & $\mathrm{P}$ Value \\
\hline LogdistAM+1 *Soil pH & 0.1982 & 0.1280 \\
LogdistAM+1 *Water Table Depth & 0.1982 & 0.2289 \\
LogdistAM+1 *Peat Bulk Density & 0.1982 & 0.7120 \\
LogdistAM+1 *Light intensity & 0.1982 & $\mathbf{0 . 0 0 0 2}$ \\
LogdistAM+1 *Ericoid Mycorrhizal Plants Cover & 0.1982 & $\mathbf{0 . 0 0 0 2}$ \\
\hline
\end{tabular}

Table 2.12. Summary of the best multiple regression models of the effect of the suite of predictor variables on the seedling response variables

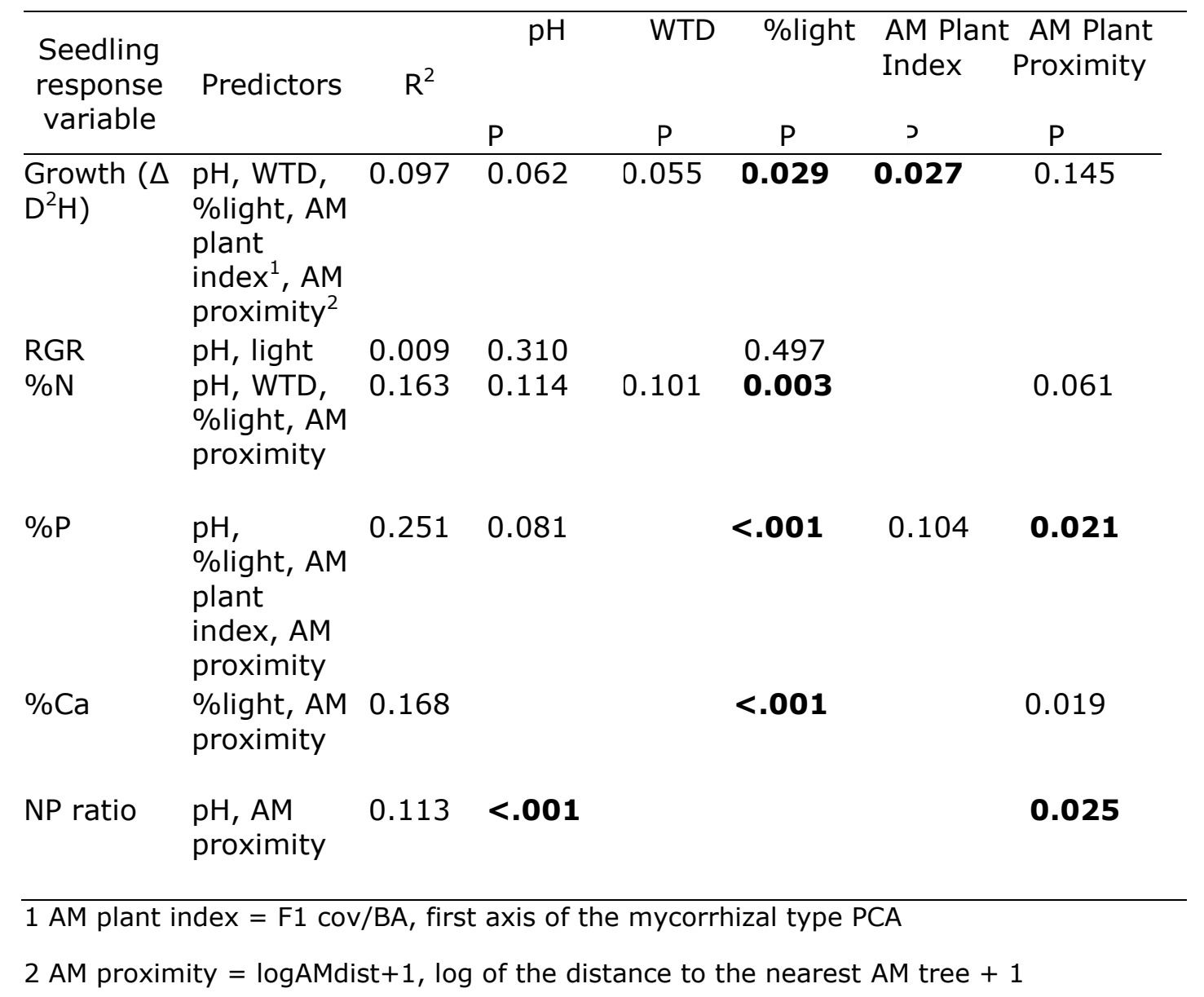


Appendix Table 2.1. Summary statistics for sample plots in the peatland field experiment.

\begin{tabular}{lccccc}
\hline Variables & Median & Average & $\begin{array}{c}\text { Standard } \\
\text { Deviation }\end{array}$ & Minimum & Maximum \\
\hline Growth $\left(\mathrm{D}^{2} \mathrm{H} / \mathrm{cm}^{3}\right)$ & 5.69 & 5.160 & 3.727 & -6.270 & 16.486 \\
RGR & 0.002 & 0.002 & 0.002 & -0.008 & 0.009 \\
Foliar \% N & 0.73 & 0.89 & 0.41 & 0.46 & 3.01 \\
Foliar \% P & 0.094 & 0.100 & 0.021 & 0.063 & 0.191 \\
Foliar \%Ca & 1.06 & 1.08 & 0.209 & 0.634 & 1.935 \\
N:P ratio & 7.85 & 8.44 & 2.150 & 5.707 & 22.447 \\
Soil pH & 4.10 & 4.16 & 0.22 & 3.76 & 4.97 \\
Bulk Density (BD) & 0.03 & 0.03 & 0.008 & 0.009 & 0.052 \\
\%full sunlight & 25.3 & 35.0 & 31.9 & 0.25 & 100 \\
Water table level (cm) & -16 & -16.08 & 8.27 & -47 & 0 \\
AM Plant Index & -0.34 & 0.0001 & 1 & -0.98 & 5.59 \\
AM Plant Proximity & 2.176 & 2.110 & 0.802 & 0.405 & 3.73 \\
(log 10 m) & & & & & 19 \\
ERM Cover & 11 & 10.03 & 3.706 & 0 & 19 \\
\hline I: data of ERMcover refer & & & & & \\
\hline
\end{tabular}

${ }^{1}$ : data of ERM cover refer to sum of cover class of ERM (Ericoid mycorrhizal) species within $1 \mathrm{~m}^{2}$ quadrat. 


\section{Chapter 3: Structure and composition of arbuscular mycorrhizal community on Thuja occidentalis roots in peatland, mesic upland, and mine tailing habitat types ${ }^{3}$}

\subsection{Abstract}

Arbuscular mycorrhizal (AM) fungi are widespread symbionts mostly found in terrestrial ecosystems and some wetlands. These fungi that are composed by fungal species belongs to phylum Glomeromycota, form a mutualistic association with most land plants including northern white cedar (NWC). We assessed certain factors influencing structure and composition of AM fungi in NWC roots in three habitat types (peatlands, mining-derived stamp sands, and uplands). We hypothesized that these root-associated fungi have habitat specificity; AM fungi are a prominent component of the fungal community in all the habitats; and soil $\mathrm{pH}$ and plant community are significant predictors of structure and composition of Glomeromycota. We conducted a molecular study using a next generation sequencing to identify structure and composition of Glomeromycota from the three habitat types. Through a study series including root sampling from all the habitats (14 locations), processing DNA extraction, sequencing with the Illumina MiSeq, bioinformatics, and multivariate statistics, we found that Glomeromycota were a significant component of the fungal community across the habitats. Habitat type significantly affected fungal community richness. Stamp sands had the lowest richness across the habitats. Some species of these fungi were indicator species of different habitat types. Fungal community composition in stamp sand differed most from the other two habitat types.

\footnotetext{
$\overline{3^{3} \text { The material contained in this chapter }}$ is in preparation for submission to a journal.
} 
Community composition was affected by soil pH for the Glomeromycota and for all fungal taxa. Likewise, \%AM tree basal area strongly affected fungal community. A diverse array of unidentified dominant Glomeraceae OTUs was found in both uplands and peatlands. These Glomeraceae merit testing as inoculum for use as general and habitat-specific inoculum in NWC restoration projects in disturbed lands.

\subsection{Introduction}

Arbuscular mycorrhizal (AM) fungi, are formed by fungi in phylum Glomeromycota. There are currently about 250 species belong to this group (Oehl et al., 2008; Oehl et al., 2011). They occur in most terrestrial ecosystems, forming a mutualistic association with a vast majority of plants (Wang and Qiu, 2006; Smith and Read, 2008) and are also found in some wetland ecosystems (Turner et al., 2004; Ypsilantis et al., 2007; Wilde et al, 2009; Wang et al., 2010). AMF also occurs in mining soils with high concentrations of heavy metals (Turnau et al., 2001; Gildon \& Tinker, 1981; Sambandan et al., 1992).

AM fungi play important roles for improving growth of plants in nutrient-poor marginal lands by mobilizing essential mineral nutrients, especially phosphorus (Smith and Read, 2008; Wang et al., 2011); metal detoxification; and reducing the effects of other plant stress factors such as drought, soil acidification, and plant pathogens (Finlay, 2008; Smith and Read, 2008). Some studies found that

Mycorrhizal fungal community function, structure, and composition are strongly affected by environmental factors (Treseder and Cross, 2006). Environmental changes might alter species composition, which can alter the diversity 
and productivity of plant communities (van der Heijden et al., 2008; Chaudhary et al., 2008; Opik et al., 2010). Major factors in structuring AM communities are nichebased processes and environmental screening (Lekberg 2007; Dumbrell et al. 2010). Soil nutrient availability, soil acidity, and soil moisture strongly affect structure and composition of AMF communities (Bethlenfalvay et al., 1982; Stahl and Smith, 1984; Fitzsimons et al., 2008; Liu et al., 2009; Johnson et al.; 2010). However, role of the niche and natural processes that affect structure of fungal communities are still poorly quantified (Dumbrell et al., 2010; Klironomomos et al., 2001). It is important to study composition and distribution of Glomeromycota fungi in various ecosystems to determine factors regulating AM fungal communities.

Northern white-cedar (NWC; Thuja occidentalis L.) forms arbuscular mycorrhizas (Malloch and Malloch, 1985; Brundrett et al., 1989; Matthes-Sears et al., 1992; chapter 1 and 2 this dissertation). NWC commonly grows in both upland and lowland habitats. In uplands, NWC generally grows in abandoned pastures, seepage areas, limestone cliffs, and boulder fields, but grows best on mesic mineral soils with neutral or slightly alkaline soils (Johnston, 1990). In lowlands, this species predominantly grows in calcareous rich swamps. However NWC can also be found in acid peatlands, including bogs (Hannah, 2004) and poor fens (Bhatt, 1969; Scott and Murphy, 1987; Johnston, 1990; Miller, 1990; Hofmeyer et al., 2009)

In addition to basic ecological interest in NWC, this species is also an important target for ecological restoration and post-mining land reclamation. However, low soil fertility due to nutrient deficiencies, drought, accumulation of heavy metal concentrations, loss of organic matters, and loss of soil microorganisms including AM propagules become primary obstacles to successful restoration and post-mining land reclamation programs (Reeves et al., 1979; Miller and Jastrow, 
1992). A number of studies have suggested application of mycorrhizal fungi to accelerate restoration and reclamation programs by reintroducing mycorrhizal propagules into the soils of their native population (Allen, 1991; Kumar et al., 2010). Mycorrhizal association with plants in the degraded lands yields numerous benefits such as plant growth improvement, mineral nutrient acquisition, pathogen protection, and metal toxicity reduction (Borowics, 2001; Al-Karaki et al., 2004).

Structure and composition of fungal communities in general, and Glomeromycota species in particular, on NWC roots have been poorly studied. Hence, we conducted research with the following aims: 1 ) to test effect of habitat specificity on fungal species, 2) to determine major indicator fungal species of each habitat, 3) to determine diversity and similarity of fungal species in each habitat, and 4) to determine effect of soil $\mathrm{pH}$ and plant community as predictors of fungal community composition and structure. We assessed some factors that could be important regulators of diversity and fungal community composition and structure. We had three questions regarding fungal communities on NWC roots in three strongly contrasting environments: 1 ) is there habitat specificity for fungal species in general, and Glomeromycota in particular, 2) are fungal communities more similar within habitat types than between them, and 3) are soil chemistry and plant community significant predictors of fungal community composition and structure?

We hypothesized that: 1 ) there is root fungal habitat specificity for the contrasting habitat types in the study, 2) Glomeromycota are the predominant root fungal community in all the habitats, and 3) soil pH and neighboring plant community are significant predictors of fungal community composition and structure in roots of NWC. 


\subsection{Materials and methods}

\subsubsection{Sampling sites}

We sampled AM fungus from NWC roots across 14 sites in Houghton and Keweenaw counties in the Upper Peninsula of Michigan (Table 1). All sites had a large component of NWC, but different in habitat type with six peatlands, three stamp sand, and five mesic upland sites. Sites varied in soil $\mathrm{pH}$, NWC foliar chemistry, and basal area of AM and ECM trees (Table 3.2-3.3)

\subsubsection{Sampling collection and analysis}

In the field

From each location, we selected 6 sample points to collect NWC roots, leaves, and soils. The site location was recorded by GPS. For sites with high tree density, we chose a center point in the middle of the study area. Then, we ran a randomly located and oriented transect and chose the first six mature focal trees at each site with a minimum distance between each pair of trees of $10 \mathrm{~m}$. For two of the three stamp sand sites tree density was lower so the transect method was too difficult to apply. At these sites we chose the tree and determined the distance arbitrarily. After arriving at the site we identified locations with NWC present, and then selected six mature trees with a minimum spacing of $10 \mathrm{~m}$.

We selected a ground cover, root and soil sampling point at about $50 \mathrm{~cm}$ distance from the sample tree. At the point of soil sampling we used a $50 \mathrm{~cm} \times 50$ cm PVC frame to estimate percent cover of grass, herb, tree seedling, moss, litter, leaf litter. Before taking the soil sample, the shovel was cleaned of any soils. We took a sampled $25 \mathrm{~cm} \times 25 \mathrm{~cm} \times 20 \mathrm{~cm}$ soil samples and put it into a 2 gallon plastic 
bag to send to the lab. Then, we identified basal area and species of trees nearby the sample point by the wedge prism method (Hemery, 2011). In addition, we picked terminal section of branch with green leaves $(\sim 10 \mathrm{~cm}$ long) of three of the lowest branches of the target NWC tree. The leaves were put in a labeled paper bag. We then measured slopes and aspect the area by clinometer and compass.

In the lab

We dried NWC leaves in oven at $60^{\circ} \mathrm{C}$ for 48 hours. The dry leaves were ground to a fine powder in a mortar. Foliar $\mathrm{N}$ and $\mathrm{C}$ were measured at the Soil Laboratory of School of Forest Resources and Environmental Science, Michigan Tech using a Costech 4010 Elemental analyzer (Costech Analytical Technologies Inc., Valencia, CA) calibrated with atropine. Foliar P and Ca were determined using the dry ash method, on a Perkin Elmer Optima 7000DV ICP-OES (PerkinElmer Inc., Waltham, MA, USA).

All the soil samples were stored at $4^{\circ} \mathrm{C}$ when we arrived in the lab. Within 24 hours we picked the fine root samples from the soil samples, gently washed them on a sieve using tap water, and selected healthy young fine NWC roots (easily identified by their distinct morphology, paler color and turgidity) from other roots. These roots were frozen in $\mathrm{a}-20^{\circ} \mathrm{C}$ freezer to await DNA extraction, and the soil samples were air dried at room temperature.

The soil samples were analyzed for $\mathrm{pH}$ and nutrient content. To measure $\mathrm{pH}$, we used a pH meter (Denver Instrument Model 220, Denver Instrument, Arvada, CO, USA) with soils rewetted with a mass ratio of 1 (dry soil):40 ( $\left(\mathrm{DI} \mathrm{H}_{2} \mathrm{O}\right)$. This ratio was chosen to accommodate the peat soils. 
To prepare DNA extract, the frozen root samples were freeze dried overnight using a Labconco Freeze Dry System/Free Zone 4.5 (Labconco, Kansas City, MO, USA). To be certain of low final moisture content, the samples were dried several days. The dried samples were stored in closed tubes in a sterilized desiccator cabinet. We took $0.03 \mathrm{~g}$ dry wt. subsamples, ground them to a fine powder in a mortar and pestle under liquid nitrogen, and put into the labeled vials.

The root DNA was extracted using the PowerSoil DNA Isolation kit following manufactured protocol (MoBio Laboratories Inc., Carslbad, CA). The DNA extract was quantified with a Qubit Fluorometer (Thermo Fisher Scientific Inc, Grand Island, NY). PCR was carried out on these samples using bar-code tagged primers appropriate for arbuscular mycorrhizal fungi. We used the forward primer 5.8SLT1 $\left(5^{\prime}\right.$ to $3^{\prime}=$ AACTTTYRRCAAYGGATCWCT) and reverse primer ITS4mod_long ( $5^{\prime}$ to $3^{\prime}$ = AGCCTCCGCTTATTGATATGCTTAART) designed to amplify the second fungal Internal Transcribed Spacer (ITS2) region (D.L. Taylor, in prep). The samples were processed at Northern Arizona University Environmental Genetics and Genomics Laboratory (EnGGEN; http://www.nau.edu/Merriam-Powell/EnGGen/), where DNA extracts was subjected to a 1:1 bead cleanup modified from Rohland and Reich (2012). The samples were normalized to $2 \mathrm{ng} / \mathrm{ul}$, and dual indexed amplicon libraries were generated with the primers 5.8SLT1 and ITS4mod_long where each end of the amplified fragment contained unique 8 bp Golay barcodes, primer pads, primer linkers, and Illumina adaptors. Paired end sequencing ( $250 \times 250 \mathrm{bp})$ was conducted on an Illumina MiSeq platform (Illumina, Inc., San Diego, CA, USA). Mi-Seq sequences were subjected to bioinformatics and statistical analysis using the QIIME pipeline. 


\subsubsection{Bioinformatics}

Sequence data processing began with removal of PhiX sequences from raw fastq sequence files (both forward and reverse reads) using the PhiX filtering workflow in akutils (https://github.com/alk224/akutils). Adaptor and primer artifacts were checked and removed using manual grep searches, as well as Fastq-mcf in eautils (https://code.google.com/p/ea-utils/). Next, dual indexed barcodes contained in separate barcode fastq files were concatenated to create $16 \mathrm{bp}$ barcodes in a single file with the concatenate_fastqs.sh script in akutils. Qiime 1.9 (Caporaso et al. 2010) was used to join paired-end reads with a minimum difference of 30 percent and a minimum 30 bp overlap. This was followed by demultiplexing and quality filtering in Qiime 1.9 with a minimum quality score of 20 , a maximum of two consecutive low quality scores prior to sequence truncation and a minimum of 95 percent of the original sequence length required for retention of truncated sequences. The ITS2 region was extracted from demultiplexed sequences using ITSx (Bengtsson-Palme et al. 2013), in order to remove conserved flanking sequences of the $5.8 \mathrm{~S}$ and large ribosomal subunit (LSU). ITS2 sequences were then subjected to reference-based chimera detection and filtering using Uchime (Edgar et al. 2011) coupled with the UNITE 7 ITS2 chimera detection database (Nilsson et al. 2015), and clustered in to operational taxonomic units (OTUs) at the 95 percent sequence similarity level with USEARCH (CITATION). UCHIME and USEARCH were implemented in Qiime 1.9. In Qiime 1.9, taxonomy was assigned to representative sequences for each OTU with the ribosomal database project (RDP) classifier (see Porras-Alfaro et al. 2014 for implementation of the RDP classifier with the fungal ITS) trained with the UNITE 7 species hypothesis dynamic clustering dataset (released 02 March 2015; https://unite.ut.ee/repository.php; Kõljalg et al. 2013) supplemented with additional 
ITS sequences from non-fungal eukaryotic lineages obtained from the NCBI nucleotide database (http://blast.ncbi.nlm.nih.gov). OTUs unclassifiable as fungi were removed from the data set. Furthermore, OTUs whose taxonomic designations were only resolved to fungal phylum were subject to manual BLAST searches in the NCBI nucleotide database and removed if there was not convincing evidence that they were fungi. The modestly conservative approach of Schmidt al. (2013) was adopted, where OTUs represented by less than 10 sequences in the entire data set were removed to filter potential sources of sequencing or clustering error. In order to avoid biases arising from differences in sequence number per sample, each sample was rarefied to 500 sequences prior to statistical analyses.

\subsubsection{Statistical analysis}

To test the effect of habitat on fungal community similarity, the OTU $x$ sample matrix was analyzed using PERMANOVA with Bray-Cutis dissimilarity. To visualize the patterns of community similarity, ordination of the communities was performed with non-metric multidimensional scaling (NMDS) with Bray Cutis dissimilarity using the fourth root transformed OTU matrix. Environmental variables were correlated against the ordination axes. Both analyses were performed in Primer 6.15 (PRIMER-E, Plymouth, UK).

Indicator species were determined using R.3.0.2 (R Foundation for Statistical Computing, Vienna, Austria). Then, to test effect of habitat, soil $\mathrm{pH}$, and plant community on rarefied OTU richness ( $\mathrm{S}$; number of unique OTUs per rarefied sample) and Pielou's evenness ( $\mathrm{J}$; a measure of evenness of relative abundances of OTUs-higher with few high-abundance taxa), we used JMP 12 (SAS Institute Inc., 
Cary, NC) with standard least squares regression and post-hoc pair wise comparison Tukey test.

\subsection{Results}

After clustering and chimera filtering, there were 1,982 OTUs that consisted of Ascomycota, Basidiomycota, Glomeromycota, and Zygomycota. Ascomycota and Glomeromycota were found to be the dominant groups in NWC roots from all habitat types. We focused primarily on Glomeromycota in this study since they are the only fungi that form arbuscular mycorrhizas.

Analysis of OTU richness showed that for both all fungal taxa and for Glomeromycota, habitat type significantly affected fungal community richness. Stamp sand richness was lower than peatland and upland (Fig. 3.1). There was negative effect of soil $\mathrm{pH}$ and plant community on fungal community richness. Meanwhile, evenness did not vary among habitat types or in response to soil pH (Fig. $3.2)$.

For Glomeromycota OTUs and all taxa pooled by class, the pair-wise comparison in PERMANOVA showed significant difference between peatland and stamp sand as well as between upland and stamp sand, but not between peatland and upland (Table 3.4). When all taxa were tested at the OTU level, all the site pairs showed significant difference, with the weakest difference between peatland and upland (Table 3.4).

Indicator species analysis with individual habitat found only 24 indicators of peatlands, 73 indicators of uplands, and 65 indicators of stamp sands. The analysis of paired habitat types found that the peatland and stamp sand pair had only one indicator species, the stamp sand and upland pair had only three indicator species, 
whereas the peatland and upland pair had 22 indicators, consistent with the higher similarity between these two habitat types relative to stamp sands (Table 3.5 ).

Analysis of NMDS showed strong correlation between soil $\mathrm{pH}$ with fungal community composition in stamp sand both within Glomeromycota and for all taxa. \%AM tree basal area had a strong correlation with fungal community composition for both Glomeromycota and all taxa (Figs 3.3; 3.4; and 3.5).

Foliar analysis showed that foliar $\% \mathrm{~N}$ was uniformly low, whereas foliar $\% \mathrm{Ca}$ and \%P was highest in stamp sands and lowest in peatlands (Figs 3.6). Stamp sand had the highest and uplands the lowest $\mathrm{Ca}: \mathrm{P}$ ratio, whereas $\mathrm{N}: \mathrm{P}$ ratios were low in all habitats (Fig 3.7). The soil $\mathrm{pH}$ reflected the foliar $\% \mathrm{Ca}$, with the highest $\mathrm{pH}$ in stamp sands and lowest in peatlands (Fig 3.8.)

\subsection{Discussion}

To our knowledge, this is the first study identifying root fungal communities on NWC using molecular approaches. The 13,000+ OTUs we found provide an indepth picture of the structure and composition of the fungal communities. Although Ascomycota was the most commonly found phylum (mean was $77 \%$ of OTUs), this number might not directly reflect the absolute richness, because Illumina favors shorter sequence reads (Lindahl, personal communication), and Ascomycota have shorter ITS2 region than Glomeromycota.

Stamp sands stood out strongly from the other two habitat types in all analyses. Our richness analysis that showed uplands and peatlands had the highest richness, whereas stamp sand richness was lowest. Similarly, all PERMANOVA analyses found the fungal community differed significantly between peatlands and uplands vs. those in stamp sands. However, in all analyses the fungal community in 
peatlands was not significant different from uplands, or only very weakly so. These findings were supported by analysis of indicator species with all combination of site pairs.

What are the likely causes of the strong divergence of the stamp sand community from that of the upland and peatland habitat? Stamp sands differ in many ways. Known as copper mining tailings, stamp sands have high copper content, low phosphorus, poor organic matter, coarse sandy loam texture, and high soil pH. Deficiency of numerous essential soil nutrients in stamp sands have been found to result in limited plant diversity and cover, productivity, and microbial activity (Li et al., 2014).

Our results are consistent with the hypotheses that the AM fungal community might be regulated by soil type (Schechter and Bruns, 2008) as well as ecological niches (McGonigle and Fitter, 1990; Helgason et al., 2002; Lekberg et al., 2006; Drumbell et al., 2010). Soil texture and moisture and total $\mathrm{P}$ have all been found to reduce AM fungal species richness (Miller et al., 1999; Lekberg 2007; Gosling et al., 2013). Soil conditions might explain the low diversity of fungal species in stamp sand where the areas have very droughty coarse sands with low nutrient levels (Li et al., 2014), while uplands had organic rich moist mineral soils and peatlands had wet organic soils. In addition, our findings showed the NWC trees on stamp sands had the highest foliar P concentrations, but the soil P is probably less available for plants due to high $\mathrm{Ca}^{+2}$ concentrations (Dumbrell et al., 2010).

The high $\mathrm{pH}$ in stamp sands contrasts with the lower $\mathrm{pH}$ of the uplands and peatlands. Our finding for NMDS analysis revealed a strong correlation between soil $\mathrm{pH}$ and fungal community composition in stamp sands either on Glomeromycota OTUs, all taxa OTUs, and all taxa pooled by class. Soil pH is a major predictor of 
AM fungal community composition and their environmental niche plant community availability. Oliveira et al. (2005) found that richness of AM fungal species was reduced by very high $\mathrm{pH}$ of the anthropogenic sediment and its salinity.

Stamp sands contain elevated concentrations of heavy metals such as copper (Cu) (Li et al., 2014) which may have reduced the richness of the AM fungal community in the stamp sands. Diversity of AM fungal community might be negatively affected by occurrence of heavy metals (Pawloska et al., 1996; Del Val et al., 1999). Stamp sands exhibited low AM plant species abundance and richness that potentially induced low richness of AM fungal community either in all taxa or Glomeromycota.

Plant community (\%AM) also had a strong correlation with fungal community, and was positively correlated with the upland and peatland habitats. Meanwhile, ectomycorrhizal plant community was positively correlated with fungal community in stamp sand areas. AM fungal communities might be influenced by proximity of individual plant species (Hausmann and Hawkes, 2009; Horn et al., 2014).

The top 20 Glomeromycota OTUs (Table 3.6-3.8) represent the large majority of AMF sequences in the present study. All belong to the order Glomerales. Thirteen of the top 20 OTUs were only classified to the family Glomeraceae (Table 3.6). These OTUs were mostly indicators of peatlands and uplands, but some were found across all habitat types. The most closely related AMF isolates from other studies occurred in acid ( $\mathrm{pH} 3.2-5.5$ ) organic and mineral soils in subalpine grassland and natural forest soils (Table 3.8; Ryzska et al., 2010; Lamarche et al., 2011). An unrelated Glomeraceae sp (OTU 11260) was found only in stamp sand. Its closest relative has been found on giant redwood roots in the mountains of California (Fahey et al. 2012). Meanwhile, Kruger et al. (2015) also found that Glomeraceae 
dominated number of AMF-OTUs. Cordoba et al. (2001) and Turrini et al. (2010) suggested that Glomeraceae is ubiquitous, occurred in high ecosystem range such as arid soils, alkaline, and acid soils. This AMF group is abundantly found in sandy soils. Meanwhile, Glomus sp 1 v12_1 (OTU 87 and OTU 46) were abundant only in peatlands and uplands. The most closely related OTUs from other studies occurred in soil pH 5.78-6.20 in mountain meadows and clay - rich soils with low fertility (Boerstler et al. 2006). A Glomerales sp. (OTU 122) was the only other stamp sand indicator in the top 20. Its close relatives were found in circumneutral ( $\mathrm{pH} 5.5-7.7)$ alpine meadow soils (Renker 2003). Overall, our findings showed composition of Glomeromycota especially AM fungal species of Glomeromycetes differ based on habitat types, perhaps mediated at least in part by soil $\mathrm{pH}$.

\subsubsection{Implications for use of Glomeraceae native inoculum in restoration}

The main goal of our study is to understand how AM fungi benefit to plants and ecosystems particularly to recover disturbed lands. Use of AM fungi as a part of restoration strategy to support growth and survival of the plants in the impoverished nutrient sites is pivotal alternative due to multiple benefits of this fungi. Consider projects of land restoration globally widespread in huge various land types and Glomeraceae sp. are abundant and occurred across all habitat types, therefore Glomeraceae spp. potentially become a potential inoculum. High species richness of Glomeraceae is important to plant biodiversity of various habitat types since we may select Glomeraceae inoculum based on their specific plant and habitat type (soil properties).

Native inoculum of selected fungi is highly recommended for ecological, and economic reasons. Klironomos (2003) and Yao et al. (2008) reported that native 
Glomeraceae boosted growth of the native plants more than introduced AM fungi. Likewise, Bois et al. (2005) reported success of native AM fungi to promote the plant performance in the reclamation project of oil sand areas. Our survey of AMF in different habitats can serve as the basis for assessing habitat generalist and habitat specific AMF in order to determine which have higher efficacy in seedling establishment, nutrition, and growth. Subsequent research phases should isolate and test Glomeromycota from these habitats for cross-habitat efficacy. 


\subsection{References}

Allen, M.F. 1991. The ecology of mycorrhizae. Cambridge University Press, Cambridge.

Al-Karaki, G, N,. B. McMichael, J. Zak. 2004. Field response of wheat to arbuscular mycorrhizal fungi and drought stress. Mycorrhiza 14: 263-269

Bengtsson-Palme J., M. Ryberg, M. Hartmann, S. Branco, Z. Wang, A. Godhe, P. De Wi, M. Sánchez-García, I. Edersberger, F. de Sousa, A.S. Amend, A. Jumpponen, M. Unterseher, E. Kristiansson, K. Abarenkov, Y.J.K. Bertrand, K. Sanli, K.M. Eriksson, U. Vik, V. Veldre, R.H. Nilsson, 2013. Improved software detection and extraction of ITS1 and ITS2 from ribosomal ITS sequences of fungi and other eukaryotes for analysis of environmental sequencing data. Methods in Ecology and Evolution 4: 914-919.

Bethlenfalvay, G.J., M.S. Brown, R.S. Pacovsky. 1982. Parasitic and mutualistic association between a mycorrhizal fungus and soybean-development of the host plant. Phytopathology 72: 889-893

Bhatt, G.C. 1970. The soil microfungi of white cedar forests in Ontario. Can.J, Bot.48: $333-339$

Boerstler,B., C. Renker, A. Kahmen, F. Buscot. 2006. Species composition of arbuscular mycorrhizal fungi in two mountain meadows with differing management types and levels of plant biodiversity. Biol Fertil Soils 42: $286-$ 298

Borowics, V.A. 2001. Mycorrhizas in natural ecosystem. In: Macfayden, A., M. Begon, A.H. Fitter (eds). Advances in ecological research. Academic, Town: 171-313. 
Brundrett, M., M. Gracia, B. Kendrick. 1990. Comparative anatomy of roots and mycorrhizae of common Ontario trees, Canadian Journal of Botany 68 (3): $551-578$

Caporaso G., J. Kuczynski, J. Stombaugh, K. Bittinger, F.D. Bushman, E.K. Costello, N. Fierer, A.G. Pena, J.K. Goodrich, J.I. Gordon, G.A. Huttley, S.T. Kelley, D. Knights, J.E. Koenig, R.E. Ley, C.A. Lozupone, D. McDonald, B.D. Muegge, M. Pirrung, J. Reeder, J.R. Sevinsky, P.J. Turnbaugh, W.A. Walters, J. Widmann, T. Yatsunenko, J. Zaneveld, R. Knight. 2010. QIIME allows analysis of highthroughput community sequencing data. Nature Methods 7: 335-336.

Chaudhary, V.B., M.K. Lau, N.C. Johnson. 2008. Macroecology of microbes biogeography of the Glomeromycota. In: Mycorrhiza: Genetics and Molecular Biology, Eco-Function, Biotechnology, Eco-physiology, Structure and Systematics (ed. Varma, A.) Springer, Berlin:529-564

Cordoba A.S., M.M. Mendonca, S.L. Sturmer, P.T. Ryglewicz (2001) Diversity of arbuscular mycorrhizal fungi along a sand dune stabilization gradient: a case study at Praia de Joaquina, Ilha de Santa Catarina, South Brazil. Mycoscience $42: 379-387$

del Val, C., J.M. Barea, A.C. Azeon. 1999. Diversity of arbuscular mycorrhizal fungus populations in heavy-metal-contaminated soils. Appl Environ Microbiol 65: $718-723$

Dumbrell, A.J., M. Nelson, T. Hegason, C. Dhytam, A.H. Fitter. 2010.

Relatives roles of niche and neutral processes in structuring a soil microbial community. ISME Journal 4: 337-345

Edgar R.C., Haas B.J., Clemente J.C., Quince C., Knight R., 2011. UCHIME improves sensitivity and speed of chimera detection. Bioinformatics 27: 2194-2200 
Fahey,C., R.A. York, T.E.Pawlowska. 2012. Arbuscular mycorrhizal colonization of giant sequoia (Sequoiadendron giganteum) in response to restoration practices. Mycologia, 104 (5): 988-997

Finlay, R.D. 2008. Ecological aspects of mycorrhizal symbiosis: with special emphasis on the functional diversity of interactions involving the extraradical mycelium. Journal of Experimental Botany 59 (5): 1115-1126

Fitzsimons, M. R. Miller, J. Jastrow. 2008. Scale-dependent niche axes of arbuscular mycorrhizal fungi. Oecologia 158: 117-127

Gildon, A. and P.B. Tinker. 1983. Interaction of vesicular-arbuscular mycorrhizal infection and heavy metals in plant. New Phytologist 95:247-261

Gosling, P., A. Mead., M. Proctor, J.P. Hammond, G.D. Bending. 2013. Contrasting arbuscular mycorrhizal communities colonizing different host plants show a similar response to a soil phosphorous concentration gradient. New Phytol 198:546-556

Hannah, P.R. 2004. Stand Structures and Height Growth Patterns in Northern White Cedar Stands on Wet Sites in Vermont. North, J, Appl, For. 21(4):173-179 Hausmann, N.T. and C.V. Hawkes. 2009. Plant neighborhood control of arbuscular mycorrhizal community composition. New Phytologist 183: 1188-1200 Helgason, T., J.W. Merrywetaher, J. Denison, P. Wilson, J.P.W. Young, A.H. Fitter. 2002. Selectivity and functional diversity in arbuscular mycorrhizas of cooccuring fungi and plants from a temperate deciduous woodlands. Journal of Ecology 90: 371-384

Hemery, G. 2011. How to use a wedge prism relascope to measure basal area. gabrielhemery.com 
Horn, S., T. Caruso, E. Verbruggen, M. C. Rillig, S. Hempel. 2014. Arbuscular mycorrhizal fungal communities are phylogenetically clustered at small scales. The ISME Journal 8: 2231-2242

Johnson, N.C. 2010. Tansley review: resource stoichiometry elucidates the structure and function of arbuscular mycorrhizas across scales. The New Phytologist $185(3): 631-647$

Johnston, W.F. 1990. Thuja occidentalis L. - Northern White-Cedar. In: Burns, R.M.; Honkala, B.H., eds. Silvics of North America. Vol. 1. Agric. Hndbk. 654. Washington, DC: U.S. Department of Agriculture, Forest Service: 580-589 Klironomos, J.N., M.M. Hart, J.E. Gurney, P. Moutoglis. 2001. Interspecific differences in the tolerance of arbuscular mycorrhizal fungi to freezing and drying. Canadian Journal of Botany 79: 1161-1166

Klironomos, J.N. 2003. Variation in plant response to native and exotic arbuscular mycorrhizal fungi. Ecology 84: 2292-2301

Kõljalg U., R.H. Nilsson, K. Abarenkov, L. Tedersoo, A.F.S. Taylor, M. Bahram, S.T. Bates, T.D. Bruns, J. Bengtsson-Palme., T.M. Callaghan, B. Douglas, T. Drenkhan, U. Eberhardt, M. Dueñas, T. Grebenc, G.W. Griffith, M. Hartmann, P.M. Kirk, P. Kohout, E. Larsson, B.D. Lindahl, R. Lücking, N.H. Nguyen, T. Niskanen, J. Oja, K.G. Peay, U. Peintner, M. Peterson, K. Põldmaa, L. Saag, I. Saar, A. Schüßler, J.A. Scott, C. Senés, M.E. Smith, A. Suija, D.L. Taylor, M.T. Telleria, M. Weiss, K. Larsson, 2013. Toward a unified paradigm for sequencebased identification of fungi. Molecular Ecology 22: 5271-5277.

Kruger, M., F.P. Teste, E. Laliberte, H. Lambers, M. Coghlan, G. Zemunik, M. Bunche. 2015. The rise and fall of arbuscular mycorrhizal fungal diversity during ecosystem retrogression. Molecular Ecology 24: 4912-4930. 
Kumar, A., R. Raghuwanshi, R.S. Upadhyay. 2010. Arbuscular mycorrhizal technology in reclamation and revegetation of coal mine spoils under various revegetation models. Engineering 2: 683-689

Lamarche, J., F.O.P. Stefani, A. Seguin, R.C. Hamelin, 2011. Impacts of endochitinase-transformed white spruce on soil fungal communities under greenhouse conditions. FEMS Microbiology Ecology 76: 199-208

Lekberg, Y., R. T. Koide., J.R. Rohr, L. A. Wolfe, J.B. Morton. 2007. Role of niche restrictions and dispersal in the compositions of arbuscular mycorrhizal fungal communities. Journal of Ecology 95: 95-105

Li, K., V.R. Pidatala, R. Shaik., R. Datta, W. Ramakrishna. 2014. Integrated metabolomics and proteomic approaches dissect the effect of metal-resistant bacteria on maize biomass and copper uptake. Environmental Science and Technology 48: 1184-1193

Liu, L. He, L.Z. an, T. Helgason, H.Y. Feng. 2009. Arbuscular mycorrhizal dynamics in a chronosequence of Caragana korshinskii plantations. FEMS Microbiology Ecology 67: 81-92

Malloch, D. and B. Malloch. 1981. The mycorrhizal status of boreal plants: species from northeastern Ontario. Canadian Journal of Botany. 59: 2167-2172

Matthes-Sears, U., C. Neeser \& D.W. Larson. 1992. Mycorrhizal colonization and macronutrient status of cliff-edge Thuja occidentalis and Acer saccharum. Ecography 15 (3): 262-266

McGonigle, T.P. and A.H. Fitter. 1990. Ecological specificity of vesicular arbuscular mycorrhizal associations. Mycol Res 94: 120-122 
Miller, R.M. and J.O. Jastrow. 1992. The application of VA mycorrhizae to ecosystem restoration and reclamation. In: Allen MF (ed) Mycorrhizal functioning, an integrative plant-fungal process. Chapman \& Hall, New York: 438-467

Miller, S.P. and J.D. Bever. 1999. Distribution of arbuscular mycorrhizal fungi in stands of the wetland grass Panicum hemitomon along a wide hydrologic gradient. Oecologia 119: 586-592

Nilsson R.H., L. Tedersoo, M. Ryberg, E. Kristiansson, M. Hartmann, M. Unterseher, T.M. Porter, J. Bengtsson-Palme, D.M. Walker, F. de Sousa, H.A. Gamper, E. Larsson, K.H. Larsson, U. Kõljalg, R.C. Edgar, K. Abarenkov. 2015. A Comprehensive, Automatically Updated Fungal ITS Sequence Dataset for Reference-Based Chimera Control in Environmental Sequencing Efforts. Microbes and Environments 30:145-150

Oehl, F., F.A. Souza, E. Sieverding. 2008. Revision of Scutellospora and description of five new genera and three new families in the arbuscular mycorrhizaforming Glomeromycetes. Mycotaxon 106: 311-360

Oehl, F., E. Sieverding, J. Palenzuela, K. Ineichen, G.A. da Silva. 2011. Advances in Glomeromycota taxonomy and classification. IMA Fungus 2 (2): 191-199

Opik, M., A. Vanatoa, E. Vanatoa. 2010. The online data-base MaarjAM reveals global and ecosystemic distribution patterns in arbuscular mycorrhizal fungi (Glomeromycota). New Phytologist 188: 223-241

Parrent, J.L. and R. Vilgays, 2007. Biomass and compositional responses of ectomycorrhizal fungal hyphae to elevated $\mathrm{CO} 2$ and nitrogen fertilization. New Phytologist 176: 164-174

Pawloska, T.E., J. Blazkowski, A. Ruhling. 1996. The mycorrhizal status of plants colonizing a calamine spoil mound in southern Poland. Mycorrhiza 6: 499-505 
Porras-Alfaro A., L. Kuan-Liang, C.R. Kuske, G. Xie. 2014. From Genus to Phylum: LSU and ITS rRNA operon regions showed similar classification accuracy influenced by database composition. Applied and Environmental Microbiology 80: $829-840$

Renker,C., J. Heinrichs, M. Kaldorf, F. Busco. 2003. Combining nested PCR and restriction digest of the internal transcribed spacer region to characterize arbuscular mycorrhizal fungi on roots from the field. Mycorrhiza 13:191-198

Reeves, F.B., D. Wagner, T. Moorman, J. Kiel. 1979. The role of endomycorrhizae in revegetation practices in the semi-arid west. I. A comparison of incidence of mycorrhizae in severely disturbed vs natural environments. Am J. Bot. 66: 613

Rohland N. and D. Reich. 2012. Cost-effective, high-throughput DNA sequencing libraries for multiplexed target capture. Genome Res. 22(5):939-46.

Ryszka, P., J. Blaszkowski, A. Jurjiewicz, K. Turnau. 2010. Arbuscular mycorrhiza of Arnica montana under firld conditions-conventional and molecular studies. Mycorrhiza 20: 551-557

Sambandan, K., K. Kannan, N. Rahman. 1992. Distribution of vesicular arbuscular mycorrhizal fungi in heavy metal polluted soils of Tamil Nadu, India. J. Environ. Biol, 13: 159-167

Schechter. S.P. and T.D. Bruns. 2008. Serpentine and non-serpentine ecotypes of Collinsia sparsiflora associate with distinct arbuscular mycorrhizal fungal assemblages. Molecular Ecology 17: 3198-3210

Schmidt, P.A., M. Balinc, B. Greshake, C. Bandow, J. Rombke, I. Schmidt. Illumina metabarcoding of a soil fungal community. Soil Biology and Biochemistry 65: $128-132$ 
Smith, S.E. and D.J. Read. (2008). Mycorrhizal symbiosis. $3^{\text {rd }}$ Edition. Academic Press.

Stahl, P.D. and W.K. Smith. 1984. Effects of different geographic isolates of Glomus on the water relations of Agropyron smithii. Mycologia 76: 261-267

Treseder, K.K. and A. Cross. 2006. Global distribution of arbuscular mycorrhizal fungi. Ecosystems 9: 305-316

Turrini A, C. Sbrana, P. Strani, B. Pezzarossa, R. Risaliti, M.Giovannetti. 2010. Arbuscular mycorrhizal fungi of a Mediterranean island (Pianosa), whitin a UNESCO Biosphere Reserve. Biol Fertil Soils 46:511-520

Turnau, K., P. Ryszka, P.V. Gianinazzi, D. van Tuinen. 2001. Identification of arbuscular mycorrhizal fungi in soils and roots of plants colonizing zinc wastes in southern Poland, Mycorrhiza 10: 169-174

Wang, B. and Y.L. Qiu, 2006. Phylogenetic distribution and evolution of mycorrhizas in land plants. Mycorrhiza 16: 299-363

Wang, Y.T., Q. Qiu, Z.Y. Yang, Z.J. Hu, N.F.Y. Tam, G. Xin. 2010. Arbuscular mycorrhizal fungi in two mangroves in South China. Plant Soil: 331:181-191 Wang, Y., Y. Huang, Q.Qiu, G.Xin, Z.Yang, S.Shi. 2011. Flooding greatly affects the diversity of arbuscular mycorrhizal fungi communities in the roots of wetland plants. Plos ONE 6 (9): e24512:1-9

Wilde, P., A. Manal, M. Stodden, E. Sieverding, U. Hildebrandt. 2009. Biodiversity of arbuscular mycorrhizal fungi in roots and soils of two salt marshes. Environ. Microbiol. 11: 1548-1546.

Van der Heijden, M.G.A., R.D. Bargett, N.M. Van Straalen, 2008. The unseen majority: soil microbes as drivers of plant diversity and productivity in terrestrial ecosystems. Ecology Letters 11: 296-310 
Yao, Q., H. Hui Zhu, Y. Li Hu, L. Qiu Li. 2008. Differential influence of native and introduced arbuscular mycorrhizal fungi on growth of dominant and subordinate plants. Plant Ecol.: 196: 261-268

Ypsilantis, I and D. Silvia. 2007. Interaction of assemblages of mycorrhizal fungi with two Florida wetland plants. Applied Soil Ecology 35: 261-271 


\subsection{Tables and Figures}

Table 3.1. Sampling site habitat types, locations, and coordinates for the fungal community analysis

\begin{tabular}{|c|c|c|c|}
\hline Habitat type & $\begin{array}{l}\text { Sampling } \\
\text { code }\end{array}$ & Location & $\begin{array}{c}\text { GPS } \\
\text { coordinate }\end{array}$ \\
\hline \multirow[t]{6}{*}{ Peatland } & PA & Marsin & $\begin{array}{l}\text { N47.181746 } \\
\text { W88.643101 }\end{array}$ \\
\hline & PB & $\begin{array}{l}\text { R.T. Brown Nature } \\
\text { Sanctuary }\end{array}$ & $\begin{array}{l}N 47.030800^{\circ} \\
\text { W88.72459 }\end{array}$ \\
\hline & PC & Painesdale & $\begin{array}{l}N 47.022740^{\circ} \\
W 88.717250^{\circ}\end{array}$ \\
\hline & PD & Black Creek & $\begin{array}{l}\mathrm{N} 47.318793^{\circ} \\
\mathrm{W}^{\circ} 88.464082^{\circ}\end{array}$ \\
\hline & PE & Cy Clark Memorial & $\begin{array}{l}\text { N47.450249 } \\
\text { W88.196379 }\end{array}$ \\
\hline & PF & Nara Trails & $\begin{array}{l}N 47.105013^{\circ} \\
\text { W88.542063 }\end{array}$ \\
\hline \multirow[t]{3}{*}{ Stamp Sand } & SA & Huron Creek & $\begin{array}{l}\text { N47.107894 } \\
\text { W88.582433 }\end{array}$ \\
\hline & SB & Red Ridge & $\begin{array}{l}N 47.154466^{\circ} \\
\text { W88.763764 }\end{array}$ \\
\hline & SC & Black Creek & $\begin{array}{l}\mathrm{N} 47.328654^{\circ} \\
\mathrm{W} 88.464813^{\circ}\end{array}$ \\
\hline \multirow[t]{5}{*}{ Upland } & UA & Swedetown Trails & $\begin{array}{l}\mathrm{N} 47.241292^{\circ} \\
\text { W88.471573 }\end{array}$ \\
\hline & UB & $\begin{array}{c}\text { Houghton Elementary } \\
\text { School }\end{array}$ & $\begin{array}{l}\mathrm{N} 47.114713^{\circ} \\
\text { W88.577005 }\end{array}$ \\
\hline & UC & Tech Trails & $\begin{array}{l}\text { N47.105220 } \\
\text { W88.541831 }\end{array}$ \\
\hline & UD & Black Creek & $\begin{array}{l}\text { N47.319236 } \\
\text { W88.465059 }\end{array}$ \\
\hline & UE & Cy Clark Memorial & $\begin{array}{l}\text { N47.449980 } \\
\text { W88.198031 }\end{array}$ \\
\hline
\end{tabular}


Table 3.2. Plot averages of NWC tree size, slope, and soil pH

\begin{tabular}{llccccc}
\hline $\begin{array}{l}\text { Habitat } \\
\text { Type }\end{array}$ & $\begin{array}{l}\text { Sampling } \\
\text { Code }\end{array}$ & \# of trees $^{1}$ & $\begin{array}{c}\text { Height } \\
(\mathrm{m})\end{array}$ & $\begin{array}{c}\text { Diameter } \\
(\mathrm{cm})\end{array}$ & Slope & $\begin{array}{c}\text { Soil } \\
\mathrm{pH}\end{array}$ \\
\hline Peatland & PA & 6 & 6.8 & 11.6 & 1.9 & 5.8 \\
& PB & 6 & 10.9 & 19.8 & 3.8 & 4.1 \\
& PC & 5 & 2.8 & 5.5 & 0 & 4.4 \\
& PD & 6 & 6.4 & 11.5 & 0.3 & 6.3 \\
& PE & 4 & 4.1 & 8.9 & 5.0 & 6.0 \\
\multirow{5}{*}{ Stamp Sand } & PF & 5 & 7.6 & 15.2 & 6.0 & 4.6 \\
& SA & 6 & 2.7 & 5.0 & 5.2 & 7.7 \\
\multirow{5}{*}{ Upland } & SB & 6 & 4.3 & 8.9 & 2.0 & 7.2 \\
& SC & 6 & 7.2 & 13.6 & 8.3 & 7.2 \\
& UA & 5 & 7.0 & 13.1 & 7.6 & 5.5 \\
& UB & 6 & 7.3 & 8.9 & 8.7 & 5.8 \\
& UC & 3 & 7.7 & 16.2 & 28.7 & 5.7 \\
& UD & 3 & 6.4 & 23.7 & 35 & 5.2 \\
& UE & 2 & 4.5 & 9.4 & 10.0 & 4.9 \\
\hline
\end{tabular}

${ }^{1}$ : number of sampling trees after sequences rarefied.

Table 3.3. Plot averages for foliar nutrient concentration of NWC foliage and \% basal area of mycorrhizal types. Data are presented only for trees with fungal communities successfully sequenced

\begin{tabular}{lccccccc}
\hline $\begin{array}{c}\text { Habitat } \\
\text { Type }\end{array}$ & $\begin{array}{c}\text { Site } \\
\text { Code }\end{array}$ & $\begin{array}{c}\text { \# of } \\
\text { trees }\end{array}$ & $\begin{array}{c}\text { Foliar N } \\
(\%)\end{array}$ & $\begin{array}{c}\text { Foliar P } \\
(\%)\end{array}$ & $\begin{array}{c}\text { Foliar Ca } \\
(\%)\end{array}$ & $\begin{array}{c}\% \text { ECM } \\
\text { Basal } \\
\text { area }\end{array}$ & $\begin{array}{c}\% \text { AM } \\
\text { Basal } \\
\text { area }\end{array}$ \\
\hline Peatland & PA & 6 & 0.87 & 0.086 & 1.51 & 22 & 71 \\
& PB & 6 & 1.05 & 0.108 & 1.15 & 49 & 51 \\
& PC & 5 & 1.10 & 0.098 & 1.21 & 10 & 90 \\
& PD & 6 & 0.99 & 0.097 & 1.21 & 29 & 71 \\
& PE & 4 & 0.62 & 0.071 & 1.34 & 12 & 88 \\
Stamp sand & PF & 5 & 1.09 & 0.128 & 0.91 & 38 & 62 \\
& SA & 6 & 0.85 & 0.111 & 2.26 & 56 & 10 \\
Upland & SB & 6 & 0.99 & 0.123 & 2.08 & 58 & 42 \\
& SC & 6 & ND & ND & ND & 96 & 4 \\
& UA & 5 & 1.03 & 0.111 & 1.19 & 22 & 78 \\
& UB & 6 & 0.85 & 0.086 & 1.45 & 20 & 80 \\
& UC & 3 & 0.93 & 0.099 & 1.14 & 34 & 66 \\
& UD & 3 & 0.98 & 0.136 & 1.46 & 58 & 42 \\
& UE & 2 & 0.85 & 0.114 & 1.09 & 72 & 28 \\
\hline
\end{tabular}

ND: No Data (due to technical reason, there were no foliar samples for SC (Stamp Sand in Black Creek). 


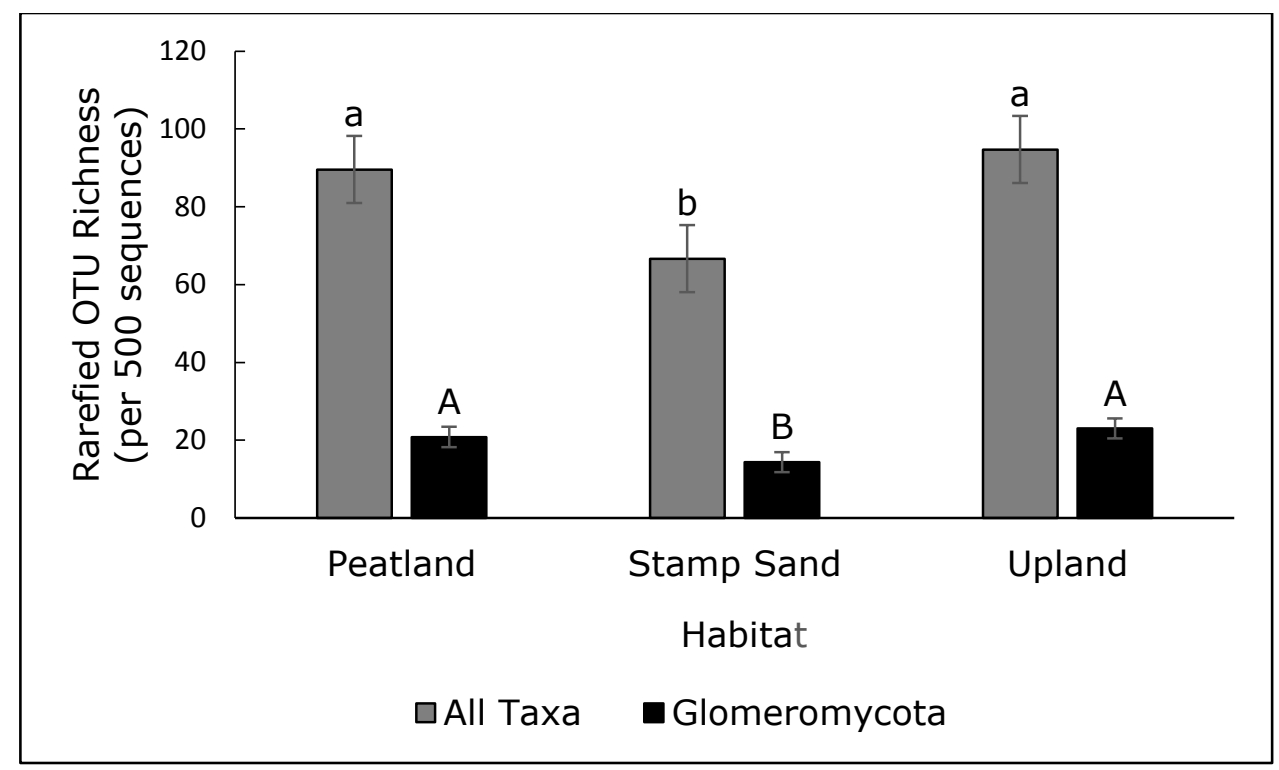

Fig 3.1. Rarefied OTU Richness of All taxa and Glomeromycota of three habitat types

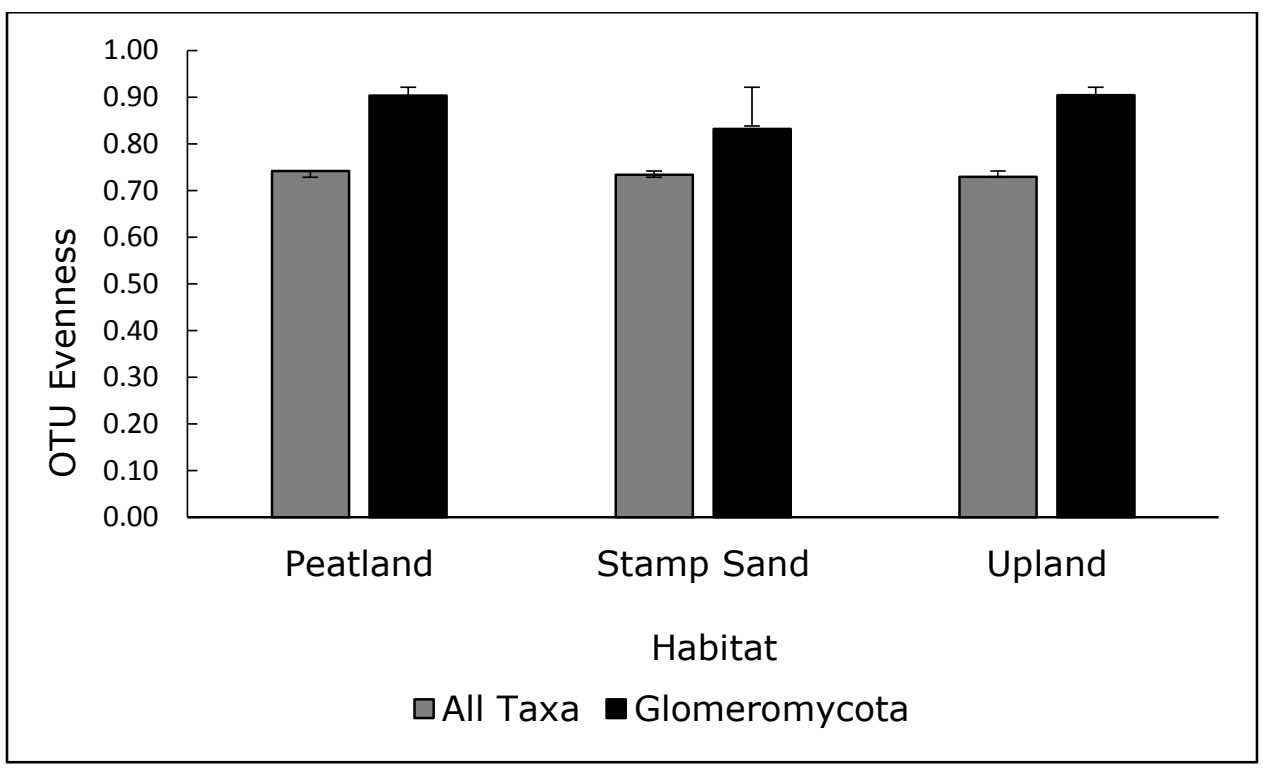

Fig 3.2. OTU evenness of all taxa and Glomeromycota of three habitat types 


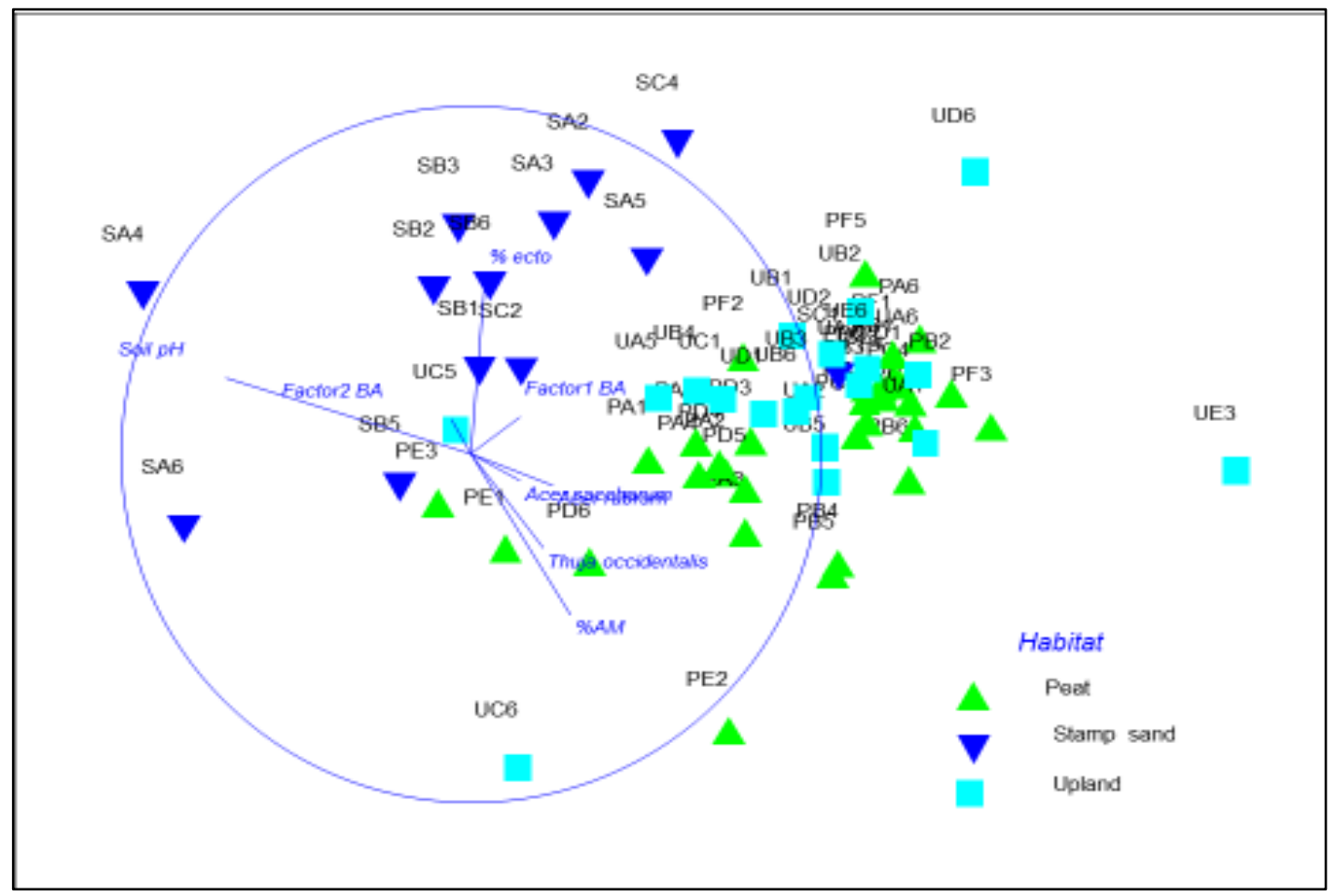

Fig 3.3. Glomeromycota OTU non-metric multidimensional scaling plot. Colored symbols represent individual samples from different sites, with individual replicates within site labelled with tree ID\#. Significant correlations of predictors with NMDS axes are shown as blue lines. 


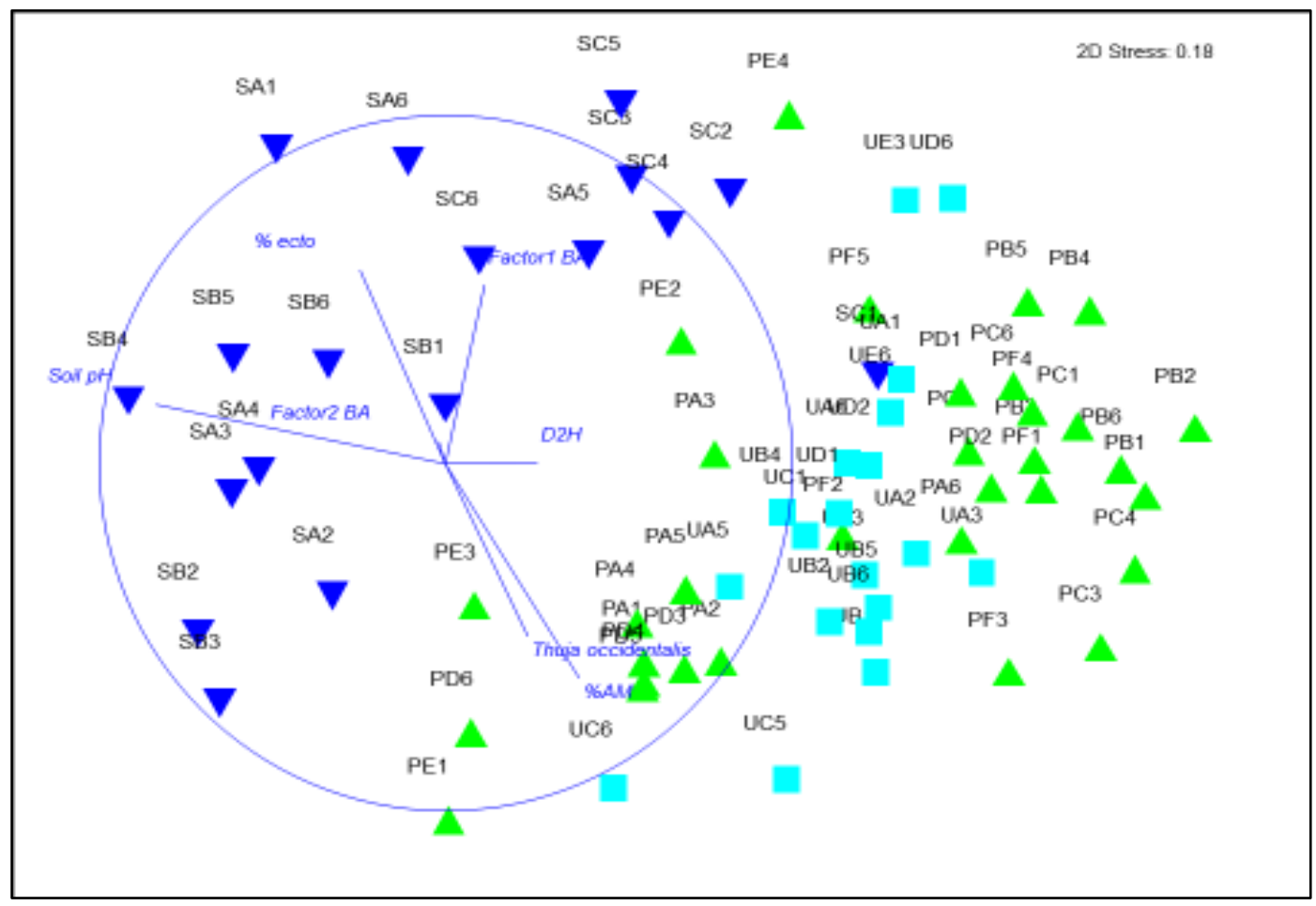

Fig 3.4. All taxa OTU non-metric multidimensional scaling plot. Colored symbols represent individual samples from different sites, with individual replicates within site labelled with tree ID\#. Significant correlations of predictors with NMDS axes are shown as blue lines. 


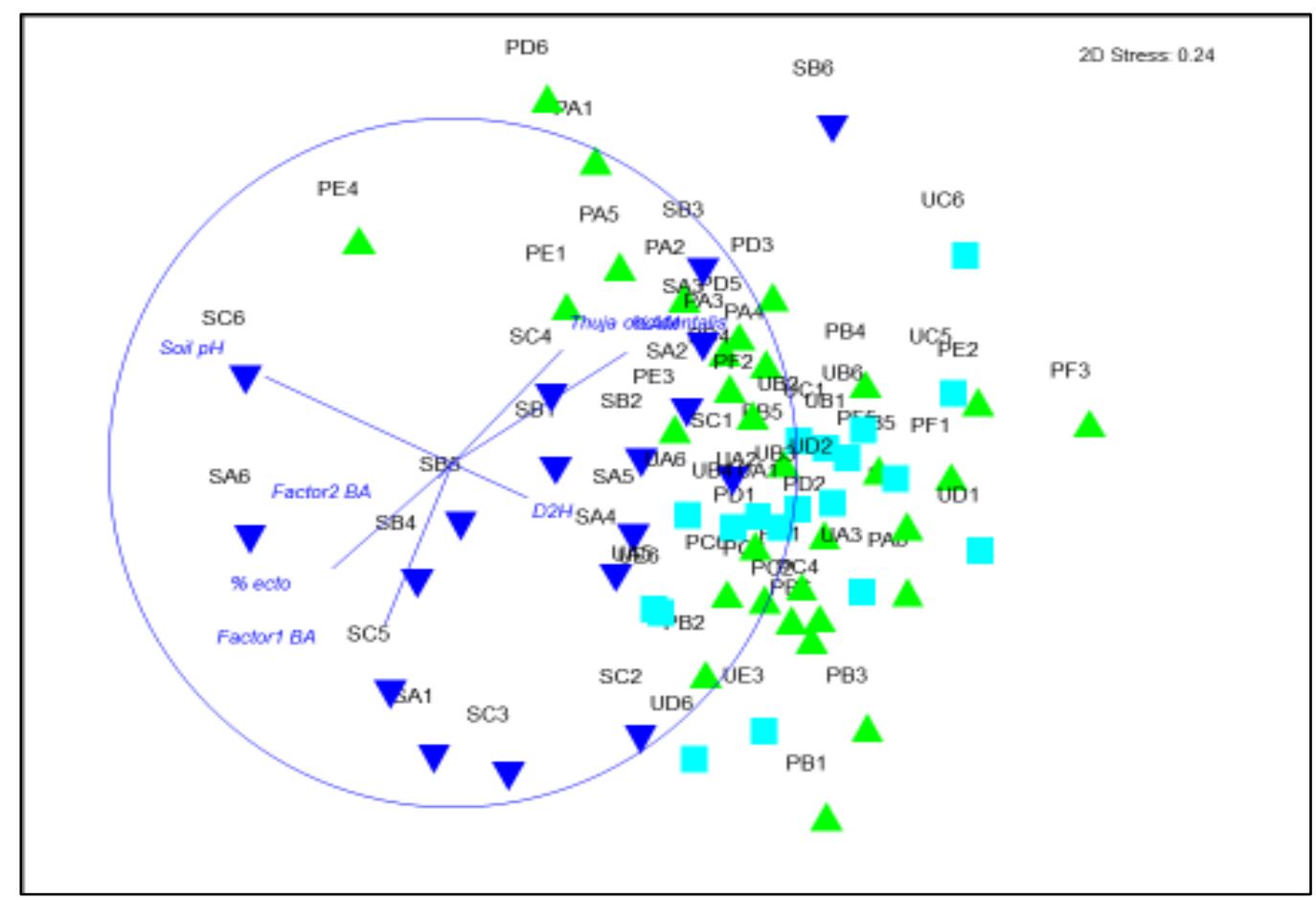

Fig 3.5. All taxa phylogenetic class non-metric multidimensional scaling plot. Colored symbols represent individual samples from different sites, with individual replicates within site labelled with tree ID\#. Significant correlations of predictors with NMDS axes are shown as blue lines. 
Table 3.4.PERMANOVA Pairwise test for Glomeromycota OTUs, all taxa by class, and all taxa by OTU

\begin{tabular}{lrc}
\hline Groups & $\mathrm{t}$ & $\mathrm{P}($ perm) \\
\hline $\begin{array}{l}\text { Glomeromycota } \\
\text { OTU }\end{array}$ & & \\
$\begin{array}{l}\text { Peat vs Stamp Sand } \\
\text { Peat vs Upland }\end{array}$ & 1.8432 & $\mathbf{0 . 0 0 0 1}$ \\
Stamp Sand vs Upland & 1.81484 & 0.8725 \\
All taxa Class & & $\mathbf{0 . 0 0 0 1}$ \\
Peat vs Stamp sand & 1.5384 & $\mathbf{0 . 0 3 5 3}$ \\
Peat vs Upland & 0.99767 & 0.4452 \\
Stamp sand vs Upland & 2.1861 & $\mathbf{0 . 0 0 0 3}$ \\
All taxa OTU & & \\
Peat vs Stamp sand & 1.4868 & $\mathbf{0 . 0 0 0 1}$ \\
Peat vs Upland & 1.1734 & $\mathbf{0 . 0 4 4 4}$ \\
Stamp sand vs Upland & 1.7582 & $\mathbf{0 . 0 0 0 1}$ \\
\hline
\end{tabular}

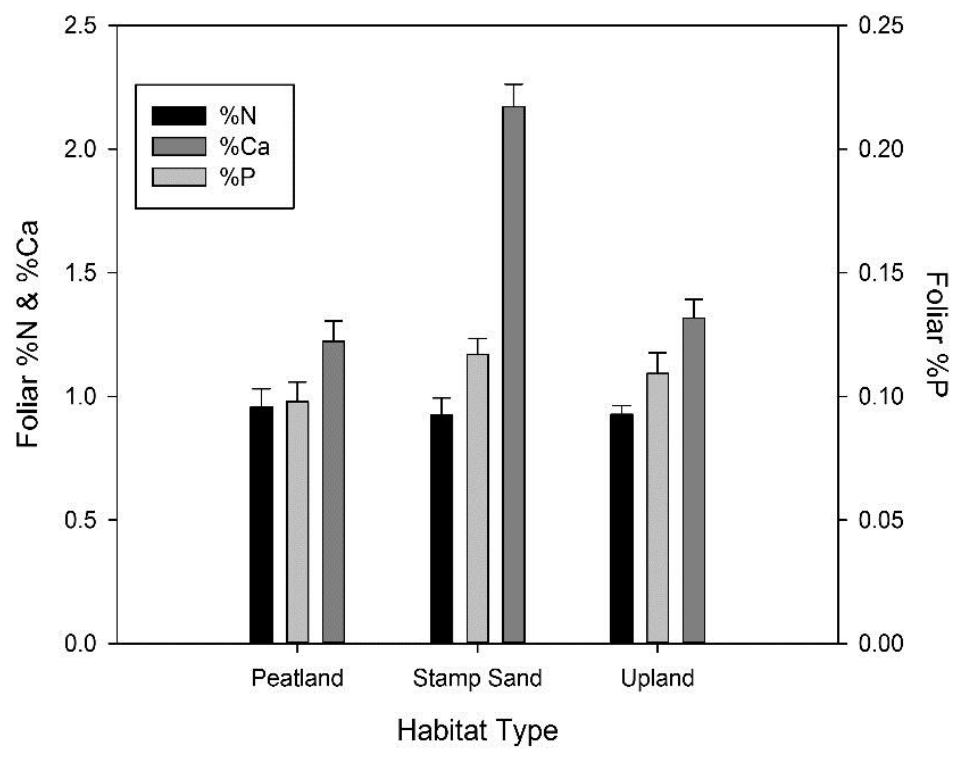

Fig 3.6. Thuja occidentalis foliar nutrient concentration in different habitat types. Error bars indicate SE. 


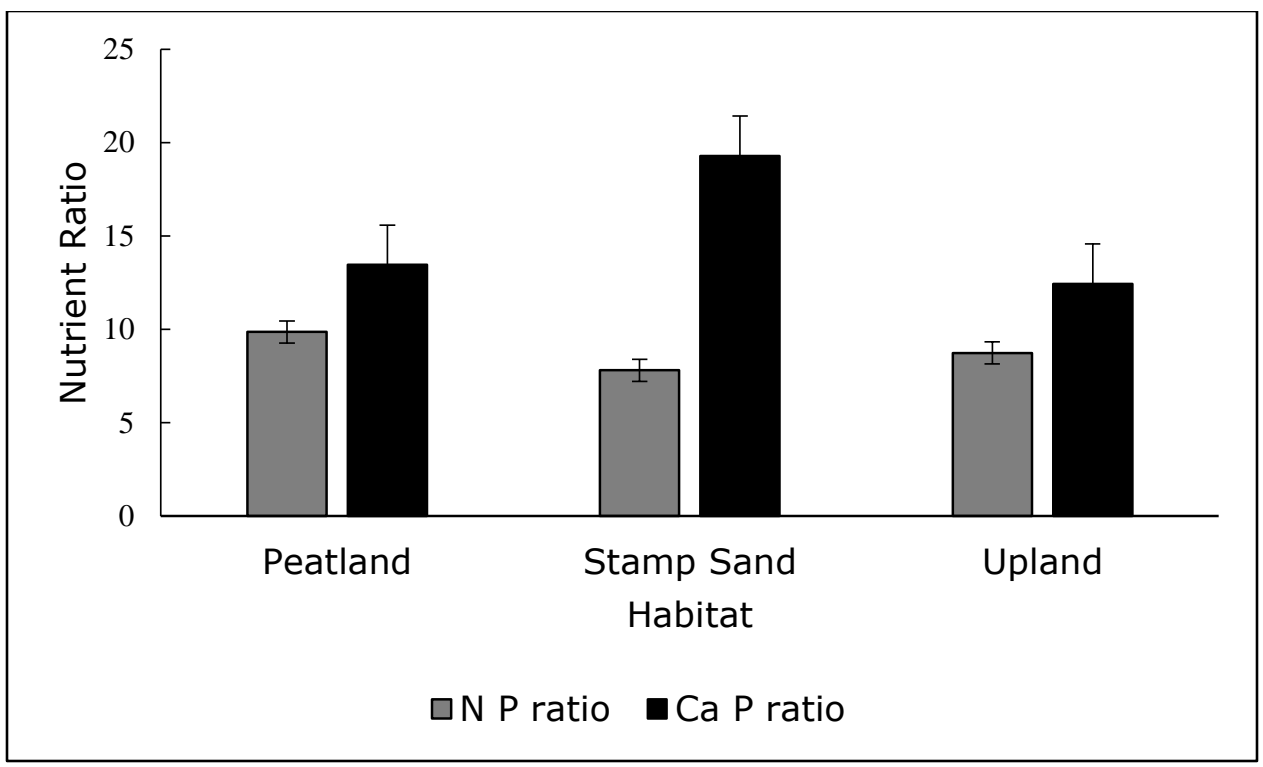

Fig 3.7. $\mathrm{N}: \mathrm{P}$ and $\mathrm{Ca}: \mathrm{P}$ ratios of $\mathrm{T}$. occidentalis foliage as a function of habitat type. Error bars indicate SE.

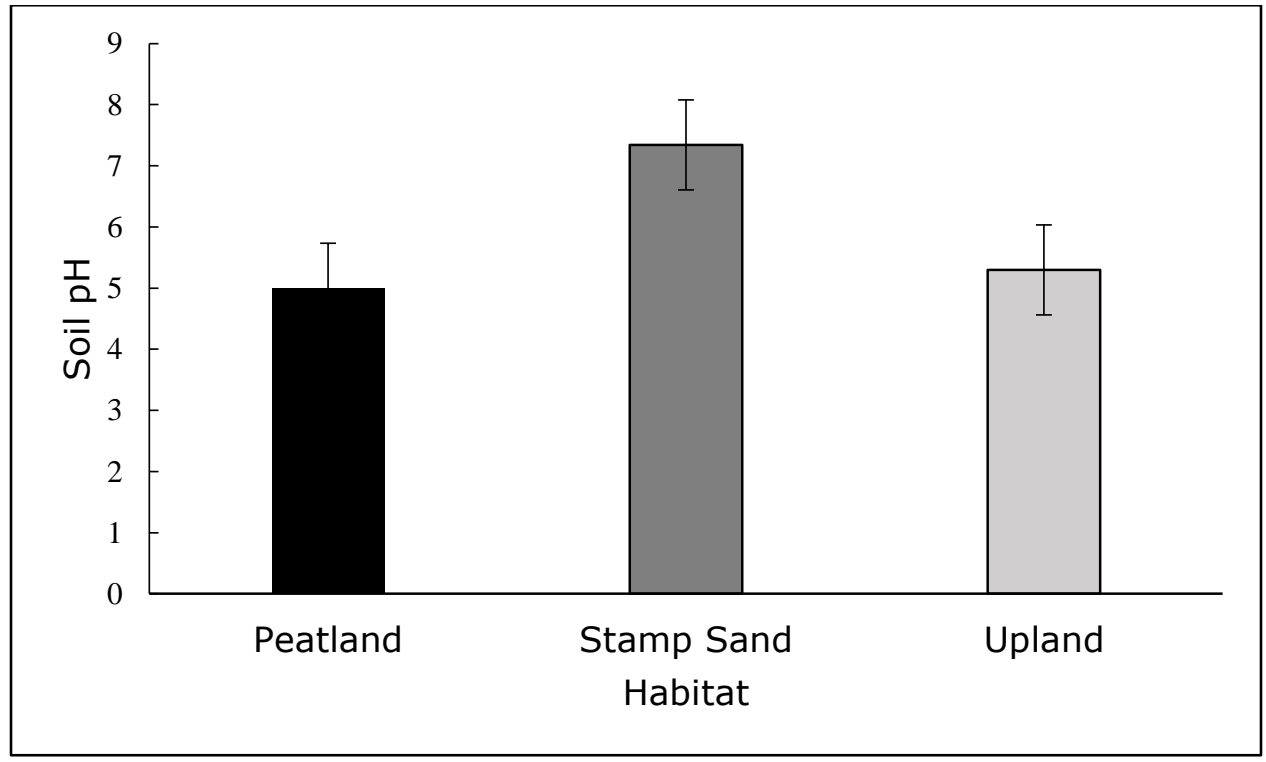

Fig 3.8. Soil pH of the habitat types. Error bars indicate SE. 
Table 3.5. Fungal indicator species (up to 20 per habitat type or pair) for individual habitat types and all habitat pairs. Glomeromycota in bold.

\begin{tabular}{|c|c|c|}
\hline Habitat/\#OTU ID & Spesies & $\mathrm{P}$ value \\
\hline PEATLAND & (20 of 24$)$ & \\
\hline 9011 & Helotiales & 0.0032 \\
\hline 448 & Chaetothyriales.sp & 0.006 \\
\hline 2521 & Meliniomyces.variabilis & 0.0018 \\
\hline 36 & Alatospora.acuminata & 0.0212 \\
\hline 4895 & Chaetothyriales.sp & 0.01 \\
\hline 161 & Glomeraceae & 0.0197 \\
\hline 108 & Helotiales.sp & 0.0085 \\
\hline 59 & Oidiodendron.maius & 0.0166 \\
\hline 9751 & Xenopolyscytalum.sp & 0.0219 \\
\hline 5 & Helotiales & 0.0171 \\
\hline 229 & Ascomycota & 0.0334 \\
\hline 12736 & Helotiales & 0.0453 \\
\hline 3542 & Helotiales & 0.0159 \\
\hline 6611 & Meliniomyces. variabilis & 0.0248 \\
\hline 166 & Helotiales & 0.0498 \\
\hline 246 & Ascomycota & 0.0482 \\
\hline 7393 & Ascomycota & 0.0464 \\
\hline 274 & Geoglossum & 0.0479 \\
\hline 12625 & Helotiales & 0.0498 \\
\hline 6850 & Helotiales & 0.0467 \\
\hline STAMP SAND & (20 of 73 ) & \\
\hline 6686 & Helotiales & 0.0001 \\
\hline 3301 & Helotiales & 0.012 \\
\hline 56 & Cenococcum & 0.0406 \\
\hline 3835 & Helotiales & 0.0001 \\
\hline 65 & Cadophora.finlandica & 0.0003 \\
\hline 1687 & Chalara.hyalocuspica & 0.0013 \\
\hline 106 & Glomeraceae.sp & 0.0005 \\
\hline 7093 & Cenococcum & 0.0162 \\
\hline 10133 & Leohumicola & 0.0022 \\
\hline 756 & Leohumicola & 0.001 \\
\hline 10735 & Phialocephala.fortinii & 0.0032 \\
\hline 179 & Rhizophagus.sp & 0.0031 \\
\hline 137 & Glomus.sp.1v12_1 & 0.0098 \\
\hline 343 & Fungi $\quad-$ & 0.0046 \\
\hline 8680 & Cenococcum.sp & 0.0047 \\
\hline 3248 & Chalara.hyalocuspica & 0.0047 \\
\hline 143 & Helotiales & 0.0039 \\
\hline 7137 & Rhexocercosporidium & 0.0037 \\
\hline 359 & Geomyces.auratus & 0.0035 \\
\hline 2912 & Alatospora.sp. & 0.004 \\
\hline
\end{tabular}


Table 3.5 cont'd.

\begin{tabular}{|c|c|c|}
\hline UPLAND & $(20$ of 65$)$ & \\
\hline 1 & Meliniomyces.sp & 0.0002 \\
\hline 12858 & Phialocephala.fortinii & 0.0002 \\
\hline 12985 & Phialocephala.fortinii & 0.0001 \\
\hline 3185 & Phialocephala.fortinii & 0.0022 \\
\hline 7316 & Meliniomyces.sp & 0.0002 \\
\hline 113 & Hysteriales.sp & 0.0002 \\
\hline 2525 & Meliniomyces.sp. & 0.0043 \\
\hline 107 & Meliniomyces.sp & 0.0003 \\
\hline 6884 & Oidiodendron & 0.0006 \\
\hline 82 & Phialocephala.fortinii & 0.0082 \\
\hline 515 & Phialocephala.fortinii & 0.0043 \\
\hline 2548 & Meliniomyces.sp & 0.0026 \\
\hline 2448 & Herpotrichiellaceae.sp. & 0.0008 \\
\hline 11254 & Glomus.sp.7.SUN_2011 & 0.0004 \\
\hline 91 & Mycena & 0.0014 \\
\hline 12150 & Fungi & 0.0065 \\
\hline 2353 & Meliniomyces.sp & 0.0068 \\
\hline 4045 & Phialocephala.fortinii & 0.0235 \\
\hline 2513 & Meliniomyces.sp & 0.0036 \\
\hline 614 & Glomus.sp.1v12_1 & 0.007 \\
\hline PEATLAND+STAMP SAND & (1 of 1$)$ & \\
\hline 4 & Chalara.holubovae & 0.0156 \\
\hline PEATLAND+UPLAND & $(20$ of 22$)$ & \\
\hline 12457 & Phialocephala.fortinii & 0.0008 \\
\hline 12 & Glomeromycetes & 0.0002 \\
\hline 22 & Cryptosporiopsis. ericae & 0.0001 \\
\hline 16 & Glomeraceae & 0.0001 \\
\hline 71 & Glomeraceae & 0.0002 \\
\hline 127 & Glomeraceae & 0.0004 \\
\hline 7 & Oidiodendron.maius & 0.0004 \\
\hline 3024 & Glomeraceae & 0.0018 \\
\hline 328 & Glomeraceae & 0.0008 \\
\hline 147 & Glomeraceae & 0.0021 \\
\hline 6185 & Meliniomyces.sp & 0.0045 \\
\hline 11762 & Glomerales & 0.0064 \\
\hline 98 & Glomeraceae & 0.0076 \\
\hline 1158 & Glomeraceae & 0.0435 \\
\hline 3500 & Glomeraceae & 0.0105 \\
\hline 68 & Glomeraceae & 0.0311 \\
\hline 2242 & Glomeraceae & 0.0353 \\
\hline 148 & Glomeraceae & 0.016 \\
\hline 1090 & Phialocephala.fortinii & 0.0335 \\
\hline 197 & Glomeraceae & 0.041 \\
\hline
\end{tabular}


Table 3.5 cont'd

\begin{tabular}{lll} 
STAMP SAND +UPLAND & $\mathbf{( 3}$ of $\mathbf{3})$ & \\
1601 & Phialocephala.fortinii & 0.0039 \\
12929 & Phialocephala.fortinii & 0.0124 \\
$\mathbf{1 1 1 7 6}$ & Glomeraceae & $\mathbf{0 . 0 3 3 3}$ \\
\hline
\end{tabular}

Table 3.6. Top 20 most abundant Glomeromycota: abundance by habitat and indicator status. Percentages are average percent of sequence reads $\pm \mathrm{SE}$.

\begin{tabular}{lccccc}
\hline \multicolumn{1}{c}{ Species } & $\begin{array}{c}\text { \#OTU } \\
\text { ID }\end{array}$ & $\begin{array}{c}\text { Peatland } \\
\text { Percentage }\end{array}$ & $\begin{array}{l}\text { Stamp sand } \\
\text { Percentage }\end{array}$ & $\begin{array}{l}\text { Upland } \\
\text { Percentage }\end{array}$ & $\begin{array}{c}\text { Indicator } \\
\text { Status* }\end{array}$ \\
\hline Glomeromycetes & 12 & $0.93 \pm 0.29$ & $0.03 \pm 0.03$ & $0.41 \pm 0.12$ & $\mathrm{P} \mathrm{U}$ \\
sp. & 16 & $0.75 \pm 0.19$ & $0.03 \pm 0.03$ & $0.67 \pm 0.21$ & $\mathrm{P} \mathrm{U}$ \\
Glomeraceae sp. & 127 & $0.53 \pm 0.11$ & $0.08 \pm 0.08$ & $0.56 \pm 0.13$ & $\mathrm{P} \mathrm{U}$ \\
Glomeraceae sp. & 87 & $0.48 \pm 0.26$ & $0.00 \pm 0.00$ & $0.72 \pm 0.36$ & $\mathrm{P} \mathrm{U}$ \\
Glomus sp 1v12_1 & 147 & $0.52 \pm 0.16$ & $0.00 \pm 0.00$ & $0.41 \pm 0.14$ & $\mathrm{P} \mathrm{U}$ \\
Glomeraceae sp. & 71 & $0.53 \pm 0.16$ & $0.00 \pm 0.00$ & $0.38 \pm 0.11$ & $\mathrm{P} \mathrm{U}$ \\
Glomeraceae sp. & 148 & $0.39 \pm 0.11$ & $0.01 \pm 0.01$ & $0.22 \pm 0.11$ & $\mathrm{P} \mathrm{U}$ \\
Glomeraceae sp. & 11762 & $0.36 \pm 0.10$ & $0.00 \pm 0.00$ & $0.28 \pm 0.13$ & $\mathrm{P} \mathrm{U}$ \\
Glomerales sp. & 122 & $0.02 \pm 0.02$ & $0.88 \pm 0.54$ & $0.00 \pm 0.00$ & $\mathrm{~S}$ \\
Glomerales sp. & 58 & $0.11 \pm 0.05$ & $0.59 \pm 0.28$ & $0.11 \pm 0.06$ & $\mathrm{P} \mathrm{S} \mathrm{U}$ \\
Rhizophagus sp & 46 & $0.38 \pm 0.31$ & $0.00 \pm 0.00$ & $0.20 \pm 0.17$ & $\mathrm{P} \mathrm{U}$ \\
Glomus sp 1v12_1 & 11260 & $0.00 \pm 0.00$ & $0.8 \pm 0.43$ & $0.00 \pm 0.00$ & $\mathrm{~S}$ \\
Glomeraceae sp & 3024 & $0.23 \pm 0.07$ & $0.02 \pm 0.02$ & $0.34 \pm 0.10$ & $\mathrm{P} \mathrm{U}$ \\
Glomeraceae sp. & 1229 & $0.21 \pm 0.07$ & $0.08 \pm 0.08$ & $0.28 \pm 0.14$ & $\mathrm{P} \mathrm{S} \mathrm{U}$ \\
Glomeraceae sp. & 2242 & $0.21 \pm 0.07$ & $0.03 \pm 0.02$ & $0.34 \pm 0.11$ & $\mathrm{P} \mathrm{U}$ \\
Glomeraceae sp. & 228 & $0.24 \pm 0.08$ & $0.00 \pm 0.00$ & $0.28 \pm 0.14$ & $\mathrm{P} \mathrm{U}$ \\
Glomeraceae sp. & 98 & $0.10 \pm 0.10$ & $0.15 \pm 0.05$ & $\mathrm{P} \mathrm{S} \mathrm{U}$ \\
Glomeraceae sp. & 11700 & $0.26 \pm 0.07$ & 0.10 & $\mathrm{P} \mathrm{S} \mathrm{U}$ \\
Glomeraceae sp. & 695 & $0.2 \pm 0.08$ & $0.10 \pm 0.10$ & $0.22 \pm 0.08$ & $\mathrm{P} \mathrm{S} \mathrm{U}$ \\
Glomeraceae sp. & 635 & $0.2 \pm 0.06$ & $0.11 \pm 0.11$ & $0.17 \pm 0.07$ & $\mathrm{P}$ \\
Rhizophagus sp & 1044 & $0.36 \pm 0.22$ & $0.00 \pm 0.00$ & $0.00 \pm 0.00$ & \\
* Indicator Status (P: Peatland; S: Stamp Sand; U: Upland) & & &
\end{tabular}


Table 3.7. Top 20 most abundant Glomeromycota: abundance by Query coverage, E value, \% Identity, and Genbank Accession \# of closest match in Genbank.

\begin{tabular}{lrcccc}
\hline \multicolumn{1}{c}{ Species } & $\begin{array}{c}\text { \#OTU } \\
\text { ID }\end{array}$ & $\begin{array}{c}\text { Query } \\
\text { Cover }\end{array}$ & E Value & Ident & Accession \\
\hline Glomeromycetes sp. & 12 & $100 \%$ & $2.00 \mathrm{E}-82$ & $98 \%$ & EU747843.1 \\
Glomeraceae sp. & 16 & $100 \%$ & $4.00 \mathrm{E}-95$ & $99 \%$ & EU690493.1 \\
Glomeraceae sp. & 127 & $98 \%$ & $5.00 \mathrm{E}-74$ & $96 \%$ & EU690493.1 \\
Glomus sp 1v12_1 & 87 & $100 \%$ & $2.00 \mathrm{E}-87$ & $97 \%$ & AJ567795.1 \\
Glomeraceae sp. & 147 & $100 \%$ & $1.00 \mathrm{E}-89$ & $98 \%$ & EU747843.1 \\
Glomeraceae sp. & 71 & $100 \%$ & $5.00 \mathrm{E}-79$ & $95 \%$ & EU747844.1 \\
Glomeraceae sp. & 148 & $100 \%$ & $3.00 \mathrm{E}-81$ & $98 \%$ & EU690493.1 \\
Glomerales sp. & 11762 & $98 \%$ & $1.00 \mathrm{E}-65$ & $93 \%$ & EU690493.1 \\
Glomerales sp. & 122 & $100 \%$ & $2.00 \mathrm{E}-89$ & $97 \%$ & AJ504646.1 \\
Rhizophagus sp & 58 & $100 \%$ & $9.00 \mathrm{E}-97$ & $99 \%$ & EF619695.1 \\
Glomus sp 1v12_1 & 46 & $100 \%$ & $2.00 \mathrm{E}-83$ & $97 \%$ & HQ895790.2 \\
Glomeraceae sp & 11260 & $100 \%$ & $1.00 \mathrm{E}-84$ & $97 \%$ & HQ895816.2 \\
Glomeraceae sp. & 3024 & $100 \%$ & $1.00 \mathrm{E}-70$ & $95 \%$ & EU690493.1 \\
Glomeraceae sp. & 1229 & $100 \%$ & $1.00 \mathrm{E}-70$ & $95 \%$ & EU690493.1 \\
Glomeraceae sp. & 2242 & $100 \%$ & $5.00 \mathrm{E}-84$ & $96 \%$ & EU747843.1 \\
Glomeraceae sp. & 98 & $100 \%$ & $7.00 \mathrm{E}-93$ & $99 \%$ & EU690493.1 \\
Glomeraceae sp. & 11700 & $99 \%$ & $1.00 \mathrm{E}-80$ & $95 \%$ & EU690493.1 \\
Glomeraceae sp. & 695 & $99 \%$ & $8.00 \mathrm{E}-72$ & $95 \%$ & EU690493.1 \\
Glomeraceae sp. & 635 & $100 \%$ & $7.00 \mathrm{E}-78$ & $94 \%$ & EU690493.1 \\
Rhizophagus sp & 1044 & $100 \%$ & $4.00 \mathrm{E}-90$ & $97 \%$ & KF836932.1 \\
\hline
\end{tabular}


Table 3.8. Top 20 most abundant Glomeromycota: abundance by habitat association of closest match in Genbank.

\begin{tabular}{|c|c|c|c|c|}
\hline Species & $\begin{array}{l}\text { OTU } \\
\text { ID }\end{array}$ & Habitat description & $\begin{array}{l}\text { Soil } \\
\mathrm{pH}\end{array}$ & $\begin{array}{c}\text { Authors } \\
\& \\
\text { Citation* }\end{array}$ \\
\hline Glomeromycetes sp. & 12 & Acidophilous subalpine grassland & $4.8-5.5$ & 1 \\
\hline Glomeraceae sp. & 16 & Natural forest soil & $3.2-3.7$ & 2 \\
\hline Glomeraceae sp. & 127 & Natural forest soil & $3.2-3.7$ & 2 \\
\hline Glomus sp 1v12_1 & 87 & Mountain meadows & $\begin{array}{l}5.78- \\
6.20\end{array}$ & 3 \\
\hline Glomeraceae sp. & 147 & Acidophilous subalpine grassland & $4.8-5.5$ & 1 \\
\hline Glomeraceae sp. & 71 & Acidophilous subalpine grassland & $4.8-5.5$ & 1 \\
\hline Glomeraceae sp. & 148 & Natural forest soil & $3.2-3.7$ & 2 \\
\hline Glomerales sp. & 11762 & Natural forest soil & $3.2-3.7$ & 2 \\
\hline Glomerales sp. & $\begin{array}{c}122 \\
58\end{array}$ & $\begin{array}{l}\text { Grassland, mountain meadows } \\
\text { Clay-rich, low-fertility Ultic }\end{array}$ & $5.5-7.7$ & 4 \\
\hline Rhizophagus sp & & Alfisols & 5.75 & 5 \\
\hline Glomus sp 1v12_1 & 46 & $\begin{array}{l}\text { Soils shallow to greater }<2 \mathrm{~m} \\
\text { deep }\end{array}$ & ND & 6 \\
\hline Glomeraceae sp & 11260 & $\begin{array}{l}\text { Soils shallow to greater }<2 \mathrm{~m} \\
\text { deep }\end{array}$ & ND & 6 \\
\hline Glomeraceae sp. & 3024 & Natural forest soil & $3.2-3.7$ & 2 \\
\hline Glomeraceae sp. & 1229 & Natural forest soil & $3.2-3.7$ & 2 \\
\hline Glomeraceae sp. & 2242 & Acidophilous subalpine grassland & $4.8-5.5$ & 1 \\
\hline Glomeraceae sp. & 98 & Natural forest soil & $3.2-3.7$ & 2 \\
\hline Glomeraceae sp. & 11700 & Natural forest soil & $3.2-3.7$ & 2 \\
\hline Glomeraceae sp. & 695 & Natural forest soil & $3.2-3.7$ & 2 \\
\hline Glomeraceae sp. & 635 & Natural forest soil & $3.2-3.7$ & 2 \\
\hline Rhizophagus sp & 1044 & No data & ND & 7 \\
\hline
\end{tabular}

* Authors \& Citation: 1) Ryszka et al., 2010; 2) Lamarche et al., 2011; 3) Boerstler,B. et al., 2006; 4) Renker, 2003; 5) Parrent and Vilgalys, 2007; 6) Fahey et $a l, .2012$; 7) Zhang, $\mathrm{N}$ et al. Abuscular mycorrhizal fungi in the grasslands of northern China (unpublished). 